Aus dem Department für Endokrinologie

(Prof. Dr. med. W. Wuttke)

der Medizinischen Fakultät der Universität Göttingen

\title{
Einfluss von Estradiol, Genistein, Equol und Resveratrol auf verschiedene östrogensensitive Organe und Parameter der ovariektomierten Maus
}

\author{
INAUGURAL-DISSERTATION \\ zur Erlangung des Doktorgrades \\ der Medizinischen Fakultät
}

der Georg-August-Universität zu Göttingen

vorgelegt von

Sandra Mählmeyer

aus Lohne

Göttingen 2010 
Dekan:

1. Berichterstatter:

2. Berichterstatter:
Prof. Dr. med. C. Frömmel

Prof. Dr. rer. nat. H. Jarry

PD Dr. rer. nat. P. Thelen 


\section{Inhaltsverzeichnis}

\section{Abkürzungsverzeichnis}

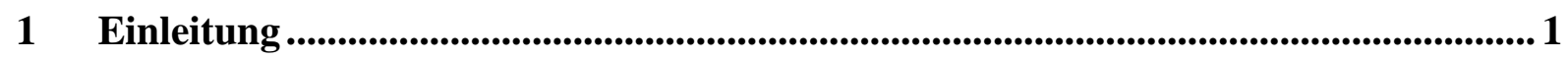

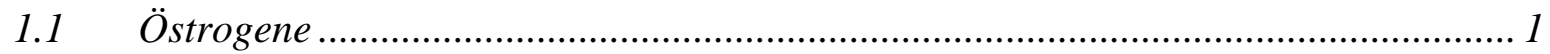

1.1.1 Östrogene im prämenopausalen Lebensabschnitt............................................... 1

1.1.2 Östrogene im peri- und postmenopausalen Lebensabschnitt.............................. 1

1.1.3 Östrogenrezeptor alpha und beta ........................................................... 2

1.2 Untersuchte Organe und ihre Beeinflussung durch Östrogene ................................. 3

1.2.1 „Klassische“, von Östrogenen beeinflusste Organe .......................................... 3

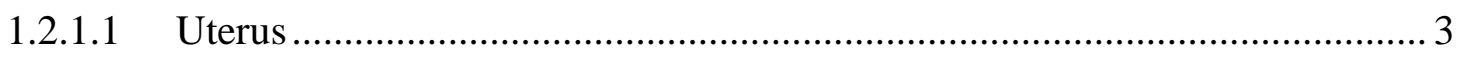

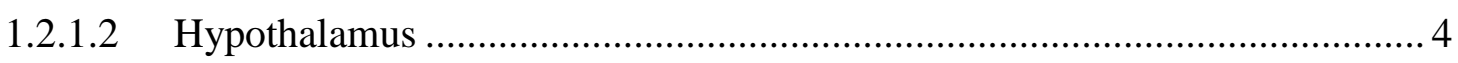

1.2.2 Andere, von Östrogenen beeinflusste Organe und Parameter ........................... 4

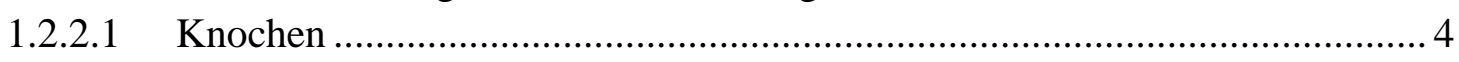

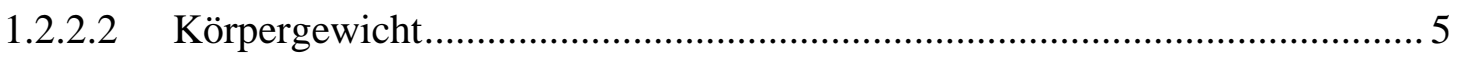

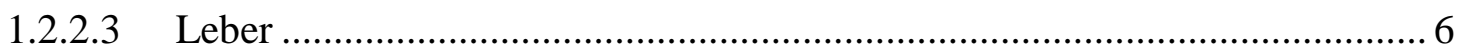

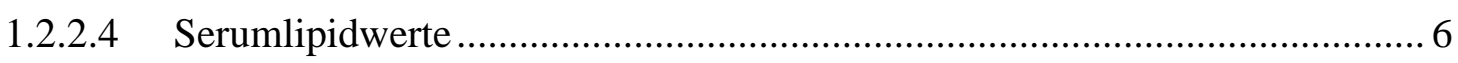

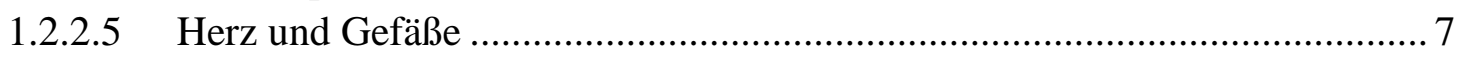

1.3 Die klassische Hormonersatztherapie und ihre Nebenwirkungen ............................ 8

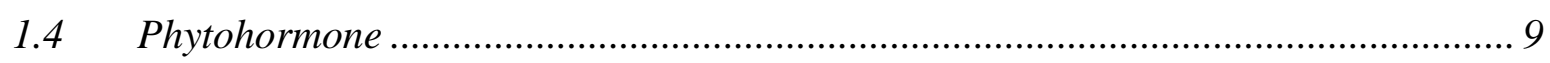

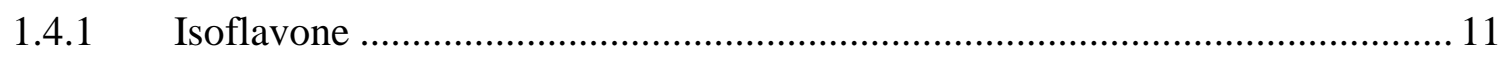

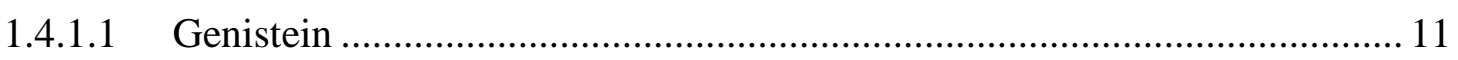

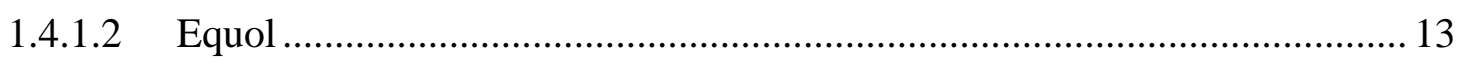

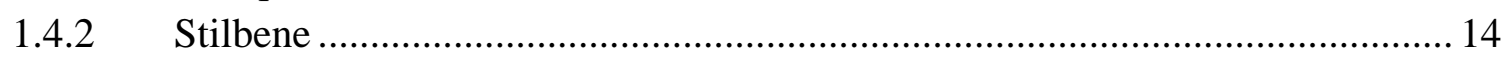

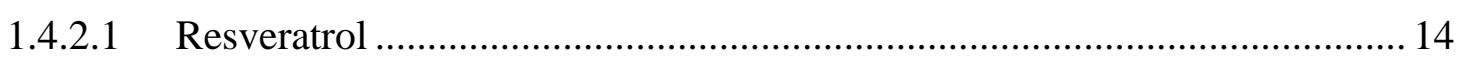

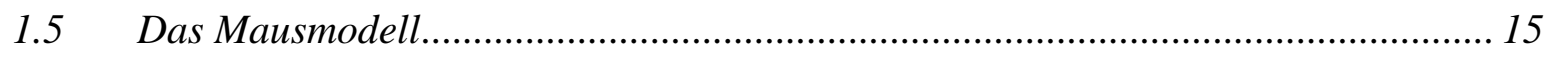

1.6 Von Östrogenen regulierte Gene/Proteine .......................................................... 16

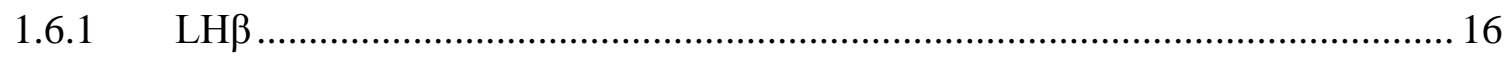

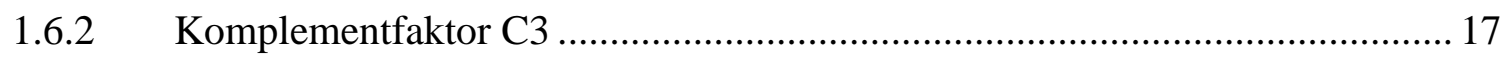

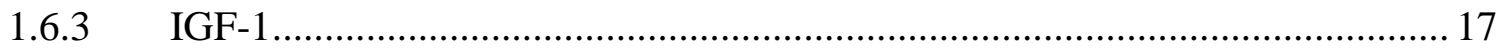

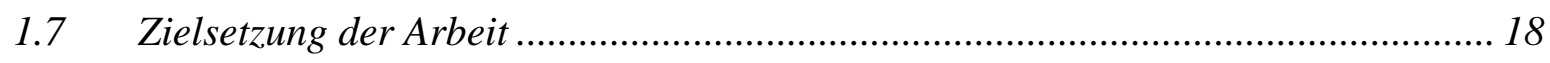

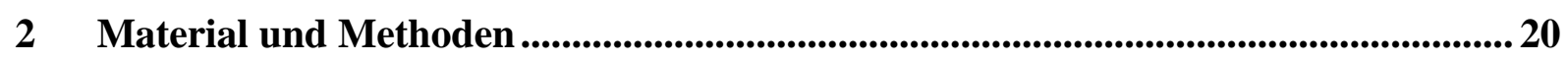

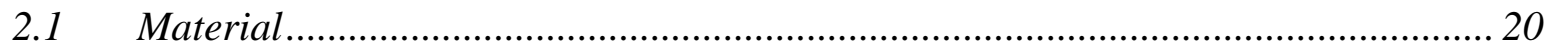

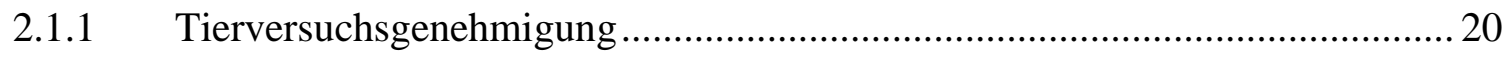

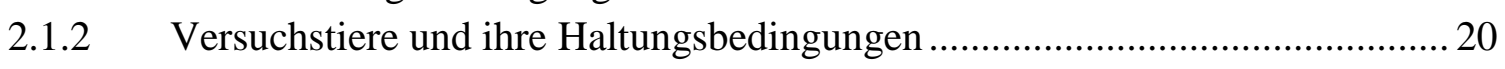

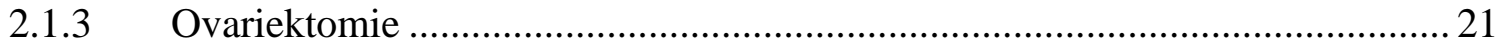

2.1.4 Gewinnung des biologischen Probenmaterials ............................................. 22

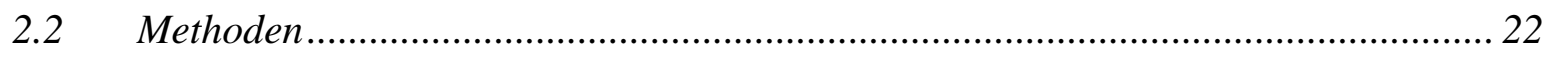

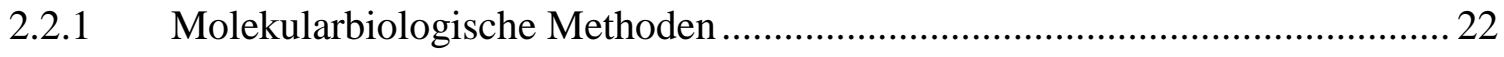

2.2.1.1 Extraktion der Gesamt-RNA ............................................................... 22 


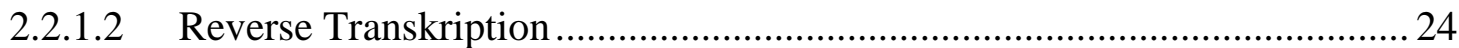

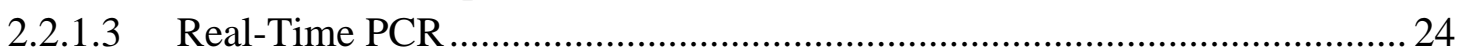

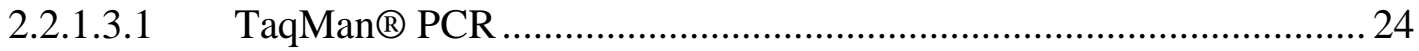

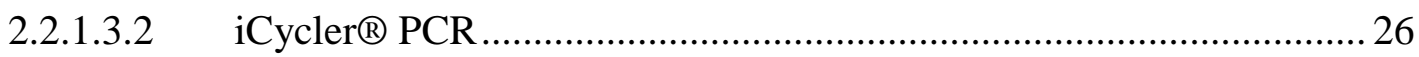

2.2.1.4 Primer und Sonden ............................................................................... 27

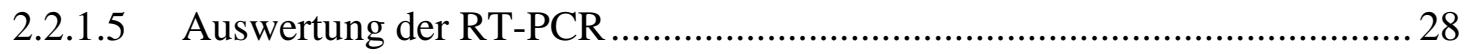

2.2.2 Serumdiagnostik .................................................................................. 28

2.2.3 Quantitative Computertomographie ............................................................ 29

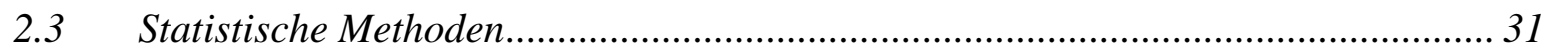

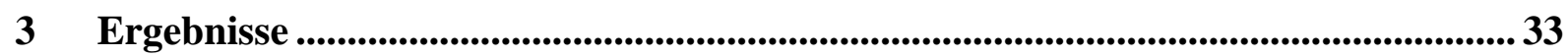

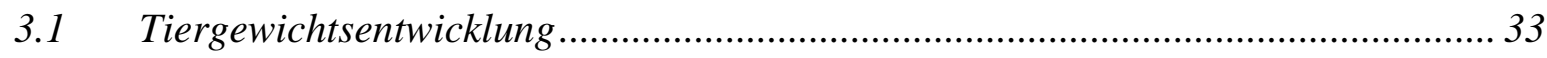

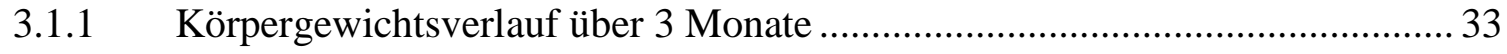

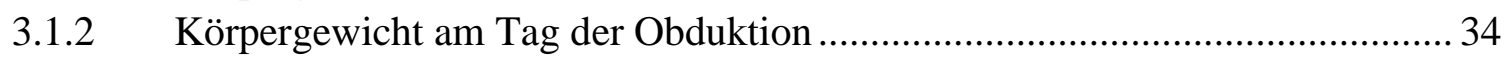

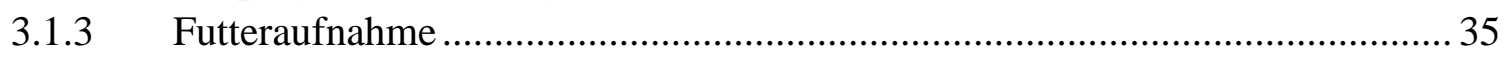

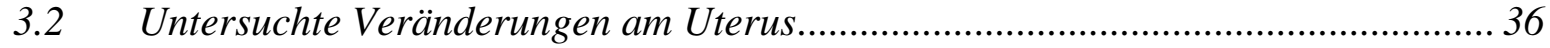

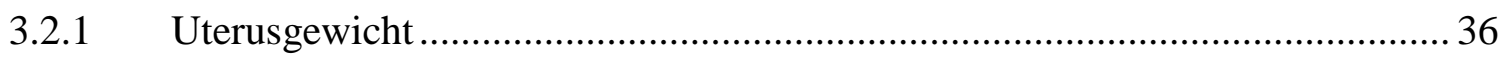

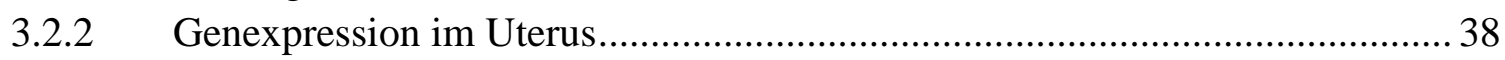

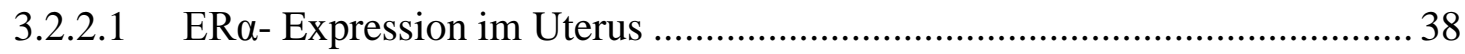

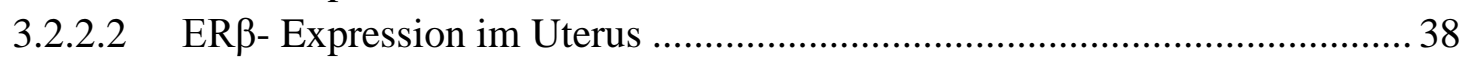

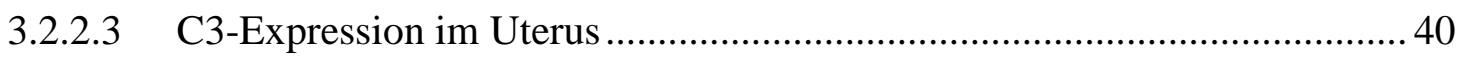

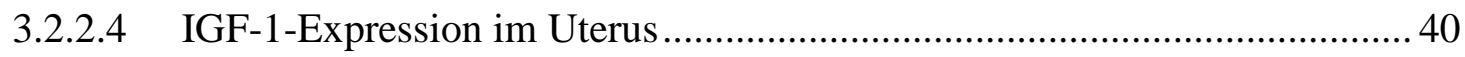

3.3 Untersuchte Veränderungen in der Leber............................................................... 42

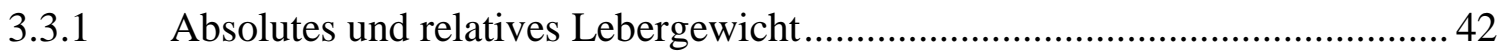

3.3.2 Genexpression in der Leber .................................................................. 44

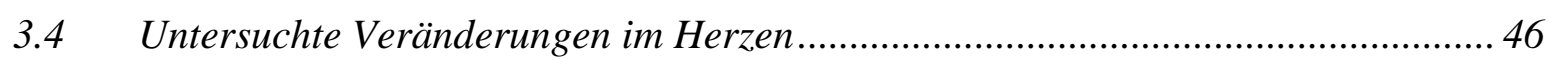

3.4.1 Absolutes und relatives Herzgewicht ........................................................ 46

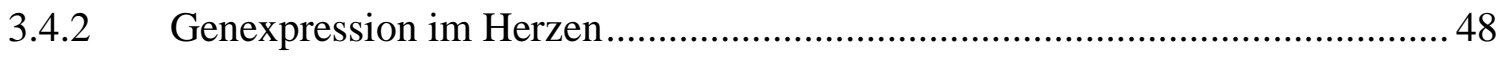

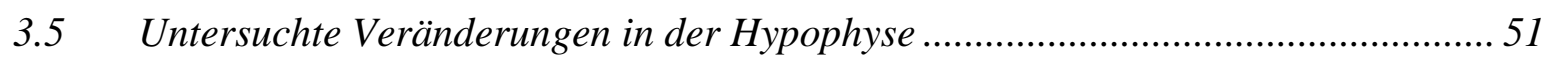

3.5.1 Genexpression in der Hypophyse ............................................................ 51

3.6 Untersuchte Veränderungen an der Tibia......................................................... 53

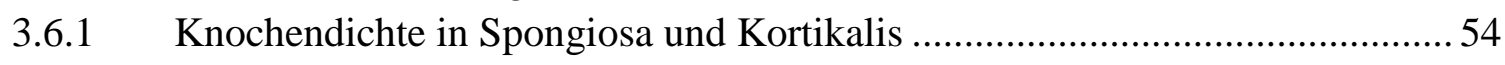

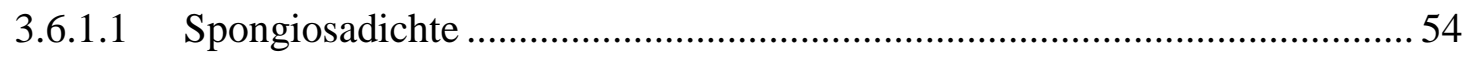

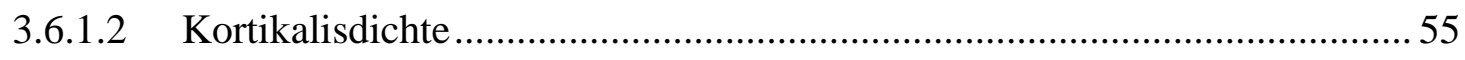

3.6.1.3 Gesamtdichte von Tibia-Meta- und Diaphyse ........................................... 56

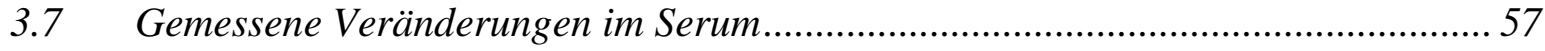

3.7.1 Cholesterol, Triglyceride, LDL und HDL im Serum ..................................... 57

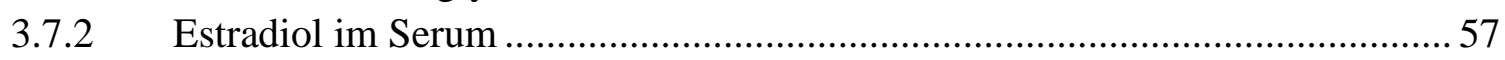

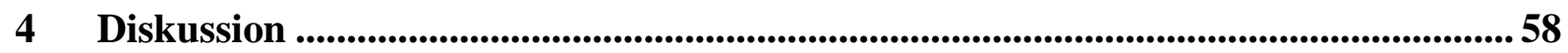

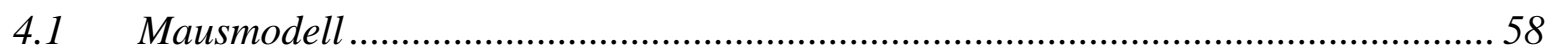

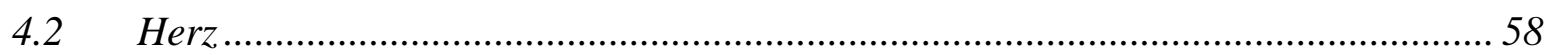




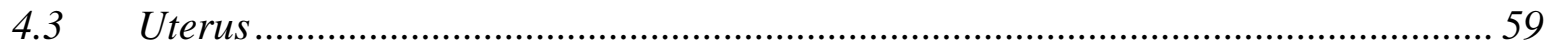

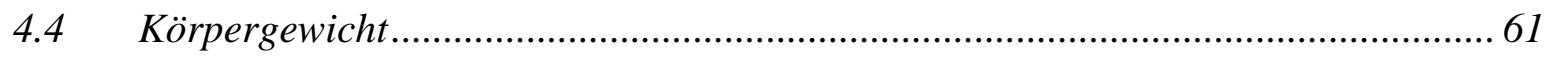

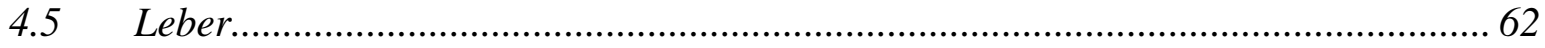

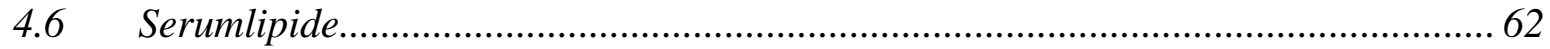

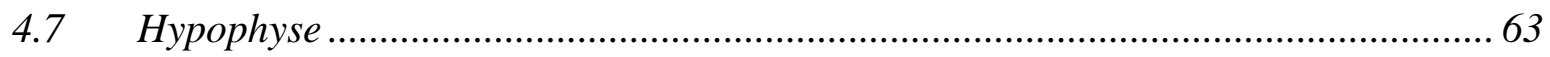

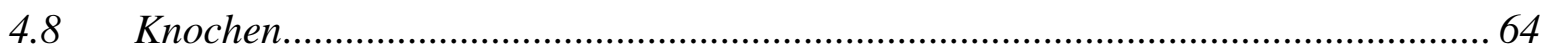

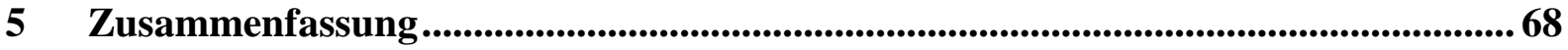

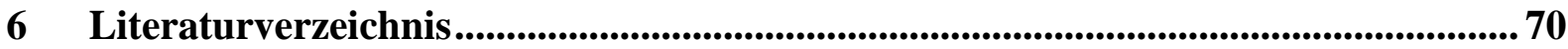

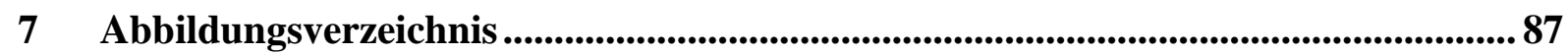

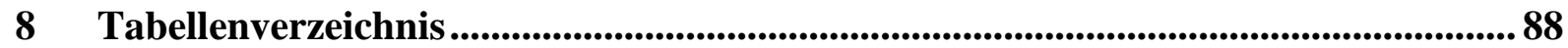


Abkürzungsverzeichnis

\begin{tabular}{|c|c|}
\hline$(\alpha / \beta)$ ERKO & Östrogenrezeptor $(\alpha / \beta)$ Knock-out \\
\hline $\mathrm{C} 3$ & Komplementfaktor 3 \\
\hline cDNA & copyDesoxyribonucleinsäure \\
\hline DNA & Desoxyribonucleinsäure \\
\hline dNTP & desoxyNucleosidtriphosphat \\
\hline dsDNA & Doppelstrang-DNA \\
\hline E2 & Estradiol \\
\hline $\mathrm{ER} \alpha$ & Östrogenrezeptor alpha \\
\hline $\mathrm{ER} \beta$ & Östrogenrezeptor beta \\
\hline FSH & Follikel stimulierendes Hormon \\
\hline $\mathrm{GH}$ & Growth Hormone \\
\hline GnRH & Gonadotropin releasing Hormone \\
\hline HDL & High Density Lipoproteine \\
\hline HRT & Hormone Replacement Therapy \\
\hline IGF-1 & Insulin-like Growth Factor 1 \\
\hline LDL & Low Density Lipoproteine \\
\hline LH & Luteinisierendes Hormon \\
\hline mRNA & messenger Ribonucleinsäure \\
\hline NO & Nitric Oxide (Stickstoffmonoxid) \\
\hline OD & Optical Density \\
\hline OECD & Organisation for Economic Co-operation and Development \\
\hline PCR & Polymerase Chain Reaction \\
\hline qCT & Quantitativer Computertomograph \\
\hline RT & Reverse Transkriptase \\
\hline SERM & Selektiver Östrogenrezeptor-Modulator \\
\hline TG & Triglyceride \\
\hline TSH & Thyreoidea stimulierendes Hormon \\
\hline UNG & Uracil-N-Glycosylase \\
\hline
\end{tabular}




\section{$1 \quad$ Einleitung}

\section{1 Östrogene}

\subsection{1 Östrogene im prämenopausalen Lebensabschnitt}

Östrogene sind Steroidhormone mit 18 C-Atomen, welche hauptsächlich durch das Enzym Aromatase aus Androstendion gebildet werden. Vorwiegend werden Östrogene in den Granulosazellen des Ovars, während der Schwangerschaft in der Plazenta und in geringem $\mathrm{Maß}$ in der Nebennierenrinde gebildet. Zudem finden sich Aromataseaktivitäten in MuskelFett- und Nervengewebe sowie in den Leydigzellen des Hodens(Gruber et al. 2002). Neben dem wichtigsten Östrogen Estradiol (E2) kommen Estron (E1) und Estriol (E3) vor. Diese werden vorrangig in der Leber aus Estradiol gebildet und zeigen eine deutlich schwächere Wirkung an den Erfolgsorganen(Hillier et al. 1994).

Die ovarielle Östrogenproduktion wird über einen Regelkreis zwischen Hypothalamus, Hypophyse und Ovar gesteuert. Im Rahmen des Menstruationszyklus verändern sich die Estradiolwerte ständig und nehmen die höchsten Werte kurz vor der Ovulation und die niedrigsten Werte prämenstruell an. Die zirkulierenden Östrogene induzieren hierbei u.a. die Proliferation des uterinen Schleimhautepithels in der Follikelphase. Östrogene fungieren darüber hinaus als Schlüsselregulatoren der Zellproliferation und -differenzierung und sind demnach an der Kontrolle von Wachstum und Aufrechterhaltung ihrer Zielgewebe beteiligt.

\subsection{2 Östrogene im peri- und postmenopausalen Lebensabschnitt}

Durch die perimenopausale Verringerung der Anzahl der ovariellen Follikel zeigt der Estradiolspiegel eine stetige Abnahme. Postmenopausal liegt die Konzentration häufig unter $20 \mathrm{pg} / \mathrm{ml}$ und das Steroid wird vorwiegend extragonadal aus Testosteron gebildet. Zudem bewirkt der Wegfall der negativen Rückkopplung durch Estradiol hohe Plasmakonzentrationen von FSH und LH.

Das Versiegen der endogenen ovariellen Östrogenproduktion tritt bei den meisten Frauen zwischen dem 45. und 55. Lebensjahr auf und führt zu einem Östrogenmangel an den Erfolgsorganen. Die hieraus resultierenden klimakterischen Veränderungen treten dabei nicht nur an den „klassischen“, durch Östrogene regulierten Reproduktionsorganen (Ovarien, Uterus, Vagina und Brustgewebe) auf, sondern auch an anderen Geweben, die über Östrogenrezeptoren einem regulierenden Einfluss der Steroide unterliegen. Hierzu zählen zum 
Beispiel Knochen, kardiovaskuläre Strukturen, Gehirn, Immunsystem und Leber. Bevor auf die Folgen des Estradiolmangels an diesen Organen eingegangen wird, sollen zum besseren Verständnis der vielfältigen Wirkungen von Östrogenen und ihnen in ihrer Wirkung ähnlichen Stoffen der Mechanismus von Östrogenrezeptor-vermittelter E2-Wirkung und Rezeptor-unabhängige Mechanismen kurz erläutert werden:

\subsection{3 Östrogenrezeptor alpha und beta}

Die meisten zellulären Reaktionen auf Östrogene sind Antworten auf die von deren Rezeptoren vermittelten Signale. Aber auch eine direkte und indirekte Einflussnahme auf die Transkription von Zielgenen ohne eine Bindung von E2 an seinen Rezeptor ist beschrieben (z.B. über membranständige Rezeptoren, mitochondriale Rezeptoren oder Ligandenunabhängige Phosphorylierung) (Moutsatsou 2007).

Es sind zwei Östrogenrezeptoren bekannt, ER $\alpha$ und ER $\beta$. Sie gehören zur Familie der Steroidhormonrezeptoren (nukleäre Rezeptoren) und arbeiten als Liganden-aktivierte Transkriptionsfaktoren(Grandien et al. 1997). ER $\alpha$ ist der zuerst, im Jahre 1958, entdeckte Rezeptor, ER $\beta$ wurde erstmals 1996 in der Prostata von Ratten gefunden(Kuiper et al. 1996). In einer Zelle können entweder nur einer der beiden ER-Subtypen oder beide, ER $\alpha$ und ER $\beta$, exprimiert werden. Vor der Bindung an die DNA erfolgt immer eine Dimerisierung von zwei ER-Molekülen, wodurch homo- oder heterodimere Rezeptorkomplexe entstehen. Für beide Rezeptoren wurden mehrere Spleißvarianten beschrieben, die untereinander und mit den kompletten Varianten der ER Homo- und Heterodimere bilden können, die bei Aktivierung durch E2 unterschiedliche Effekte in ihrer Natur als Transkriptionsfaktor haben können. So verursachen einige Spleißvarianten eine Inhibierung, andere eine Stimulierung der östrogenartigen Wirkung in der Zielzelle. Diese Erkenntnis wird als Basis für die Erklärung der organselektiven Wirkung von Estradiol herangezogen(Wuttke et al. 2002) (s. SERMs).

ER $\alpha$ und ER $\beta$ liegen in vielen Geweben nebeneinander vor, jedoch ist die Quantität für den jeweiligen Rezeptor in den unterschiedlichen Geweben verschieden. ER $\alpha$ zeigt eine deutliche Expression in Uterus, Ovar, Hoden, Hypophyse, Nebenhoden, Nieren und Nebennieren, welche alle keine bis mäßige Expression von ER $\beta$-mRNA zeigen, so Kuiper et al.(Kuiper et al. 1997). Die Autoren fanden weiterhin die höchste ER $\beta$-mRNA-Expression in den Ovarien und in der Prostata. Zusätzlich zeigt sich eine Expression in Hoden, Uterus, Blase und Lunge, wobei in Hypophyse, Nebenhoden, Thymus und verschiedenen Hirnregionen nur eine geringe Expression zu finden ist. Nachweislich sind außerdem ER $\alpha$ und ER $\beta$ im Myokard präsent (Grohe et al. 1998, Nordmeyer et al. 2004). Im Knochen sind sowohl ER $\alpha$ als auch ERß zu 
finden(Arts et al. 1997, Bodine et al. 1998), wobei je nach Art des Knochens oder nach dessen Differenzierungsgrad der eine oder der andere ER-Subtyp überwiegt (Bord et al. 2001). So findet sich im kortikalen Knochen überwiegend ER $\alpha$; im spongiösen Knochen herrscht ERß $\operatorname{vor}($ Bord et al. 2001).

Zur weiteren Differenzierung der Wirkung von Östrogenen in vivo sind „knock-out-Mäuse“ entwickelt worden, denen entweder einer ( $\alpha$-ERKO, $\beta$-ERKO) oder beide (ERKO) Östrogenrezeptoren fehlen (s. „Mausmodell“). Diese Tiere sind sinnvolle Modelle zur Forschung im Bereich der gewebespezifischen Wirkungen und zum Erkennen von Nebeneffekten des Estradiols sowie von selektiven Östrogenrezeptor-Modulatoren (SERMs)(Emmen und Korach 2001).

Über das Zusammenwirken der beiden Östrogenrezeptoren gibt es bislang keine gesicherten Erkenntnisse. Eine Möglichkeit stellt die ,Yin/Yang“-Theorie dar, nach der ER $\beta$ die durch ER $\alpha$ aktivierte Transkription moduliert oder in Geweben ohne ER $\alpha$-Expression die Aufgaben von ER $\alpha$ übernimmt (Lindberg et al. 2003, Liu MM et al. 2002).

\subsection{Untersuchte Organe und ihre Beeinflussung durch Östrogene}

\subsection{1 „Klassische“, von Östrogenen beeinflusste Organe}

Bei den „klassischen“ Zielorganen der Östrogene, die in dieser Arbeit untersucht wurden, ist im Rahmen der Peri- und Postmenopause von folgenden Veränderungen auszugehen:

\subsubsection{Uterus}

Im Klimakterium kommt es durch den fehlenden wachstumsstimulierenden Einfluss des Estradiols physiologischerweise $\mathrm{zu}$ einer Atrophie des Organs. Die ausbleibende Estradiolproduktion führt hierbei zu keinen subjektiven Beschwerden in Hinblick auf die unterbleibenden Wirkungen am Uterus. Vielmehr stellt der Uterus mit seiner proliferierenden Reaktion auf Estradiol ein Problem bei der Behandlung der anderen postmenopausalen Symptome dar. Die diesbezüglich erhobenen Resultate im Tierversuch zeigen dies deutlich: schon die einmalige Applikation von Estradiol führte bei Ratten zu einer massiven Erhöhung des Uterusgewichts, was auf die gestiegene vaskuläre Permeabilität zurückgeführt wird. Die akute Stimulierung der Gen- und Proteinexpression des VEGF (vascular endothelial growth factor), des IGF1 (insulin-like growth factor 1) und des HbEGF (heparin binding epidermal growth factor) wird in erster Linie für diesen Effekt verantwortlich gemacht(Cullinan-Bove und Koos 1993). Eine Erhöhung des Uterusgewichts ist auch nach einer stetigen Zufuhr von Estradiol über drei Monate via Futter zu verzeichnen(Wuttke et al. 2002). In diesem Fall wird 
jedoch von einem, von der vaskulären Permeabilität unabhängigen Mechanismus ausgegangen. Bei chronischer Estradiolzufuhr zeigt sich sowohl eine Vergrößerung des Endoals auch des Myometriums, in diesem Falle am ehesten ausgelöst durch eine erhöhte IGF1Genexpression.

Durch eine vermehrte oder verlängerte Exposition mit Östrogenen, zum Beispiel hervorgerufen durch eine frühe Menarche, eine späte Menopause, die lange Einnahme von exogenen Östrogenen als HRT und durch ein hohes postmenopausales Körpergewicht steigt deshalb das Risiko, an einem Endometrium Karzinom zu erkranken(Pathirage et al. 2006).

\subsubsection{Hypothalamus}

Das mit am häufigsten und am stärksten beklagte klimakterische Symptom sind die typischen Hitzewallungen (bei 50-70\% der Frauen), welche mit dem Beginn der Perimenopause auftreten. Zusätzlich kommt es häufig zu weiteren vasomotorischen Symptomen wie Schlafstörungen und Stimmungsschwankungen mit Depressionen. Der Grund für dieses Leiden ist die Überaktivität des hypothalamischen GnRH-Pulsgenerators(Tataryn et al. 1979). Da der negative Feedbackmechanismus des Estradiols durch die verminderte ovarielle Estradiolproduktion in der Perimenopause zum Erliegen kommt, stimulieren die Neurotransmitter, die den Pulsgenerator auch unter normalen Umständen steuern, ihr Erfolgsorgan weiterhin synchron, aber in einem inadäquat hohen Maße. Durch die Hypersekretion von Neurotransmittern werden nun Neurone, die die Körpertemperatur regulieren und das kardiovaskuläre System beeinflussen, ebenfalls phasenweise und synchron stimuliert, was zu den ungebetenen Perioden von Hitzewallungen führt.

\subsubsection{Andere, von Östrogenen beeinflusste Organe und Parameter}

Weiterhin gibt es umfangreiche Auswirkungen des postmenopausalen Estradiolmangels auf andere von Östrogenen beeinflusste Organe und Parameter:

\subsubsection{Knochen}

Östrogene spielen eine zentrale Rolle im Knochenstoffwechsel. Zusammen mit den „Calcium regulierenden Hormonen“, Wachstumsfaktoren und Zytokinen halten sie das Gleichgewicht bei ossären Resorptions- und Aufbauvorgängen. Das Absinken des Östrogenspiegels zu Beginn der Menopause ist verantwortlich für den beschleunigten Knochenabbau bei Frauen, die so genannte Typ-I-Osteoporose(Rizzoli und Bonjour 1997), da bei einem zirkulierenden Östrogenlevel unterhalb von $200 \mathrm{pmol} / \mathrm{l}$ das resorptive Potential der Osteoklasten gegenüber den Osteoblasten überwiegt. Der Netto-Knochenmasseverlust ist dabei mehr trabekulär als 
kortikal. Neben der Hauptursache, dem Östrogenmangel, gibt es weitere wichtige Faktoren, die auf das Ausmaß des Knochenverlustes einwirken wie kulturelle Herkunft, genetische Veranlagung und Ernährungsgewohnheiten. Auch die maximal während des Heranwachsens erreichte Knochenmasse hat Einfluss auf das Risiko, im Zuge der Menopause eine Osteoporose zu entwickeln(Bilezikian 1998). $30 \%$ aller Frauen entwickeln nach der Menopause eine klinische relevante Osteoporose Typ I. Die klinisch bedeutsame Folge ist die Häufung von Schenkelhals-, Vorderarm- und Wirbelfrakturen.

\subsubsection{Körpergewicht}

Die Phase der Postmenopause ist häufig assoziiert mit einer Zunahme an Körpergewicht, was einen wichtigen Risikofaktor in der Entwicklung von Hyperlipidämie, Hyperurikämie, Diabetes Typ 2 und Hypertonie darstellt. Zudem stellt auch der Zustand der Postmenopause selbst aufgrund des Estradiolmangels einen Grund für eine verminderte Insulinsensitivität dar. Die Insulinsensitivität kann, genau wie auch das Übergewicht, im Modell der ovariektomierten Ratte günstig durch eine Östrogen Ersatztherapie beeinflusst werden(D'Eon et al. 2005).

In Langzeitversuchen über zwölf Monate konnte gefunden werden, dass ovariektomierte Ratten eine deutliche Gewichtszunahme bei zeitlich begrenzt vermehrter Futteraufnahme sowie eine reduzierte Beweglichkeit im Verhältnis zu intakten Tieren zeigen(Landau und Zucker 1976, Shimomura Y et al. 1990). Zahlreiche Hypothesen und Resultate sind zu der Kausalität dieses Phänomens veröffentlicht:

So wurde in Versuchen mit Nagetieren festgestellt, dass Östrogene und Androgene unterschiedliche Effekte auf die mRNA Expression von Transkriptionsfaktoren, die die mitochondriale Funktion inklusive der Fettsäureoxidation modifizieren, haben. Östrogene führen hierbei zu einer Stimulierung der Fettsäureoxidation(D'Eon et al. 2005, Hsieh et al. 2005, Kamei et al. 2005).

Östrogen moduliert außerdem direkt die Erregbarkeit der Neurone im Hypothalamus (Minami et al. 1990) und die Genexpression von Neuropeptiden, die die Energiehomöostase regulieren(Mystkowski et al. 2000, Shimizu et al. 1996b).

Auch die Verringerung des Leptinlevels unter Östrogenmangel könnte in diesem Zusammenhang eine entscheidende Rolle spielen (Shimomura K et al. 2002). D`Eon et al. zeigten weiterhin an ovariektomierten Mäusen, dass bestimmte genetische und nicht genetische Mechanismen unter Estradioleinfluss für die Verringerung des Fettgewebes, v.a. 
intraabdominal, und für die Verringerung der Adipozytengröße zuständig sind (D'Eon et al. 2005).

\subsubsection{Leber}

Schon ältere Untersuchungen haben gezeigt, dass Östrogene einen indirekten Einfluss auf die Funktion der Leber haben, indem Sie die Plasmakonzentrationen von Cholesterol, HDL und LDL (high bzw. low density lipoprotein) modifizieren(Sacks und Walsh 1990, Walsh et al. 1991). Neuere Studien gewähren einen Einblick in die hieran maßgeblich beteiligten Mechanismen: Der Entzug von Östrogen in der Postmenopause wird hierbei für die Entwicklung einer Steatosis Hepatis verantwortlich gemacht. Diese These gründet auf der Tatsache, dass Östrogen tiefgreifend in den hepatischen Fettsäuremetabolismus involviert ist (Nemoto et al. 2000) (vgl. 1.3.1). So konnte gezeigt werden, dass bei Aromatase-Knock-outMäusen eine Verschlechterung der mitochondrialen und peroxisomalen $\beta$-Oxidation der Fettsäuren durch eine Behandlung mit 17ß-Estradiol wieder rückgängig gemacht werden konnte. Diese Resultate verdeutlichen die fundamentale Rolle, die Östrogene in der konstitutiven Expression von Enzymen des Fettsäuremetabolismus spielen, um die hepatische Lipidhomöostase aufrecht zu erhalten.

\subsubsection{Serumlipidwerte}

Es ist bekannt, dass sich mit dem Eintreten der Wechseljahre der Fettstoffwechsel rasch verändert. Grund hierfür ist vor allem die Abnahme von Östrogenen, die kontrollierend auf die LDL- und HDL-Produktion wirken. So kommt es in der Postmenopause zu einem Anstieg der LDL-Konzentration und einem Abfall der HDL-Konzentration im Serum(Blum und Cannon 1998, Matthews et al. 1989) (s. auch „Leber“). Durch exogene Zufuhr von Estradiol konnte in randomisierten Studien eine LDL- und Insulin-Reduktion, sowie eine HDLErhöhung herbeigeführt werden(Hodis et al. 2001, Pickar et al. 1998). Auch die Insulinsensitivität sowie weitere metabolische Parameter konnten günstig beeinflusst werden (Kardos und Casadei 1999). In einer Studie von Mackey et al. wurde jedoch keine Einflussnahme auf die Serum-LDL-Subklassenverteilung bei HRT-Einnahme festgestellt (Mackey et al. 2005). Die häufig beschriebenen, positiven Wirkungen einer Hormonersatztherapie auf das kardiovaskuläre Profil von postmenopausalen Frauen werden demnach oft als indirekter Effekt gedeutet, da ein hohes LDL und ein niedriges HDL bekanntermaßen das Risiko für die Entwicklung einer Atherosklerose erhöhen(Karim et al. 2005). In neueren Studien wird in Frage gestellt, ob allein der LDL/HDL-Quotient der Hauptmechanismus ist, über den Östrogene kardioprotektiv wirken. So gibt es Ansätze, dass 
Östrogene zusätzlich die Oxidation von LDL inhibieren (was für die Pathogenität des LDLs nötig ist) und die Zytotoxizität des oxidierten LDLs auf neuronale Zellen herabsetzen können (Berco und Bhavnani 2001, Bhavnani et al. 2001) (s. auch 1.2.2.5. Herz und Gefäße).

\subsubsection{Herz und Gefäße}

Die epidemiologisch bewiesene Tatsache, dass sich das Risiko für die Entwicklung von Herz/Kreislauferkrankungen bei Frauen erst in der Postmenopause dem der gleichaltrigen Männer angleicht(Gordon et al. 1978), lässt vermuten, dass hier ein kausaler Zusammenhang zwischen vermindertem Östrogenangebot und der Entwicklung einer Erkrankung aus diesem Formenkreis besteht. Vor allem wird diese These durch die Erkenntnis untermauert, dass in Studien unter Estradioltherapie eine reduzierte Inzidenz von koronarer Herzkrankheit sowie eine verminderte Mortalität in Bezug auf kardiovaskuläre Erkrankungen gefunden werden konnte(Stampfer et al. 1991). Auch die Tatsache, dass der Anstieg des Risikos für die Entwicklung solcher Erkrankungen in den Wechseljahren unabhängig vom Alter und anderen Risikofaktoren, aber abhängig vom Zeitpunkt der Postmenopause auftritt, bestärkt diese Vermutung(Carr 2003, Colditz et al. 1987, Cooper et al. 1999, Fioretti et al. 2000, Gordon et al. 1978, Matthews et al. 1989, Mudali et al. 2005, Palmer et al. 1992, Rosenberg et al. 1981). $\mathrm{Ob}$ jedoch ein tatsächlicher Nutzen einer HRT zur Reduzierung von Herzkreislauferkrankungen besteht, wird kontrovers diskutiert (Rees und Stevenson 2008, Rossouw et al. 2002).

Es finden sich multiple Studien, die die Zusammenhänge zwischen Estradiolmangel und der Entwicklung von Arteriosklerose, arterieller Hypertonie und koronarer Herzkrankheit zu ergründen suchen:

Zunächst verändert Estradiol den Serumlipidspiegel günstig, so dass indirekt die Entstehung von atherosklerotischen Veränderungen minimiert wird (s. 1.2.2.4 Serumlipidwerte).

Darüber hinaus weiß man um die Wirkungen des E2 auf den Blutdruck. So führt Estradiol zu einer Abnahme des Gefäßtonus, und zwar hauptsächlich durch direkte Effekte auf die endotheliale Funktion via Östrogen-stimulierte Erhöhung der NO-Plasmakonzentration(Miller und Mulvagh 2007). Auch ist eine Inhibierung des Renin-Angiotensin-Systems durch Reduzierung der ACE(Angiotensin Converting Enzyme)-Transkription in Endothelzellen durch den Einfluss von Östrogen(Brosnihan et al. 1994, Gallagher et al. 1999) und eine Down-Regulation des Angiotensin-1-Rezeptors(Nickenig et al. 1998) bekannt. Viele weitere Effekte des Estradiols, z.B. auf vegetative Mechanismen, werden in Hinblick auf die 
Entwicklung eines Bluthochdrucks verantwortlich gemacht, bzw. verdächtigt(Miller und Duckles 2008).

Die vermehrte Entstehung einer koronaren Verkalkung bei Frauen in der frühen Postmenopause kann ebenfalls durch die Behandlung mit Östrogenen reduziert werden(Hodis et al. 2001, Manson et al. 2007). Dem entgegengesetzt stehen die Daten aus der Women's Health Initiative, wo eine positive Assoziation zwischen HRT und koronarer Herzerkrankung hergestellt werden konnte (s. 1.3 Die klassische HRT und ihre Nebenwirkungen). Aufgrund dieser Widersprüche wurden Metastudien durchgeführt, die ergaben, dass eine HRT bei Beginn in der frühen Postmenopause positive Effekte auf das Herz hat. Bei später begonnener Therapie und somit eventuell schon vorliegender, fortgeschrittener Arteriosklerose seien die Wirkungen der HRT auf das kardiovaskuläre System dann negativ(Manson und Bassuk 2007). In Bezug auf koronare Verkalkung, endotheliale Dysfunktion, Intimaverdickung, vaskuläre Entzündungsreaktionen und angrenzende Themengebiete wie Thromboseentstehung gibt es verschiedenste Hypothesen über die Pathomechanismen, über die das in der Postmenopause verringerte Estradiollevel kausal zu diesen Erkankungen in Beziehung steht(Miller und Duckles 2008, Saltiki und Alevizaki 2007).

Über die positiven Effekte von Estradiol am vaskulären System hinaus sind nun auch Studien über direkte Effekte am Myokard in das Zentrum des Interesses gerückt(Arias-Loza et al. 2008, Ling et al. 2006). Als molekulare Basis für eine direkte Estradiolwirkung am Herzen findet sich eine ER $\alpha$ - und ER $\beta$-Expression an Kardiomyozyten (Grohe et al. 1998, Nordmeyer et al. 2004). Die Regulation der Expression der beiden Rezeptoren wurde in vitro und in vivo unter pathologischen Bedingungen, wie z.B. bei Hypertonie, kardialer Hypertrophie und Myokardinfarkt, untersucht(Arias-Loza et al. 2008, Regitz-Zagrosek et al. 2007, Saltiki und Alevizaki 2007). Über die Regulation der Genexpression der Östrogenrezeptoren unter physiologischen Bedingungen liegen jedoch nur sehr limitiert Daten vor.

\subsection{Die klassische Hormonersatztherapie und ihre Nebenwirkungen}

Mittel der Wahl gegen Wechseljahresbeschwerden ist seit Jahrzehnten die Hormonersatztherapie (HRT), bestehend aus entweder einer Kombination aus Östrogen- und Progesteronderivaten (kombinierte HRT) oder auch einem Östrogenderivat allein. In Deutschland nehmen etwa vier bis fünf Millionen Frauen Präparate zur Hormonsubstitution ein. Dabei handelt es sich meist um Kombinationspräparate. Vor allem vasomotorische Symptome wie Hitzewallungen und die Entwicklung einer Osteoporose können durch eine 
solche Therapie nachgewiesenerweise günstig beeinflusst werden(Greendale et al. 1998, O'Connell et al. 1998).

Leider führt die HRT nicht nur zur Linderung von klimakterischen Beschwerden, sondern sie birgt auch gewisse Risiken in sich. So konnten zahlreiche Langzeitstudien, u.a. die „MillionWomen"-Studie zeigen, dass eine über einen längeren Zeitraum verabreichte kombinierte HRT mit erheblichen Gefahren, wie zum Beispiel mit einem gesteigerten Risiko für die Entwicklung von Brust-(Beral 2003) und Ovarialkarzinomen(Beral et al. 2007), einer Erhöhung des Risikos für kardiovaskuläre Erkrankungen, für thrombembolische Ereignisse und Schlaganfall, sowie eventuell sogar mit der Entwicklung einer Demenz, einhergeht(Breast cancer...1997, Rossouw et al. 2002). Eine Therapie mit ausschließlich einem isolierten Östrogenderivat kann bei nicht-hysterektomierten Frauen durch die Hyperplasie fördernde Wirkung des Estradiols zu einem Endometriumkarzinom führen und verbietet sich demnach(Cushing et al. 1998, Grady et al. 1995, Weiderpass et al. 1999). Trotz der Tatsache, dass die Inzidenz für Knochenfrakturen und Darmkrebs unter HRT gesenkt werden kann(Cauley et al. 2003, Rossouw et al. 2002), überwiegen also die Nachteile einer solchen Therapie, vor allem über einen längeren Zeitraum. Die mit einer Erhöhung der Risiken verbundene Dauer der HRT ist noch umstritten, nach 5 Jahren ist sie aber signifikant(Davis 2003, Rossouw et al. 2002).

Vor diesem Hintergrund wird deutlich, dass es von großer Bedeutung ist, Alternativen für die konventionelle HRT zur Linderung der Wechseljahresbeschwerden und zur Prävention von Osteoporose zu finden, die nicht mit den gefürchteten Nebenwirkungen einher gehen.

\subsection{Phytohormone}

Die Problematiken der konventionellen HRT und das hieraus entstandene, große Interesse an Alternativen zur Behandlung klimakterischer Symptome haben $\mathrm{zu}$ umfangreichen Forschungen auf dem Gebiet der Phytohormone geführt. Warum gerade diese Stoffgruppe in Bezug auf postmenopausale Beschwerden und andere hormonassoziierte Erkrankungen als interessant gilt, verdeutlichen folgende Erkenntnisse: Phytohormone sind, unter anderem, in relativ großer Menge in Soja enthalten. Epidemiologische Untersuchungen haben nun gezeigt, dass das verstärkte Auftreten hormonabhängiger Erkrankungen und klimakterischer Beschwerden mit westlichen Ernährungsgewohnheiten korreliert. So zeigen Bewohner ostasiatischer Länder, deren Ernährung einen hohen Gehalt an Soja aufweist, deutlich niedrigere Raten von verschiedenen Krebserkrankungen wie z.B. Mamma- und Endometriumkarzinomen, sowie ebenfalls ein gemindertes Auftreten von osteoporotischen 
Frakturen, von Herz-Kreislauferkrankungen und generellen, postmenopausalen Symptomen als Einwohner westlicher Länder(Adlercreutz H und Mazur 1997, Yamamoto et al. 2003). Eine Ursache für die niedrigere Inzidenz der oben genannten Karzinome könnte darin liegen, dass die Konzentrationen der im Blutplasma zirkulierenden Östrogene bei asiatischen Frauen um 20-30\% niedriger sind(Shimizu et al. 1990, Wang et al. 1991) und die Menstruationszyklen 2-3 Tage länger andauern(Henderson et al. 1985, Wu AH et al. 1996) als bei Frauen aus westlichen Ländern. Als Ursache für die niedrigeren Östrogenspiegel werden verschiedene Wirkungen von Phytoöstrogenen in Betracht gezogen(Loukovaara et al. 1995, Lu et al. 2000, Nagata et al. 1998, Pino et al. 2000). Fakt ist demnach, dass Frauen in ostasiatischen Ländern lebenslang einem deutlich niedrigeren Estradioleinfluss ausgesetzt sind. Hier wird ein Zusammenhang mit dem 4-5mal niedrigeren Brustkrebsrisiko vermutet(Bernstein et al. 1990, Key und Pike 1988). Bei Asiaten, die westliche Ernährungsgewohnheiten adaptieren, steigt das Erkrankungsrisiko auf ein westliches Niveau(Adlercreutz H und Mazur 1997, Ziegler et al. 1993), was genetische Unterschiede als Ursache ausschließt und Ernährungsgewohnheiten als Erklärung in den Vordergrund rückt. Untersuchungen dieser Korrelation haben verschiedene Forschungsgruppen daher zu der These geführt, dass das verstärkte Auftreten von hormonassoziierten Erkrankungen in westlichen Populationen mit der vergleichsweise deutlich reduzierten Aufnahme von Phytoöstrogenen über die Nahrung einhergehen könnte(Adlercreutz H 1998, Setchell 1998).

Doch durch welche Mechanismen ist es den Phytohormonen möglich, eventuell in die Pathogenese oben genannter Beschwerden und Erkrankungen einzugreifen? Phytohormone sind sekundäre Pflanzeninhaltsstoffe, die im menschlichen Körper eine dem endogenen Steroidhormon 17 $\beta$-Estradiol ähnliche Wirkung haben. Sie sind nicht-steroidaler Herkunft, teilen aber dennoch einige strukturelle Voraussetzungen mit dem endogenen Estradiol. Zur Entfaltung östrogenartiger oder antiöstrogenartiger Wirkungen sind sie deshalb unter anderem in der Lage, an die Östrogenrezeptoren zu binden(Price und Fenwick 1985, Setchell 1998), wobei die Bindung an den ER $\beta$ dominiert(Kuiper et al. 1998). Diese Eigenschaft macht sie zu potentiellen SERMs, selektiven Östrogen-Rezeptor-Modulatoren(Jordan 2001). Hierunter versteht man Substanzen, deren östrogenartige Wirkungen sich nur selektiv an den gewünschten Zielorganen entfalten. Ein perfekter SERM führt demnach zu östrogenartiger Wirkung im Gehirn inklusive der Hypophyse, am Urogenitalepithel, am kardiovaskulären System und an den Knochen, verfügt aber im Gegensatz zum Estradiol über keine proliferationsfördernden Eigenschaften an Brust und Uterus, wirkt also hier antiöstrogenartig(Wuttke et al. 2002). Ob und in welchem Maße es sich bei welchen 
Phytohormonen tatsächlich um wahre SERMs handelt und welche Nebenwirkungen ihr pharmakologischer Einsatz über einen langen Zeitraum mit sich bringt, ist jedoch noch nicht abschließend geklärt.

Auf der Basis ihrer chemischen Struktur lassen sich die Phytohormone in 5 Hauptgruppen unterteilen: Isoflavone, Flavone, Stilbene, Coumestane und Lignane.

In dieser Arbeit wurden die Effekte der Isoflavone Genistein und Equol und des Stilbens Resveratrol untersucht, sodass im Folgenden genauer auf diese Stoffgruppen eingegangen wird.

\subsubsection{Isoflavone}

\subsubsection{Genistein}

Genistein ist ein Phytohormon aus der Gruppe der Isoflavone, welches vor allem in Sojaprodukten(Glycine max), aber auch in Besenginster, Hauhechel und Kleearten(Trifolium pratense), enthalten ist.

Genistein zeigt strukturelle Ähnlichkeiten zum Östrogen und bindet an Östrogenrezeptoren verschiedener Organe(Boue et al. 2003, Cos et al. 2003). Studien zum Bindungsverhalten von Genistein zeigten eine stärkere Aktivität des Stoffes an ER (Kuiper et al. 1997), sodass Genistein als potentieller SERM imponiert(Patisaul et al. 2002, Setchell und Lydeking-Olsen 2003). In Reporterzellsystemen transaktiviert Genistein jedoch beide Östrogenrezeptoren mit ähnlicher Potenz (Mueller et al. 2004).

In vielen Publikationen wurden positive Effekte von Genistein sowie anderer Isoflavone auf den Knochenstoffwechsel nachgewiesen(Alekel et al. 2000, Draper et al. 1997, Fanti et al. 1998, Picherit et al. 2001, Scheiber et al. 2001). In Zellkulturen inhibiert Genistein die Expansion von Osteoklasten und regt gleichzeitig das Wachstum von Osteoblasten an(Rickard et al. 2003, Yamagishi et al. 2001). Auch in randomisierten, klinischen Studien konnte ein signifikant weniger ausgeprägter Verlust an Knochendichte nach Genisteinzufuhr verzeichnet werden(Atkinson et al. 2004, Morabito et al. 2002). Es liegt jedoch auch eine Studie vor, die anhand von Untersuchungen an ovariektomierten Ratten nachweist, dass zwar ein knochensparender Effekt mit niedrigen Dosierungen von Genistein (0,5 und 1,6mg pro Tag) als osteoprotektiv zu verzeichnen ist, höhere Dosen (5mg pro Tag) jedoch zum gegenteiligen Effekt einer beschleunigten Osteoporoseentstehung führen(Anderson et al. 1998). 
Genistein agiert zwar an Knochen und im Gehirn, verfügt jedoch auch über uterotrophe Effekte. So konnte in Kurzzeit Tierversuchen und in einer klinischen Studie nachgewiesen werden, dass Genistein das Uteruswachstum stimuliert(Diel et al. 2004, Kanno et al. 2003, Unfer et al. 2004). In Bezug auf die Genisteinwirkungen auf das Brustgewebe wurde eine Proliferationsförderung nachgewiesen(Rimoldi et al. 2007). Von Diel et al.(Diel et al. 2001) wurde in vitro und in transplantierten Tieren eine Stimulierung des Wachstums von humanen Mammakarzinomzellen gefunden. Der Effekt des Genisteins auf die Proliferation von humanen Mammakarzinomzellen und bestehenden Mammakarzinomen wurde jedoch anhand mehrerer Tiermodelle beschrieben und bleibt weiterhin kontrovers diskutiert (Allred et al. 2004, Dave et al. 2005, Harris et al. 2005, Jeune et al. 2005, Kijkuokool et al. 2006, Kousidou et al. 2005, Liu B et al. 2005, Schmidt et al. 2005, Vantyghem et al. 2005). Entwicklungsstudien vermuten außerdem, dass eine präventive Wirkung auf die Entwicklung eines Mammakarzinoms abhängig ist von einem lebenslangen Sojakonsum. So konnte bei einer frühen Exposition von Ratten oder jungen Mädchen mit Soja oder Genistein ein präventiver Effekt auf die Entwicklung eines Mammakarzinoms im Erwachsenenalter beobachtet werden(Cabanes et al. 2004, Lamartiniere 2002). Diese positive Wirkung kann im späteren Leben nicht ,,nachgeholt“" werden und kann dann sogar einen gegenteiligen Effekt haben(Allred et al. 2004, Lamartiniere 2002).

Isoflavone wie Genistein können außerdem durch ihre stimulierende Einflussnahme auf die Bildung und Freisetzung von SHBG (sex hormone binding globuline)(Carusi 2000) und durch ihren modulierenden Effekt auf diverse Enzyme (Aromatase, 17 Hydroxysteroiddehydrogenase)(Basly und Lavier 2005, Kao et al. 1998, Whitehead et al. 2002) zu einer Verminderung von verfügbarem Estradiol führen. Darüber hinaus greifen Phytohormone scheinbar in viele andere endokrine Systeme ein, da gezeigt werden konnte, dass sie Einfluss auf die Rezeptor Gen- und Proteinexpression anderer (Steroid-)Hormone haben(Liang et al. 2001).

Für Genistein ist zudem bekannt, dass es in hoher Dosis hemmend auf die Tyrosinkinase und die DNA-Topoisomerase II(Akiyama et al. 1987, Boersma et al. 2001, Yamagishi et al. 2001) wirkt. Da die Inhibierung der Tyrosinkinase eine Inhibierung GH-vermittelter Proliferationsförderung impliziert, wurde diese Tatsache oft als antionkogenetischer Effekt tituliert. Bewiesen wurde eine tatsächliche antikarzinogenetische Wirkung bisher allerdings nicht(Ren et al. 2001). Dem entgegengesetzt wurde für Genistein jedoch auch berichtet, dass es zu DNA-Strangbrüchen führen kann(Boos und Stopper 2000). 
Weiterhin wurden für Genistein klinisch relevante Wirkungen auf die Schilddrüsenfunktion entdeckt (Suppression der TSH-Sekretion, Inhibierung der Peroxidase Aktivität und hieraus resultierende Inhibierung der Thyroxin Synthese), was eventuell in jodarmen Gebieten zur Entwicklung von Strumata führen könnte(Chang und Doerge 2000).

Auf klimakterische Hitzewallungen ist, wenn überhaupt, nur ein spärlicher Effekt zu verzeichnen(Krebs et al. 2004, Phipps et al. 2002).

\subsubsection{Equol}

Equol ist ein Metabolit des Isoflavons Daidzein, welches ebenfalls in Soja enthalten ist. Es wird von der intestinalen Mikroflora durch reduktive Metabolisierung gebildet(Axelson et al. 1984, Joannou et al. 1995). Da die Metabolisierungsrate interindividuell unterschiedlich ist, wird in experimentellen und klinischen Studien mit dem aktiven Metaboliten Equol gearbeitet(Rowland et al. 2000). Es ähnelt strukturell dem 17 $\beta$-Estradiol und bindet an ER $\alpha$ und ER $\beta$, und zwar mit einer 100-mal höheren Affinität als Daidzein(Sathyamoorthy und Wang 1997). Die Bindungsaffinität entspricht der des Genisteins, jedoch wurde beobachtet, dass im Vergleich aller Isoflavone die höchste Transkriptionsaktivität in den Zielzellen durch Equol ausgelöst wird.

Tatsächlich sind nur 30-50\% der Menschen in der Lage, Equol zu produzieren. Man geht davon aus, dass das Maß der klinischen Wirksamkeit der Isoflavonaufnahme somit mit der Kompetenz Equol zu bilden, einhergeht. So beobachtet man einen besonders großen Nutzen der Isoflavone bei Menschen, die besonders viel Equol produzieren können(Rowland et al. 2000, Setchell et al. 2002, Setchell et al. 2003). Epidemiologische Studien weisen einerseits darauf hin, dass viel Equol produzierende Individuen ein niedrigeres Risiko für die Entwicklung eines Mammakarzinoms aufweisen als Menschen, die wenig Equol metabolisieren(Adlercreutz CH et al. 1995, Adlercreutz H 2002, Adlercreutz H et al. 1991, Duncan et al. 2000, Yamamoto et al. 2003). Andererseits wurde beobachtet, dass die Aufnahme hoher Dosen von Equol über die Nahrung zu klar mammotrophen Effekten führt(Rachon et al. 2008). Auch verlieren viel Equol bildende Frauen in der Postmenopause weniger Knochenmasse(Fujioka et al. 2004, Lydeking-Olsen et al. 2004). Durch die Behandlung mit Equol konnte eine signifikante Zunahme der Knochendichte bei osteopenischen Mäusen demonstriert werden(Fujioka et al. 2004), und zwar in einigen Studien ohne einen proliferativen Effekt am Uterus(Sehmisch et al. 2009), in anderen mit proliferativem Effekt(Phrakonkham et al. 2007, Rachon et al. 2007b, Rachon et al. 2007d). Im Rattenmodell führten hohe Dosen von über die Nahrung aufgenommenem Equol zu 
östrogenartigen Effekten auf den Prolaktinspiegel (Erhöhung) und entgegengesetzten Effekten auf die Gonadotropine (Erhöhung des Serum-LH)(Rachon et al. 2007c). Außerdem wurden durch die Equolapplikation eine verminderte Körpergewichtszunahme und günstige Auswirkungen auf metabolische Parameter provoziert(Rachon et al. 2007a). Für Equol ist außerdem bekannt, dass es im Vergleich zu den anderen Phytohormonen das stärkste antioxidative Potential besitzt. Dies wird auf seine strukturellen Ähnlichkeiten mit dem Tocopherol (Vitamin E) zurückgeführt.

\subsubsection{Stilbene}

\subsubsection{Resveratrol}

Resveratrol ist ein Polyphenol aus der Klasse der Stilbene und ist in mehr als 70 Pflanzen zu finden(Turner et al. 1999). Hier fungiert es vorwiegend als Phytoalexin, also als Abwehrstoff, der die Pflanze vor Infektionen, vor allem mit Pilzen, schützt. Die Aufnahme erfolgt beim Menschen hauptsächlich über Trauben und Erdnüsse, bzw. über aus diesen Lebensmitteln gefertigten Produkten. Der Gehalt an Resveratrol variiert verarbeitungsbedingt in Trauben bzw. Wein sehr stark zwischen 0,2 bis 8,0 mg/l(Mattivi 1993, Romero-Perez et al. 1999) und kann durch erhöhte UV-Einstrahlung gesteigert werden(Cantos et al. 2000, Celotti et al. 1996).

Resveratrol hat strukturelle Ähnlichkeiten mit Diethylstilbestrol, einem synthetischen Östrogen, und es kann an den Östrogenrezeptoren sowohl agonistische als auch antagonistische Wirkungen ausüben, abhängig von der Verfügbarkeit der spezifischen ERIsoform(Henry und Witt 2002). Es bindet im Gegensatz zu den anderen Phytohormonen gleich stark an beide Östrogenrezeptorsubtypen, jedoch mit einer 7000-fach geringeren Affinität als Estradiol.

Dem Resveratrol wird eine ganze Reihe positiver Eigenschaften zugesprochen. So hat es eine chemoprotektive Wirkung (Calabrese 1999, Jang et al. 1997, Lee et al. 1998), da es bei oxidativer Schädigung der DNA als natürliches Antioxidans fungiert(Cadenas und Barja 1999, Lin und Tsai 1999). Diese Erkenntnisse untermauernd wurde eine antikarzinogene Wirkung des Resveratrols in humanen Mammakarzinom- und Prostatakarzinomzellen, sowie in Karzinominduktionsmodellen an Ratten und Mäusen beobachtet(Haneke 2002). Das Abfangen freier Radikale soll außerdem einen protektiven Einfluss auf die Entwicklung von kardiovaskulären Krankheiten haben. Die Entdeckung, dass sich in Frankreich ein erniedrigtes Risiko für Herz-/Kreislauferkrankungen bei regelmäßigem Konsum von Rotwein, der bekanntermaßen Resveratrol enthält, findet, wurde demnach als „French-Paradoxon“ 
bekannt(Kopp 1998, Wu JM et al. 2001). Ebenfalls soll Resveratrol aufgrund seiner antioxidativen Eigenschaft die Entstehung von arthritischen Entzündungen inhibieren, Linderung bei klimakterischen Beschwerden bringen(Haneke 2002) und positiv in den LDLMetabolismus eingreifen. Auch eine Hemmung der Thrombozytenaggregation und neuroprotektive Effekte konnten in vitro beobachtet werden(Bhat KPL et al. 2001, Hao und He 2004). Weiterhin wurde eine antiinflammatorische Wirkung des Resveratrols durch Suppression der Prostaglandinsynthese beschrieben(Martinez und Moreno 2000). Eine außerdem für Schlagzeilen sorgende Entdeckung ist, dass Resveratrol in Tierversuchen eine lebensverlängernde Wirkung gezeigt hat(Valenzano et al. 2006) und vor ernährungsinduziertem Übergewicht und metabolischem Syndrom schützen soll(Lagouge et al. 2006). Uterotrophe Effekte des Resveratrol konnten bisher in ovariektomierten Ratten nicht nachgewiesen werden(Freyberger et al. 2001), aber von einer Beeinflussung der gonadalen Achse bei intakten Ratten wurde berichtet(Henry und Witt 2002). Die in vitro beobachteten Resveratrolwirkungen lassen sich jedoch nur schwierig auf die Situation in vivo übertragen. Bisher wurde in einer retrospektiven, epidemiologischen Studie eine 50\%-ige Reduktion des Brustkrebsrisikos bei Resveratrol über Trauben konsumierenden Frauen festgestellt(Levi et al. 2005), ansonsten fehlen aber aussagekräftige klinische Studien zur Resveratrolwirkung bei Menschen.

Zur Beantwortung der Frage, ob und in welchem Maße es sich bei den oben vorgestellten Phytohormonen tatsächlich um wahre SERMs handelt, die zur Behandlung von mit dem Klimakterium assoziierten Erkrankungen eingesetzt werden könnten, ist es unbedingt nötig, deren Eigenschaften an einem adäquaten Tiermodell zu testen.

\subsection{Das Mausmodell}

Zur Einschätzung des endokrinen Potentials von Testsubstanzen auf einen Organismus, ist die Durchführung von Tierversuchen nötig, da in vitro Parameter des intakten Organismus wie Aufnahme, Verteilung, Metabolisierung, Akkumulation und Exkretion des zu untersuchenden Stoffes nicht berücksichtigt werden können. Ein etabliertes und von der OECD validiertes Modell zur Erforschung östrogener Effekte in vivo ist die immature oder die ovariektomierte Ratte. Basierend auf der Regulation des Uteruswachstums im natürlichen Zyklus des Tieres, der nur 4-5 Tage dauert, ist im Rahmen des uterotrophen Assays eine dreitägige, subkutane oder orale Applikation von der Testsubstanz an die zuvor ovariektomierten, bzw. noch immaturen Tiere, vorgesehen. Nach der Tötung der Tiere (Tag 4) zeigt ein signifikant 
gesteigertes Uterusgewicht eine östrogene Wirkung der Testsubstanzen an(Kanno et al. 2001). Neben den Auswirkungen auf den Uterus können an diesem Tiermodell zudem die Effekte östrogener Substanzen auf weitere Organsysteme erforscht werden(Gallo et al. 2005, Kalu 1991). Die ovariektomierte Ratte ist somit ein ideales Modell zu Erforschung östrogener Wirkungen in vivo und wurde aus diesem Grund in der Vergangenheit in multiplen Studien verwendet.

Zur weitergehenden Erforschung Östrogen-vermittelter Wirkungen wird mittlerweile vermehrt mit Knock-out-Tieren gearbeitet. Ein Beispiel hierfür sind die ER $\alpha$ - und ER $\beta$ Knock-out-Tiere, auch $\alpha$ ERKO und $\beta E R K O$ genannt(Couse et al. 1995, Lubahn et al. 1993). Die Herstellung von ER $\alpha$ - und ER $\beta$-Knock-out-Ratten ist technisch gesehen sehr schwierig, so dass es sich bei den verwendeten Nagern um Knock-out-Mäuse handelt. Die mit diesen Tieren generierten Ergebnisse lassen sich allerdings nicht direkt mit den Resultaten aus älteren Studien am Modell der Ratte vergleichen. Es ist somit von enormer Wichtigkeit, die Effekte von Estradiol und endokrinen Disruptoren an normalen Mäusen zu erforschen, damit diese zum Vergleich mit an KO-Mäusen erhobenen Ergebnissen zur Verfügung stehen.

In Anlehnung an den uterotrophen Assay der OECD sind die meisten Studien zur östrogenen Wirkung als Kurzzeitversuche von wenigen Tagen angelegt. Auswirkungen, die durch eine Applikation über einen längeren Zeitraum an verschiedenen Organsystemen auftreten könnten, werden hierbei nicht erfasst. Dabei sind gerade diese Erkenntnisse in Bezug auf die Nebenwirkungen einer Langzeiteinnahme von Präparaten, die östrogenartig wirkende Substanzen enthalten, von großer Wichtigkeit. Schließlich erfolgt die Einnahme dieser Präparate in den wenigsten Fällen nur für die Länge eines Zyklus‘. Tierexperimentelle Studien über einen Zeitraum von drei Monaten sind deshalb von immenser Bedeutung, um positive wie auch negative Effekte der untersuchten Substanzen zu entdecken.

\subsection{Von Östrogenen regulierte Gene/Proteine}

Eine große Zahl von Genen wird in ihrer Transkription durch Östrogene direkt oder indirekt beeinflusst. Sie können somit als biologische Marker für die Östrogenwirkung dienen. Im folgenden Kapitel sollen einige Beispiele aufgeführt werden.

\subsubsection{LH及}

LH ist ein Hormon aus der Gruppe der Glykoproteine. Diese liegen als Heterodimere von zwei nicht-kovalent aneinandergebundenen Untereinheiten vor. Während die $\alpha$-Untereinheit 
für die Glykopeptidhormone TSH, FSH und LH gleich ist, determiniert die $\beta$-Untereinheit die biologische Spezifität für den jeweiligen Rezeptor(Pierce und Parsons 1981).

LH wird in der Hypophyse produziert. Die LH-Sekretion wird durch Estradiol über einen negativen Feedbackmechanismus niedrig gehalten. Durch die Ovariektomie entfällt dieser negative Feedbackmechanismus. Die Folge ist eine erhöhte LH-Sekretion und eine Erhöhung der Expression von LH-mRNA in der Hypophyse. Bei Verabreichung von Estradiol nach Ovariektomie bleibt dieser Effekt jedoch aus. Deshalb kann LH $\beta$ als biologischer Marker für die Estradiolwirkung benutzt werden.

\subsubsection{Komplementfaktor C3}

Komplementfaktor C3 ist eines der Proteine des Komplementsystems, welches Bestandteil der humoralen, unspezifischen Immunabwehr ist. Unter Estradiolstimulation findet in Rattenuteri eine Synthese und Ausschüttung von C3-Protein statt. Die Produktion von C3 als Reaktion auf Estradiol ist dabei spezifisch und kann nicht durch andere Steroidhormone ausgelöst werden, womit C3 einen verlässlichen Marker für die östrogene Reaktion am Uterus darstellt(Komm et al. 1986, Sundstrom et al. 1990).

\subsubsection{IGF-1}

Der menschliche Insulin-like growth factor-1 (IGF-1), auch als Somatomedin C bekannt, besteht aus einer einzelnen Polypeptidkette mit 70 Aminosäuren und zeigt große strukturelle Ähnlichkeiten zum Pro-Insulin(Rinderknecht und Humbel 1978).

Er vermittelt die anabole und mitogene Wirkung von GH (Growth Hormone). IGF-1 wird unter dem Einfluss von GH vor allem in der Leber, aber auch in Niere und Bindegewebe gebildet und wirkt über spezifische Rezeptoren v.a. auf Osteoblasten, Fibroblasten und Knorpelgewebe. Postnatales Wachstum und Organentwicklung sind abhängig von eben jenem Growth Hormone (GH). Im Organismus Erwachsener ist die Funktion von IGF-1 spezieller und wird von der Differenzierung des entsprechenden Gewebes vorgegeben(Dupont und Le Roith 2001). Die GH-IGF-1-Interaktion und ihr Einfluss auf Wachstum und Organentwicklung wird in Studien mit Knock-out-Tieren immer genauer untersucht(Le Roith et al. 2001). In jedem Fall ist jedoch davon auszugehen, dass eine GH-unabhängige Aktivität des IGF-1 besteht: IGF-1 wird, genau wie IGF binding proteins (IGFBPs), unter anderem in den endometrialen Stromazellen produziert. IGF-1 hat im Uterus einen stimulierenden Effekt auf die Proliferation, die Differenzierung und den Metabolismus des Gewebes. Diese wird über den membranständigen IGF-Rezeptor in Epithel- und Bindegewebszellen vermittelt. 
Östrogen stimuliert die Genexpression von IGF-1 im Endometrium und jenes IGF-1 vermittelt daraufhin die östrogenartige Wirkung(Rutanen 1998). Die Messung der IGF-1Genexpression kann somit Aufschluss darüber geben, ob eine molekulare Antwort auf exooder endogenes Östrogen im Endometrium stattfindet. Nach einmaliger Injektion von 17 $\beta$ Estradiol an präpubertäre, ovariektomierte Ratten steigt die IGF-1-mRNA-Expression im Uterus deutlich an, wobei keine signifikanten IGF-1-Veränderungen in Leber, Nieren und Serum festgestellt werden können(Murphy et al. 1987)

\subsection{Zielsetzung der Arbeit}

Die unerwünschten Arzneimittelwirkungen der konventionellen Hormonersatztherapie im Rahmen der Behandlung von postmenopausalen Beschwerden haben $\mathrm{zu}$ einem großen Interesse an alternativen Behandlungsmöglichkeiten geführt. Im Zuge dessen sind Phytohormone ins Zentrum des Interesses gerückt. Wobei diese Stoffe potentielle, selektive Östrogenrezeptor-Modulatoren sein könnten. Zum einen ist somit das Ziel dieser Arbeit zu klären, ob es sich bei Genistein, Equol und Resveratrol tatsächlich um SERMs handelt, die für die Behandlung von mit dem Klimakterium einhergehenden Beschwerden und Erkrankungen genutzt werden können.

Darüber hinaus ist die Etablierung des Tiermodells der ovariektomierten Maus das zweite Ziel dieser Arbeit. Aufgrund der unzulänglichen Vergleichbarkeit von an Ratten erhobenen Ergebnissen mit den neuen, an KO-Mäusen gewonnenen Resultaten ist es von enormer Wichtigkeit, Informationen über die Wirkung von Estradiol und anderen Substanzen auf die verschiedenen Organe von genetisch intakten, ovariektomierten Mäusen zu erhalten.

Zudem soll im Rahmen dieser Arbeit der Einfluss von Estradiol, Genistein, Equol und Resveratrol im Langzeitversuch über 3 Monate beobachtet werden. Bisher liegen keine Studien mit einem vergleichbaren Design an Mäusen vor. Die Beobachtung über einen längeren Zeitraum soll eventuell vorliegende, noch unbekannte Effekte der Substanzen bei Langzeiteinnahme aufzeigen.

Neben den Effekten, die die untersuchten Substanzen auf Uterus, Leber, Hypophyse und Knochen haben, werden auch die Veränderungen in Bezug auf das Körpergewicht und den Serumlipidspiegel analysiert. Besondere Beachtung soll in dieser Arbeit zudem den Wirkungen von Estradiol und den anderen Stoffen auf das Herz geschenkt werden, da zu diesem Thema bisher nur sehr limitierte Daten vorliegen und noch immer nicht beantwortet werden kann, aus welchem Grund ein so beträchtlicher Unterschied in der Inzidenz kardiovaskulärer Erkrankungen zwischen den Geschlechtern bis zum Eintreten der 
Menopause vorliegt. So fehlen beispielsweise Informationen über die Regulation der Genexpression der kardialen Östrogenrezeptoren unter physiologischen Bedingungen. 


\section{Material und Methoden}

\subsection{Material}

\subsubsection{Tierversuchsgenehmigung}

Für die Tierexperimente lag eine Genehmigung der Bezirksregierung Braunschweig vor. Das Aktenzeichen lautet 33.42502/01-30.05.

\subsubsection{Versuchstiere und ihre Haltungsbedingungen}

Die tierexperimentellen Versuche wurden an 75 weiblichen Wildtyp Mäusen (C 57 BL/6J) durchgeführt, welche von der Firma Winkelmann GmbH, Borchen bezogen wurden. $\mathrm{Zu}$ Beginn des Versuches waren die Tiere zwei Monate alt. Sie wurden unter standardisierten Bedingungen gehalten: Die durchschnittliche Umgebungstemperatur in den Tierställen betrug $23^{\circ} \mathrm{C}$ bei einer durchschnittlichen Luftfeuchtigkeit von 50-55\% .Je sieben Mäuse lebten in einem Makrolon-Käfig vom Typ IV. Der Haltungsraum wurde täglich von 6:00 bis 18:00 Uhr beleuchtet. Den Tieren standen ohne Einschränkungen Wasser und Futter zur Verfügung. Sie wogen bei Versuchsbeginn im Durchschnitt $19 \mathrm{~g}$.

Bei dem zugeführten Futter handelte es sich um eine spezielle, sojafreie Anfertigung der Firma Ssniff, Soest. Über dieses Futter wurden die untersuchten Phytohormone und die Substanz für die Positivkontrolle (Estradiol) verabreicht. Hierzu wurden die Tiere in fünf Gruppen à 15 Mäuse aufgeteilt. Die Tiere der Negativkontrolle erhielten das sojafreie Futter ohne jedwede Zusätze.

Substanzen per os: Sojafrei Estradiol Genistein Resveratrol Equol

$\begin{array}{llllll}\text { Anzahl der Tiere: } & 15 & 15 & 15 & 15 & 15\end{array}$

Es wurde von einer täglichen Futteraufnahme von 4g pro Tier und Tag ausgegangen.

Die Futterinhaltstoffe wurden wie folgt dosiert: 4,32 mg 17ß-Estradiolbenzoat, bzw. 1000mg Genistein, 840mg Resveratrol oder 400mg Equol pro kg sojafreies Futter. Die gewählten Konzentrationen orientieren sich hierbei an Erfahrungen aus vorigen Studien, im Rahmen derer Ratten mit den oben genannten Substanzen in gleicher Quantität behandelt wurden und bei denen unter diesen Umständen östrogene Effekte nachweisbar waren(Bottner et al. 2006, Rachon et al. 2007b). Während des gesamten Versuchsverlaufs wurden die Tiere täglich auf 
eventuell auftretende gesundheitliche Schäden untersucht. Keines der Tiere zeigte zu irgendeinem Zeitpunkt Anzeichen für eine Vergiftung oder andere körperliche Missstände. Es wurden wöchentlich Körpergewicht und Futteraufnahme der Versuchstiere bestimmt. Die Behandlung mit den Testsubstanzen erfolgte für drei Monate. Am Ende des Versuches wurden die Tiere unter tiefer $\mathrm{CO}_{2}$-Narkose dekapitiert und seziert.

Tabelle 1: Konzentration der Substanzen im Futter und ihre Aufnahme pro Tier pro Tag

\begin{tabular}{|l|l|l|}
\hline & $\begin{array}{l}\text { Konzentration der Substanzen } \\
\text { im Futter }\end{array}$ & $\begin{array}{l}\text { Quantitative Aufnahme der } \\
\text { Substanzen } \\
\text { pro Tier und pro Tag }\end{array}$ \\
\hline Soja frei & - & - \\
\hline Estradiol & $4,3 \mathrm{mg} / \mathrm{kg}$ & $0,011 \mathrm{mg}$ \\
\hline Genistein & $1000 \mathrm{mg} / \mathrm{kg}$ & $2,34 \mathrm{mg}$ \\
\hline Resveratrol & $840 \mathrm{mg} / \mathrm{kg}$ & $2,12 \mathrm{mg}$ \\
\hline Equol & $400 \mathrm{mg} / \mathrm{kg}$ & $0,83 \mathrm{mg}$ \\
\hline
\end{tabular}

\subsubsection{Ovariektomie}

Die Ovariektomie wurde unter Ketamin-(90 mg/kg) und Rompun-(7,5 mg/kg) Narkose durchgeführt (ip-Applikation). Im Bereich der Flanken wurde das Fell beidseitig geschoren und das Tier in Seitenlage verbracht.

Nach Desinfektion des Operationsgebietes und Eröffnung der Bauchhöhle unter Durchtrennung von Haut und Muskulatur im Winkel zwischen Wirbelsäule und Rippenbogen wurde das nun unmittelbar zugängliche Ovar mittels einer Pinzette vorgelagert und von dem umgebenden Fettgewebe befreit.

Das Ovidukt bzw. der distale Anteil der Uterushornspitze wurde mit einer Arterienklemme gequetscht, mit Catgut (3 metric, Ethicon) ligiert und das Ovar mit einem Skalpell abgesetzt. Nach Reposition des Uterushornes in die Bauchhöhle wurde diese durch einschichtigen Verschluss der Muskulatur mittels eines einfachen Knopfheftes unter Verwendung von Catgut (s.o.) geschlossen. Eine Adaptation der Wundräder des Hautschnittes wurde durch zwei Knopfhefte mit nicht-resorbierbarem Nahtmaterial (Supramid, B.Braun) erreicht. 
Zur Vermeidung exsikkotischer Zustände erhielten die Mäuse post operationem je $1 \mathrm{ml}$ isotone NaCI-Lösung (Braun) subkutan (s.c.). Zur Schmerzprophylaxe wird Rimadyl einmalig postoperativ s.c appliziert $(5 \mathrm{mg} / \mathrm{kg})$. Bis zum vollständigen Erwachen wurden die Tiere überwacht.

\subsubsection{Gewinnung des biologischen Probenmaterials}

Für die vorliegenden Untersuchungen wurden den Versuchstieren jeweils Blut, die Leber, der Uterus, die Hypophyse, die Lunge, das Herz und die linke Tibia entnommen. Die Unterschenkelknochen wurden von Fett-, Muskel- und Sehnenresten befreit und wie die restlichen Organe in einzelnen Eppendorf-Cups in flüssigem Stickstoff tiefgefroren und bei $-80^{\circ} \mathrm{C}$ gelagert.

\subsection{Methoden}

\subsubsection{Molekularbiologische Methoden}

\subsubsection{Extraktion der Gesamt-RNA}

Zur Extraktion der Gesamt-RNA wurde zunächst das tiefgekühlte Gewebe von Leber und Uterus im Mikro-Dismembrator (Fa.Braun, Melsungen) pulverisiert. Dazu wird ein Teil des Gewebes in ein durch Stickstoff gekühltes Teflongefäß gegeben, in welchem sich eine Metallkugel befindet, die das Gewebe im Gefäß unter den Schüttelbewegungen des Dismembrators (bei 2500 Upm, 15 Sekunden lang) zerkleinert. Das gewonnene Pulver wird in 600 $\mu 1$ RLT-Lysis Puffer (aus dem RNeasy Kit, QUIAGEN, Hilden) suspendiert, mit $6 \mu 1$ Mercaptoethanol (Firma Merck, Darmstadt) versetzt und weiter in flüssigem Stickstoff gekühlt.

Der so in Pufferflüssigkeit suspendierte Organpuder wird nun in QIAshredder-Säulen (Firma QUIAGEN, Hilden) pipettiert und für zwei Minuten bei 12.000 RPM zentrifugiert. Dieser Arbeitsschritt dient der weiteren Zerkleinerung. Das im Puffer gelöste Gewebe wird nun mit $600 \mu 1$ 70\%-igem Ethanol versetzt und anschließend in RNeasy Mini Spin Columns (Firma QUIAGEN, Hilden) überführt. Diesem Arbeitsschritt schließt sich eine 15-sekündige Zentrifugation bei 10.000 RPM an. Die zu extrahierende RNA findet sich hiernach im Filter der Säule. Der abzentrifugierte Flüssigkeitsrest kann deshalb verworfen werden. Auf das Säulengefäß wird nun $700 \mu 1$ RW1-Puffer, ebenfalls aus dem RNeasy Mini Kit, gegeben. Es folgt eine erneute Zentrifugation bei 10.000 RPM für 15 Sekunden. Das Säulengefäß 
inklusive Filter mit RNA wird nun in ein neues Auffangröhrchen (Collection Tubes aus dem RNeasy Mini Kit) gesteckt. Es werden 500 $\mu 1$ RPE Puffer aus dem RNeasy Mini Kit auf die Säule pipettiert, das Ganze für 15 Sekunden bei 10.000 RPM zentrifugiert und die aufgefangene Flüssigkeit erneut verworfen. Der Spülvorgang mit $500 \mu$ l RPE-Puffer (RNeasy Mini Kit) wurde wiederholt und die Säule anschließend für zwei Minuten bei 12.000 RPM zentrifugiert.

Um die extrahierte RNA aus der Säulenmembran auszuspülen und aufzufangen werden die Säulen nun in 1,5 ml Eppendorf-Cups (Firma Sarstedt, Nümbrecht) gestellt, mit $50 \mu 1$ RNase freiem Wasser (ebenfalls aus dem RNeasy Mini Kit) befüllt und eine Minute lang bei 10.000 RPM zentrifugiert.

Der linke Ventrikel, die Adenohypophyse und ein Stück der Lunge wurden in $600 \mu$ RTLysis-Puffer mit einem Ultra Turrax (TP18/10, Janke \& Kunkel, Staufen) in ca. $30 \mathrm{~s}$ zerkleinert. Die Suspensionen wurden für $15 \mathrm{~s}$ in einem Ultraschallbad (Bransonic 32 Sonicator Bath, Branson Instruments, Danbury, CT, USA) homogenisiert. Auch dieses Homogenat wurde über QIAshredder Säulen (Qiagen, Hilden) von groben Gewebestückchen befreit und, wie oben beschrieben, über drei Waschzyklen aufgearbeitet.

Die so extrahierte und gelöste RNA wurde dann umgehend bei $-70^{\circ} \mathrm{C}$ tiefgekühlt.

Zur Quantifizierung der Menge an RNA in den einzelnen Proben schloss sich der Extraktion eine photometrische Analyse an. Somit konnte für die folgenden Verdünnungsreihen eine Berechnungsgrundlage erstellt werden.

Zur Bestimmung der Konzentration der RNA wurde diese 1:16 mit $\mathrm{H}_{2} \mathrm{O}_{\text {velc }}$ verdünnt. Die Extinktion bei $260 \mathrm{~nm}$ wurde in Quarzküvetten (Suprasil, Hellma, Müllheim) in einem Biophotometer (Eppendorf, Hamburg) gemessen. Eine $\mathrm{OD}_{260}$ von 1 entspricht einer RNAKonzentration von ca. $40 \mu \mathrm{g} / \mathrm{ml}$ bei einer Schichtdicken von $1 \mathrm{~cm}$. Da organische Verunreinigungen wie z.B. Aminosäuren bei einer Wellenlänge von $280 \mathrm{~nm}$ absorbieren, kann durch den Quotienten $\mathrm{OD}_{260 \mathrm{~nm}} \mathrm{zu} \mathrm{OD}_{280 \mathrm{~nm}}$ der Grad der Verunreinigung durch Aminosäuren bestimmt werden. Bei einem Quotienten von 1,8 bis 2 kann die RNA als rein angesehen werden. 


\subsubsection{Reverse Transkription}

Für die Genanalyse in TaqMan® und iCycler ${ }^{\circledR}$ ist die Herstellung von amplifizierbarer cDNA aus mRNA durch die RNA-abhängige DNA-Polymerase Reverse Transkriptase notwendig.

Für die Umwandlung von mRNA zu cDNA wurde hier ein Kit (Promega, Mannheim), welches eine murine, retrovirale RT ohne RNase-Aktivität enthält, eingesetzt.

Zunächst wurden $10 \mu 1$ der gewonnenen RNA-Lösung in einer Konzentration von 20ng/ $\mu 1$ mit $3 \mu 1 \mathrm{H}_{2} \mathrm{O}$ velc und $1 \mu \mathrm{l}$ Random-Primer (Invitrogen, Karlsruhe; 1:30) versetzt. Random-Primer sind sequenzunspezifische Hexamere.

Dieser Ansatz wurde im Thermocycler (Fa. Biometra, Göttingen) bei $70^{\circ} \mathrm{C}$ für 10 Minuten inkubiert, um eine Denaturierung der Sekundärstrukturen zu erreichen.

Hiernach wurden dem Reaktionsvolumen folgende Substanzen zugesetzt:

$1 \mu \mathrm{l}$ M-MLV Reverse Transcriptase RNase H Minus, Point Mutant, Promega, Mannheim $4 \mu \mathrm{l}$ M-MLV RT 5x Reaction Buffer

$1 \mu 110$ mM dNTP-Mix Invitrogen, Karlsruhe

0,1 $\mu$ l RNasin, Recombinant RNasin Ribonuclease Inhibitor, Promega, Mannheim.

Nun wurde dieser Mix bei $22^{\circ} \mathrm{C}$ für 10 Minuten inkubiert, um eine Anlagerung der Primer zu ermöglichen.

Daran schloss sich automatisch eine weitere Inkubation von 50 Minuten bei $42^{\circ} \mathrm{C}$ zur Synthese des Gegenstranges an.

Zur abschließenden Denaturierung der Stränge wurde für weitere 10 Minuten bei $95^{\circ} \mathrm{C}$ inkubiert.

Die Proben wurden nach kurzem Abkühlen zentrifugiert und bei $-20^{\circ} \mathrm{C}$ gelagert.

\subsubsection{Real-Time PCR}

Die Bestimmung der IGF-1- und ER $\alpha$-Expression wurde im TaqMan®) -PCR-Assay (Fa. Applied Biosystems GmbH, Darmstadt) durchgeführt, während die Analysen von ER $\beta$, LH $\beta$ und C3 auf dem iCycler® (BioRad iCycler, Hercules, CA, USA) vorgenommen wurden.

\subsection{TaqMan ${ }^{\circledR}$ PCR}

\section{Durchführung}

Zunächst wurde ein zweifach TaqMan® ${ }^{\circledR}$-PCR-Puffer aus Reagenzien der Firma Eurogentec (Köln) angesetzt, der aus den folgende Inhaltsstoffen bestand: 
$2500 \mu 110$ x Reaction Buffer

$1750 \mu \mathrm{l} 50 \mathrm{nM} \mathrm{MgCl} 2$

$1000 \mu \mathrm{l}$ 5,0 mM dNTP-Mix

$125 \mu 1$ PCR Enzym

$250 \mu \mathrm{UNG}$

$6875 \mu$ Ampuwa.

Der hergestellte Puffer konnte einen Monat im Kühlschrank gelagert und somit in voraus für 1000 Reaktionen hergestellt werden.

Der Ansatz wurde in 96-Well Mikrotiterplatten pipettiert (MicroAmp Optical 96-Well reaction Plate, PE Applied Biosystems, Weiterstadt) und mit optischen Deckelketten (MicroAmp Optical Caps, PE Applied Biosystems, Weiterstadt) verschlossen.

Jeder Ansatz beinhaltete eine Standardkurve mit einer cDNA aus sechs bis acht Punkten in Doppelbestimmung sowie Negativkontrollen ohne cDNA.

Je eine Vertiefung der Well-Platten enthielt hierbei $25 \mu 1$ der folgenden Reaktionslösung:

Tabelle 2: Reaktionslösung Taqman

\begin{tabular}{|l|l|}
\hline & ER $\alpha$ / IGF-1 \\
\hline cDNA der Probe & $2 \mu \mathrm{l}$ \\
\hline Taqman PCR Puffer $(2 \mathrm{x})$ & $12,5 \mu \mathrm{l}$ \\
\hline Primer sense $(300 \mu \mathrm{M})$ & $0,75 \mu \mathrm{l}$ \\
\hline Primer antisense $(300 \mu \mathrm{M})$ & $0,75 \mu \mathrm{l}$ \\
\hline Sonde $(225 \mu \mathrm{M})$ & $0,5 \mu \mathrm{l}$ \\
\hline Ampuwa & $8,5 \mu \mathrm{l}$ \\
\hline
\end{tabular}

Die Reaktionsanalyse der PCR fand im ABI PRISM 7700 Sequence Detection System (Fa. PE Applied Biosystems GmbH, Darmstadt) statt. Hierzu durchliefen die Proben einmal die Temperaturzyklen 1. und 2. und anschließend 40mal die Temperaturzyklen 3. und 4.: 
1. 2 min bei $50^{\circ} \mathrm{C}$

2. $10 \min$ bei $95^{\circ} \mathrm{C}$

3. $15 \mathrm{sec}$ bei $95^{\circ} \mathrm{C}$

4. $1 \mathrm{~min}$ bei $60^{\circ} \mathrm{C}$.

Dabei befand sich über jeder der Well-Vertiefungen eine Linse, die den Strahl eines Argon Lasers $(488 \mathrm{~nm})$ weiterlenkte. Somit wurde eine Fluoreszenzanregung herbeigeführt, deren Fluoreszenzemissionen im gleichen Arbeitsschritt gemessen und von einem Power Macintosh 4400 aufgezeichnet wurden. Die Analyse dieser Aufzeichnungen fand später statistisch durch den Vergleich mit den Standardkurven statt.

\subsubsection{2 iCycler ${ }^{\circledR}$ PCR}

Im iCycler® System erfolgt die Detektierung des PCR-Produktes mittels SYBRGreenMarkierung. Hierbei lagert sich der unspezifische Fluoreszenzfarbstoff direkt in die dsDNA ein, wodurch es zu einem Anstieg der zu messenden Fluoreszenz dieses Farbstoffes kommt. Auch hier besteht, wie beim Taq-Man-Assay eine direkte Korrelation zwischen der Zunahme der Fluoreszenz und der Zunahme der DNA.

Zur Quantifizierung des DNA-Gehaltes der Proben werden die Ergebnisse mit einer relativen Standardkurve verglichen. Diese besteht aus acht Verdünnungsreihen in Doppelbestimmung, die im Verhältnis von 1:2 aus einem cDNA-Pool der Proben erzeugt wird. Nur die Standardkurve für IGF-1 wird in Verdünnungsreihen von 1:10 angesetzt.

Jeder untersuchte Probenansatz enthält außerdem Negativkontrollen ohne cDNA-Inhalt.

\section{Durchführung}

Zunächst wurde auch bei dieser Form der RT-PCR ein Mastermix aus 2x Supermix (IQ BioRad SYBR Green Supermix, Hercules, CA, USA), den beiden Primerpaaren und Ampuwa hergestellt.

Für die PCR wurde das Reaktionsgemisch auf 96-Well Mikrotiterplatten (96 Multiply PCR plate, Sarstedt, Nümbrecht) aufgebracht und anschließend mit einer optischen Klebefolie (Adhäsiv Folie, Sarstedt, Nümbrecht) verschlossen.

In jede Vertiefung der Well-Platte wurden $22 \mu 1$ der Reaktionslösung mit folgender Zusammensetzung pipettiert: 
Tabelle 3: Reaktionsansatz iCycler

\begin{tabular}{|l|l|l|}
\hline & C3 / ER $\alpha$ & LH $\beta$ \\
\hline cDNA der Probe & $2 \mu \mathrm{l}$ & $\begin{array}{l}2 \mu \mathrm{l}(1: 10 \text { verdünnt } \\
\text { mit Ampuwa })\end{array}$ \\
\hline $\begin{array}{l}\text { BioRad IQ SYBR } \\
\text { Green Supermix }(2 \mathrm{x})\end{array}$ & $10 \mu \mathrm{l}$ & $10 \mu \mathrm{l}$ \\
\hline Primer sense & $1 \mu \mathrm{l}$ & $1 \mu \mathrm{l}$ \\
\hline Primer antisense & $1 \mu \mathrm{l}$ & $1 \mu \mathrm{l}$ \\
\hline Ampuwa & $8 \mu \mathrm{l}$ & $8 \mu \mathrm{l}$ \\
\hline
\end{tabular}

Die Analyse der Proben erfolgte im iCycler IQ Real-Time Detection System (BioRad, Hercules, CA, USA). Hierbei wurde Schritt 1. einmal, alle weiteren Temperaturzyklen 50mal durchlaufen:

Tabelle 4: Temperaturzyklen, iCycler

\begin{tabular}{|c|c|}
\hline $\mathrm{C} 3 / \mathrm{ER} \alpha$ & $\mathrm{LH} \beta$ \\
\hline 1. $15 \mathrm{~min}-95^{\circ} \mathrm{C}$ & 1. $10 \mathrm{~min}-95^{\circ} \mathrm{C}$ \\
\hline 2. $30 \mathrm{sec}-95^{\circ} \mathrm{C}$ & 2. $30 \mathrm{sec}-95^{\circ} \mathrm{C}$ \\
\hline 3. $30 \mathrm{sec}-60^{\circ} \mathrm{C}$ & 3. $1 \mathrm{~min}-60^{\circ} \mathrm{C}$ \\
\hline 4. $30 \mathrm{sec}-72^{\circ} \mathrm{C}$ & 4. $10 \mathrm{sec}-55^{\circ} \mathrm{C}$ \\
\hline 5. $10 \mathrm{sec}-55^{\circ} \mathrm{C}$ & \\
\hline
\end{tabular}

Die Auswertung des Ergebnisses erfolgte über die iCycler Optical System Software (BioRad, Hercules, CA, USA).

\subsubsection{Primer und Sonden}

Folgende Sonden und Primer wurden für diese Arbeit verwendet:

ER $\alpha$ (Gen Bank Accession No.: X61098, vom eigenen Labor entworfen):

Sense Primer: 5'-AAGCTGGCCTGACTCTGCAG-3'

Antisense Primer: 5'-GCAGGTCATAGAGAGGCACGA-3'

TaqMan Sonde: 5'-CGTCTGGCCCAGCTCCTCCTCATC-3' (5'-FAM-3'TAMRA) 
IGF-1 (Gen Bank Accession No.: NM_12754, vom eigenen Labor entworfen):

Sense Primer: 5 -CTTCAACAAGCCCACAGGCTA-3`

Antisense Primer: 5'-GCTCCGGAAGCAACACTCAT-3`

TaqMan Sonde: 5`FAM-CTCCAGCATTCGGAGGGCACCTC-TAMRA3`

LH $\beta$ (QuantiTect Primer Assay, Qiagen Kat. Nr. QT00262829):

Sonde: SYBR Green

C3 (QuantiTect Primer Assay, Qiagen Kat. Nr. QT00109270):

Sonde: SYBR Green

ERß (QuantiTect Primer Assay, Qiagen Kat. Nr. QT00096222)

Sonde: SYBR Green.

\subsubsection{Auswertung der RT-PCR}

Zur quantitativen Bestimmung des gewonnenen DNA-Materials wird der so genannte Threshold-Zyklus $\left(\mathrm{C}_{\mathrm{t}}\right)$ bestimmt.

Dazu wird ein Diagramm erstellt, in dem die Fluoreszenz (abgeglichen gegen die Hintergrundfluoreszens) gegen die Zeit (in PCR Zyklen) aufgetragen wird. Die Daten, mit denen dieses Diagramm gespeist wird, werden direkt während der PCR registriert.

Der gesuchte $C_{t}$ Wert entspricht hierbei dem Zyklus, in dem die Fluoreszenz einer Probe erstmalig deutlich über der Hintergrundfluoreszenz liegt. Der $\mathrm{C}_{\mathrm{t}}$ Wert ist somit umso kleiner, je mehr Ziel-Gen in der Ausgangsprobe vorhanden ist.

\subsubsection{Serumdiagnostik}

Zur Gewinnung des Serums wurde das den Mäusen nach der Dekapitation entnommene Blut bei 2800 Upm für 30 min zentrifugiert (Rotixa RP, Hettich, Tuttlingen). Das Serum wurde mit einer Pasteurpipette vorsichtig abgenommen und bei $-20^{\circ} \mathrm{C}$ tiefgefroren.

Es konnten nun aus diesem Serum die metabolischen Parameter Triglyceride, Cholesterin, HDL und LDL bestimmt werden. 
Dies geschah mittels kommerziell erhältlichen Kits der Firma Roche (Mannheim) auf einem Hitachi 902 Automatic Analyser. Im Speziellen handelte es sich dabei um folgende Kits:

Triglyceride: Triglycerides GPO-PAP

Cholesterin: Cholesterin CHOD-PAP

HDL: HDL-Cholesterin $2^{\text {nd }}$ Generation

LDL: LDL-Cholesterin $2^{\text {nd }}$ Generation.

\subsubsection{Quantitative Computertomographie}

Die direkt nach der Sektion der Tiere präparierten Tibiae (s. Abb.2) wurden zur Knochendichtemessung in einem quantitativen Computertomographen (qCT) untersucht. Dieser qCT (XCT Research SA, Stratec, Pforzheim, s. Abb.1) ist speziell zum Messen von Knochendichten im experimentellen Rahmen bei Kleintieren entwickelt worden (Helterbrand et al. 1997).

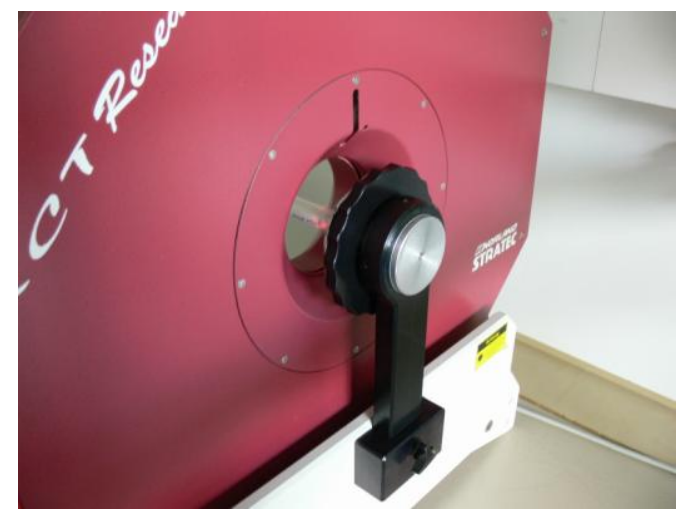

Abbildung 1: XCT Research SA

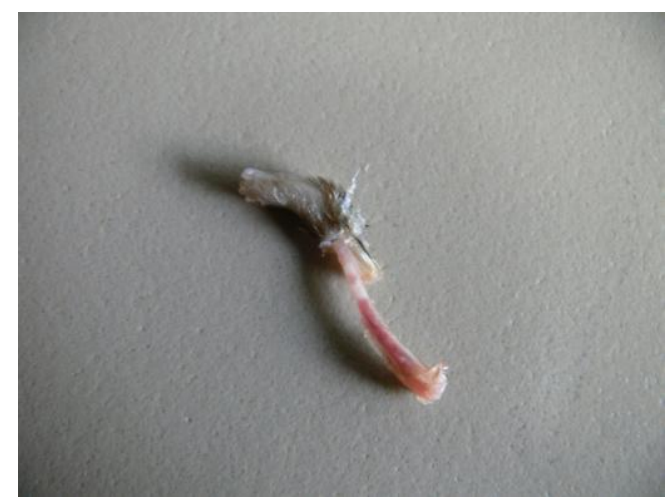

Abbildung 2: präparierte Tibia 
Das Gerät scannt die Metaphyse der Tibiae im Querschnitt in drei immer gleich weit auseinander liegenden Ebenen. Als manuell einzustellende Referenzlinie sind die proximalen Kondylen festgelegt, sodass vom Gerät zwei Messungen in der metaphysären Spongiosa und eine Messung in der diaphysären Kortikalis durchgeführt werden (s. Abb. 3)

Der Abstand zwischen Referenzlinie und Messlinien der Spongiosa beträgt 1,75mm, bzw. 2mm. Die Messlinie innerhalb der Kortikalis befindet sich 7,5 $\mathrm{mm}$ von der Referenzlinie entfernt.

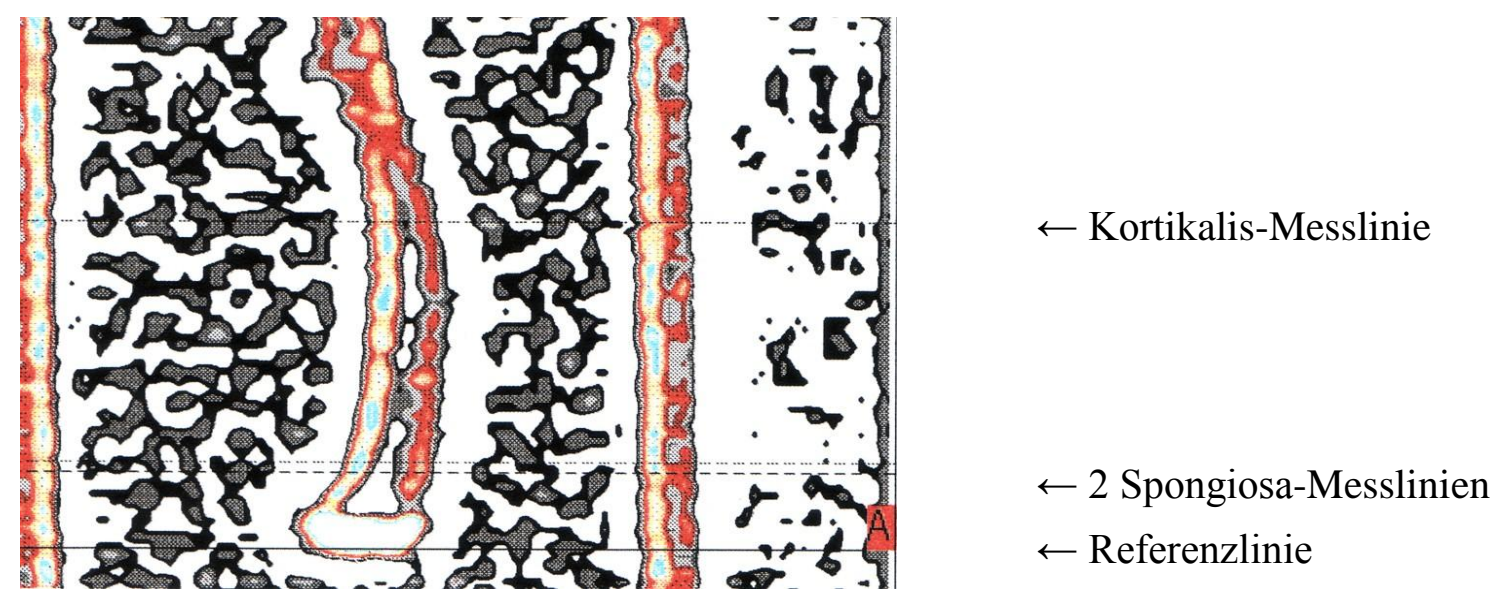

Abbildung 3: Pre-Scan mit eingezeichneten Messlinien

Die Bestimmung der Knochendichte wird über eine farbliche Codierung bewerkstelligt. Eine vom Hersteller mitgelieferte Software ermöglicht anschließend die quantitative Auswertung der so gemessenen trabekulären und kortikalen Knochendichte.

Die Werte für die Knochendichte werden hierbei durchgehend in $\mathrm{mg} / \mathrm{mm}^{3}$ angegeben.

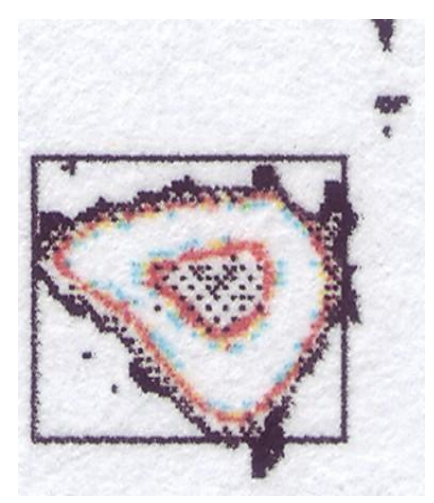

Abbildung 4: Slice 1, erste Messlinie auf Höhe Spongiosa 


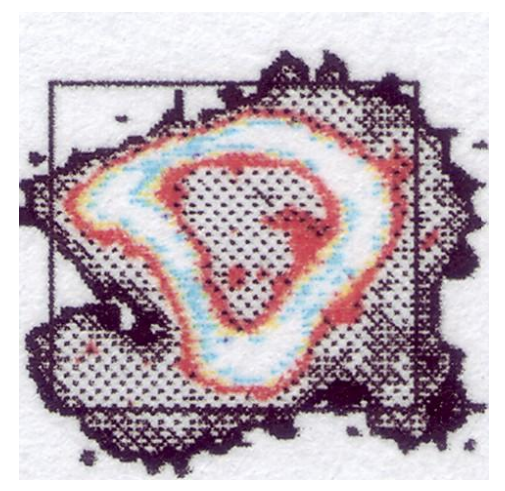

Abbildung 5: Slice 2, zweite Messlinie auf Höhe Spongiosa

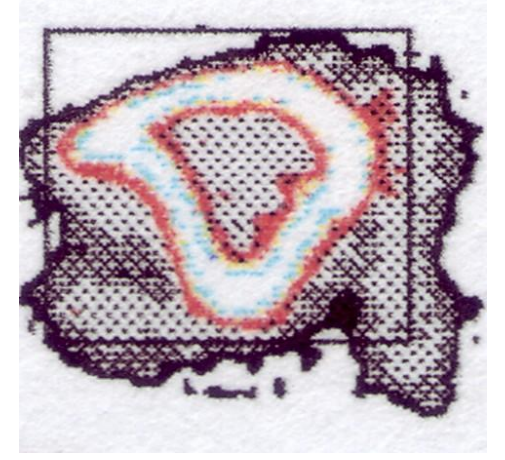

Abbildung 6: Slice 3, Messlinie auf Höhe Kortikalis

Um falsche Messergebnisse zu vermeiden, mussten die Ergebnisse der Dichteberechnung in einem festgelegten Rahmen angesiedelt sein, um in die Auswertung einzugehen. So wurden Dichtemessungen außerhalb des Intervalls von $280-400 \mathrm{mg} / \mathrm{cm}^{3}$ für die Spongiosa und Dichtemessungen unter einem Wert von $700 \mathrm{mg} / \mathrm{cm}^{3}$ für die Kortikalis verworfen.

Zur Auswertung der Ergebnisse wurden die Werte der Tiere, die mit einer der Testsubstanzen behandelt worden waren, mit denen der Kontrolltiere verglichen und prozentrelativiert.

\subsection{Statistische Methoden}

Alle Werte für die Statistik wurden mit dem Computerprogramm PRISM® (GraphPad, San Diego, USA) berechnet.

Um eventuell auftretende, labortechnisch bedingte Schwankungen zwischen den absoluten Messwerten der verschiedenen Aufarbeitungsgruppen zu vermeiden, wurde bei der 
Auswertung der Genanalysen und der Knochendichtemessungen mit Prozentwerten gearbeitet.

Bei allen Auswertungen der durchgeführten Versuche dienten die ovariektomierten Tiere der Kontrollgruppe als Vergleichstiere. Die Mittelwerte der bei ihnen erhobenen Ergebnisse wurden $100 \%$ gleichgesetzt. Die einzelnen Ergebnisse aller weiteren Behandlungsgruppen wurden dann in Relation zu diesem 100\%-Wert gesetzt. Auf diesem Wege konnten prozentrelativierte Mittelwerte und deren Standardfehler der Mittelwerte (SEM) berechnet werden. Auf eine Präsentation der Absolutwerte wird in dieser Arbeit verzichtet.

Die statistische Auswertung erfolgte durch Anwendung einer einfachen Varianzanalyse (ANOVA) und anschließenden multiplen T-Test nach Dunnett.

Das Signifikanzniveau wurde in sämtlichen Versuchen auf $\mathrm{p}<0,05$ gesetzt und in den Graphen mit dem Symbol * kenntlich gemacht. 


\section{Ergebnisse}

Bei den Graphiken des Ergebnisteils (außer bei Abbildung 7) sind Standardfehler des Mittelwertes in Form von Fehlerbalken dargestellt. Das Symbol * kennzeichnet p<0,05 vs. Kontrolle.

\subsection{Tiergewichtsentwicklung}

\subsubsection{Körpergewichtsverlauf über 3 Monate}

In Abbildung 7 ist die Körpergewichtsentwicklung der mit Estradiol, Genistein, Resveratrol und Equol behandelten Versuchstiere im Vergleich zur Kontrollgruppe dargestellt.

In allen Substanzgruppen ist eine stetige Zunahme des Körpergewichts über den gesamten Versuchszeitraum festzustellen.

Schon nach drei Wochen wurde deutlich, dass die mit Estradiol versetztem Futter ernährten Mäuse nur sehr wenig an Gewicht zunahmen, bzw. nach der zweiten Woche sogar einige Gramm an Körpergewicht verloren, während ihre Artgenossen der übrigen Substanzgruppen von Versuchsbeginn an deutlich an Gewicht zunahmen. Diese Tendenz blieb über den gesamten 16-wöchigen Versuchszeitraum bestehen, so dass am Ende die in Abbildung 3.2 dargestellten Unterschiede im Körpergewicht am Tag der Obduktion zu erheben waren. 


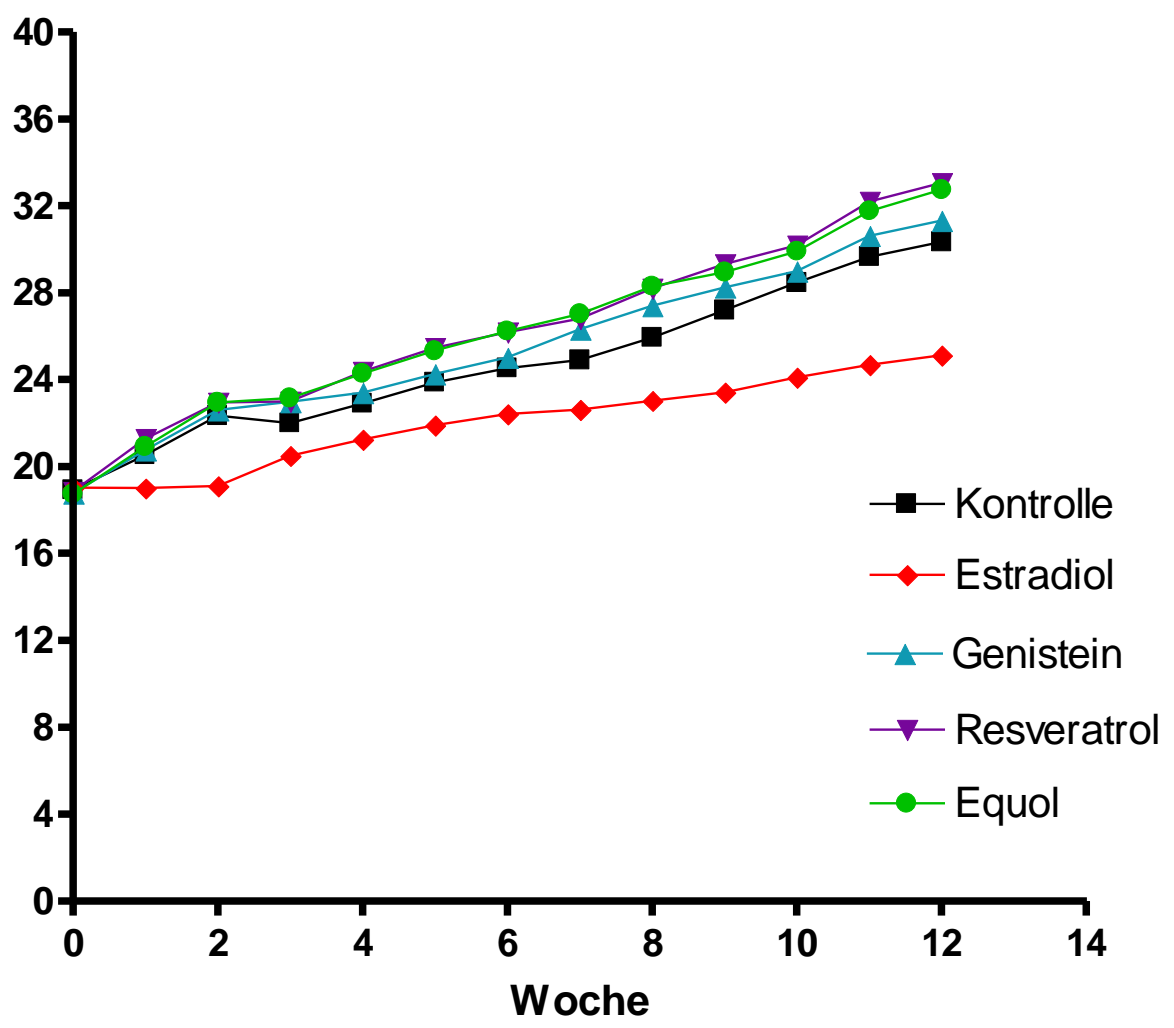

Abbildung 7: Körpergewichtsverlauf über 3 Monate. Dargestellt sind die Mittelwerte. Der Übersichtlichkeit halber sind keine Fehlerbalken dargestellt.

\subsubsection{Körpergewicht am Tag der Obduktion}

Am Tag der Obduktion wogen die Mäuse der Kontrollgruppe durchschnittlich 30,35g (s. Abb. 8, S.35). Das Gewicht der Tiere, welche mit Estradiol-haltigem Futter ernährt wurden, lag im Vergleich dazu bei durchschnittlich 25,12g. Es handelt sich hierbei um einen signifikanten Gewichtsunterschied zwischen den beiden Testgruppen.

Während die Mäuse, deren Futter Genistein oder Equol enthielt, ein der Kontrollgruppe ähnliches Endgewicht erreichten, waren die mit Resveratrol gefütterten Tiere am Ende des Versuchs mit durchschnittlich 33.06g signifikant schwerer. 


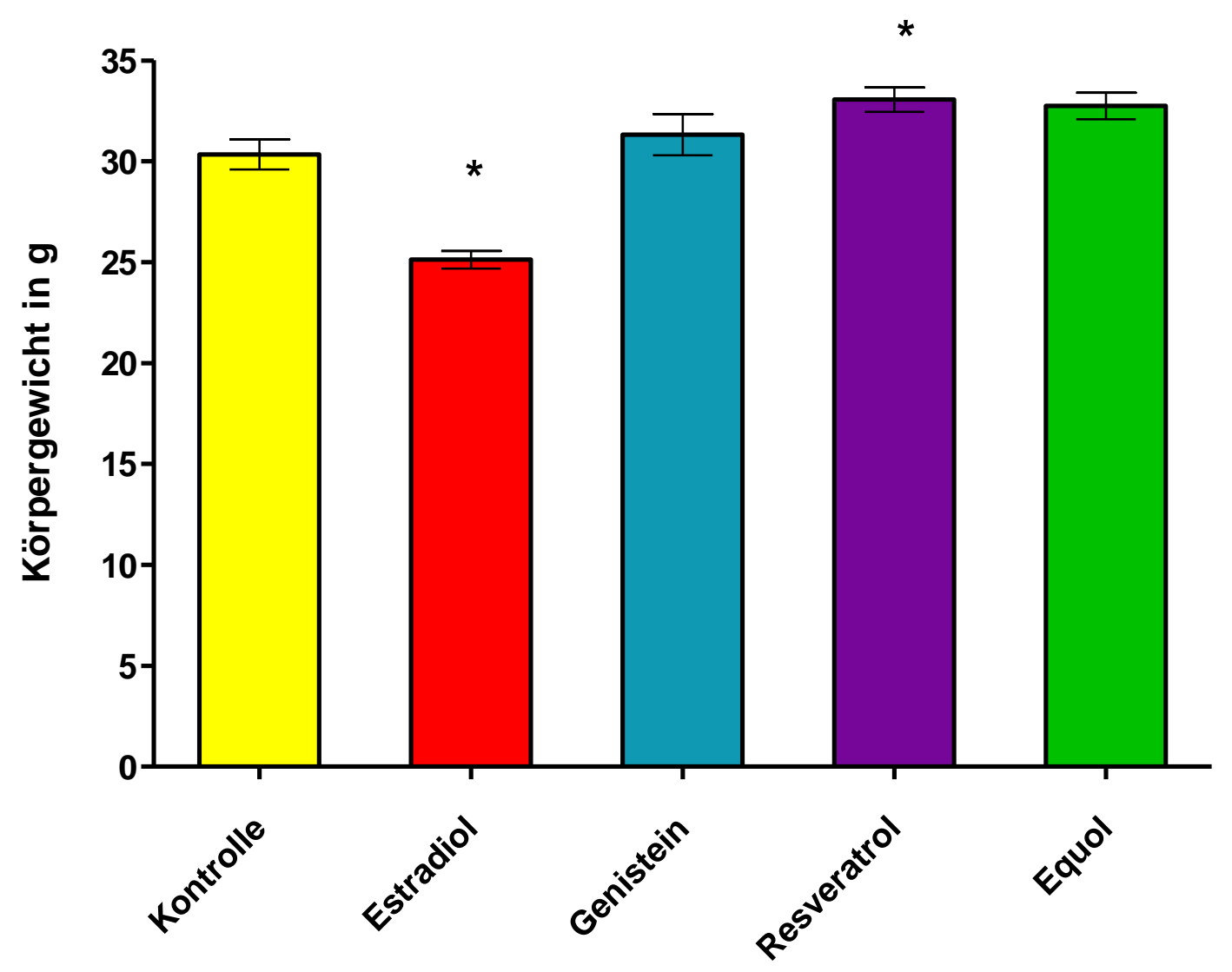

Abbildung 8: Einfluss von Estradiol, Genistein, Resveratrol und Equol auf das Körpergewicht (in g) der Versuchstiere bei Obduktion

\subsubsection{Futteraufnahme}

In Tabelle 5 werden die Unterschiede in der täglichen Futteraufnahme und die hieraus errechnete quantitative Aufnahme der verabreichten Substanzen pro Tier und Tag dargestellt.

Tabelle 5: Futter- und quantitative Substanzaufnahme

\begin{tabular}{|l|l|l|}
\hline & $\begin{array}{l}\text { Tägliche Futteraufnahme pro } \\
\text { Tier in } \mathrm{g}\end{array}$ & $\begin{array}{l}\text { Quantitative Aufnahme der } \\
\text { Substanzen pro Tier und Tag } \\
\text { in } \mathrm{mg}\end{array}$ \\
\hline Kontrolle & 2,84 & --- \\
\hline Estradiol & 3,77 & 0.02 \\
\hline Genistein & 2,93 & 2,93 \\
\hline Resveratrol & 2,95 & 2,48 \\
\hline Equol & 3,07 & 1,23 \\
\hline
\end{tabular}


Hier wird deutlich, dass die mit Estradiol-haltiger Nahrung versorgten Tiere die mit Abstand höchste Futteraufnahme pro Tag zeigten (3,77g/d/Tier). Es ergibt sich hier ein signifikantes Abweichen von den Werten der Kontrollgruppe, sowie auch von den Werten der übrigen Gruppen.

Am Wenigsten fraßen mit 2,84g/d/Tier die Mäuse der Kontrollgruppe. Die Mäuse der „schwergewichtigen“ Resveratrol-Gruppe nahmen in punkto Futteraufnahme mit 2,95g pro Tag und Tier einen Platz im Mittelfeld ein.

\subsection{Untersuchte Veränderungen am Uterus}

\subsubsection{Uterusgewicht}

In Bezug auf das Uterusgewicht lassen sich klare Unterschiede zwischen der Estradiolgruppe und den übrigen vier Substanzgruppen aufzeigen (s. Abb. 9):

Während die Gebärmutter einer Maus, die sojafreies Futter oder mit Genistein, Resveratrol oder Equol versetztes Futter zu sich nimmt, etwa 0,01 g wiegt, liegt das Gewicht der Gebärmutter einer Maus, die mit Estradiol versetztes Futter zur Verfügung hat, mit durchschnittlich $0,12 \mathrm{~g}$ weit über diesem Wert. Es ist eine deutliche Signifikanz dieses Parameters zu erkennen.

Auch bezogen auf das Körpergewicht einer jeden Maus zeigte sich ein gleichartiges Ergebnis mit einer ebenso deutlichen, signifikanten Erhöhung des Uterusgewichts in der Gruppe der Estradiol-behandelten Tiere im Vergleich zu den restlichen Versuchsgruppen. 

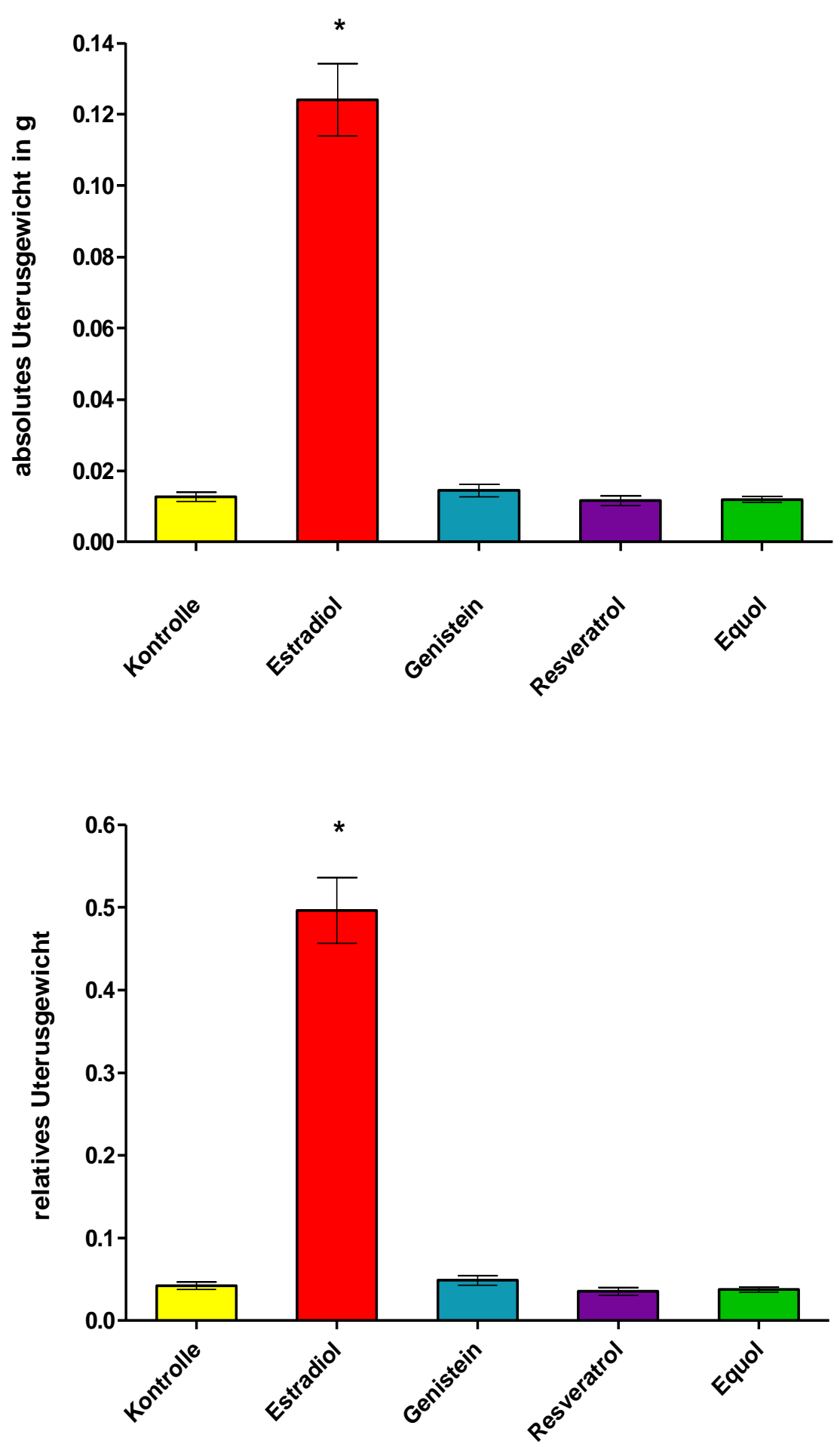

Abbildung 9: Wirkung von Estradiol, Genistein, Resveratrol und Equol auf das absolute und relative Uterusgewicht 


\subsubsection{Genexpression im Uterus}

\subsubsection{ER $\alpha$ - Expression im Uterus}

Die Expression von Östrogenrezeptor-alpha in den Zellen des Uterus ist in den fünf Substanzgruppen unterschiedlich stark messbar, es lassen sich jedoch keine Signifikanzen nachweisen (s. Abb. 10).

Es sei auf die verhältnismäßig große Schwankungsbreite der erhobenen Ergebnisse hingewiesen.

\subsubsection{ERß- Expression im Uterus}

Auch die Expression des Östrogenrezeptors-beta ist unterschiedlich stark, ohne jedoch eine Signifikanz aufweisen zu können (s. Abb. 10).

Allerdings zeigt sich ein tendenziell größerer Unterschied zwischen den erhobenen Werten in der Kontrollgruppe, wo vergleichsweise wenig ER $\beta$ exprimiert wird, und den übrigen Substanzgruppen.

Gleichermaßen sei auch hier auf die Schwankungsbreite der Ergebnisse hingewiesen. 


\section{ER $\alpha$ - Uterus}

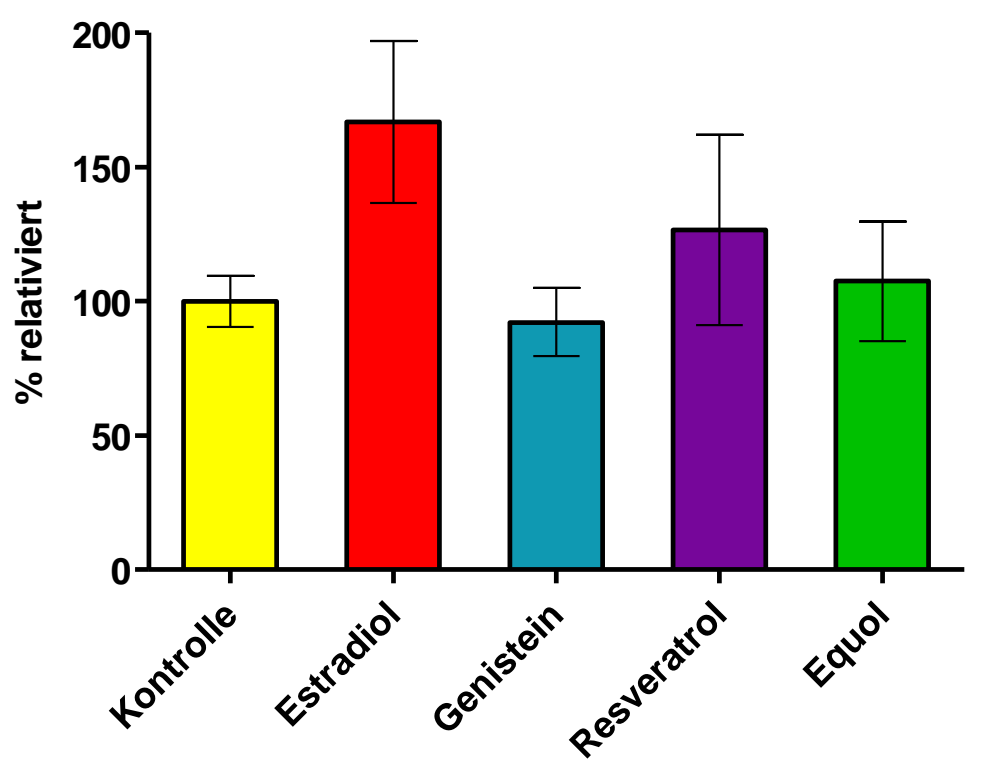

ER $\beta$-Uterus

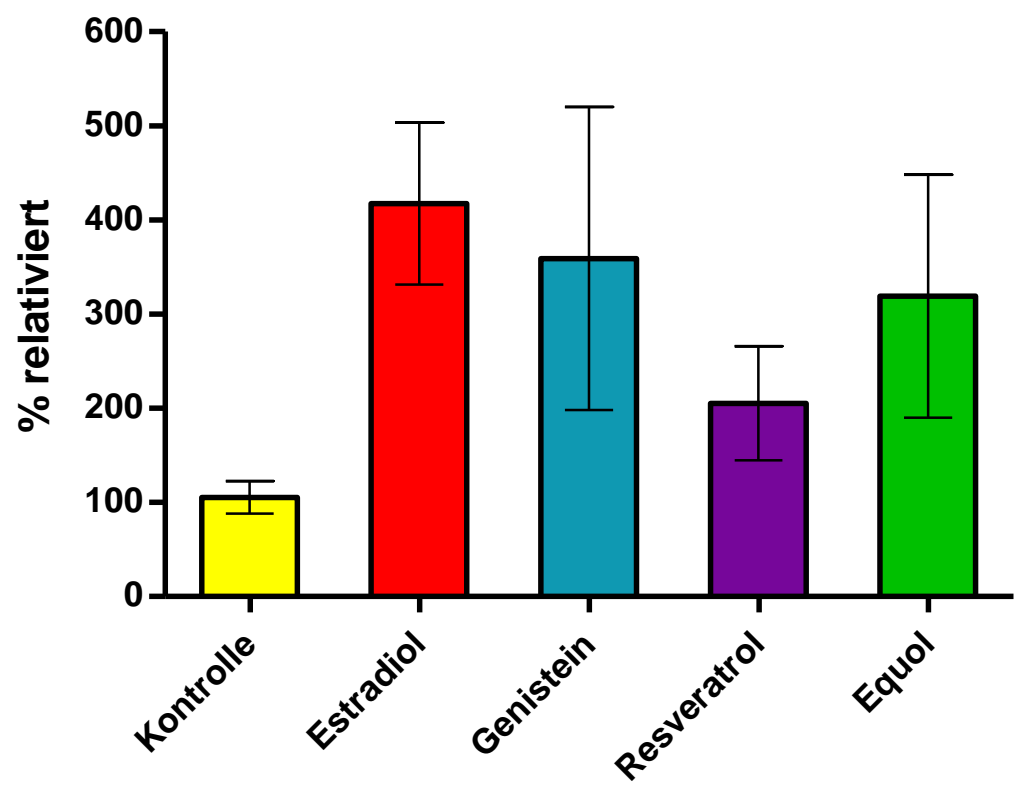

Abbildung 10: Einfluss von Estradiol, Genistein, Resveratrol und Equol auf die Expression von ERa und ERß im Uterus 


\subsubsection{C3-Expression im Uterus}

In Abbildung 11 ist die Expression von C3 im Uterus dargestellt.

Es konnte in diesem Fall eine klare, signifikante Erhöhung des Wertes für C3 bei den Tieren der Estradiolgruppe nachgewiesen werden. Die Genexpression war hier um mehr als das Zehnfache im Vergleich zur Kontrollgruppe erhöht.

Die nur leichte Erhöhung der Genexpression bei den mit Genistein, Equol und Resveratrol behandelten Tieren ist nicht signifikant.

\subsubsection{IGF-1-Expression im Uterus}

Im zweiten Teil von Abbildung 11 wird die Expression von IGF-1-Protein aufgezeigt. Auch hier ist eine deutlich signifikante Erhöhung der IGF-1-Expression in der Gruppe der mit Estradiol behandelten Tiere zu vermerken. Im Uterus von unter Estradioleinfluss stehenden Mäusen ist die Expression um das Vierfache erhöht.

Zudem zeigt sich ein ebenfalls signifikant erhöhter Wert bei den Tieren, deren Futter mit Genistein versetzt war. Hier war eine doppelt so hohe Expression des Proteins messbar.

Resveratrol und Equol haben nicht zu einer vermehrten Expression des untersuchten Stoffes geführt. Die Werte für IGF-1 entsprechen denen in der Soja-freien Kontrollgruppe. 


\section{C3 Uterus}

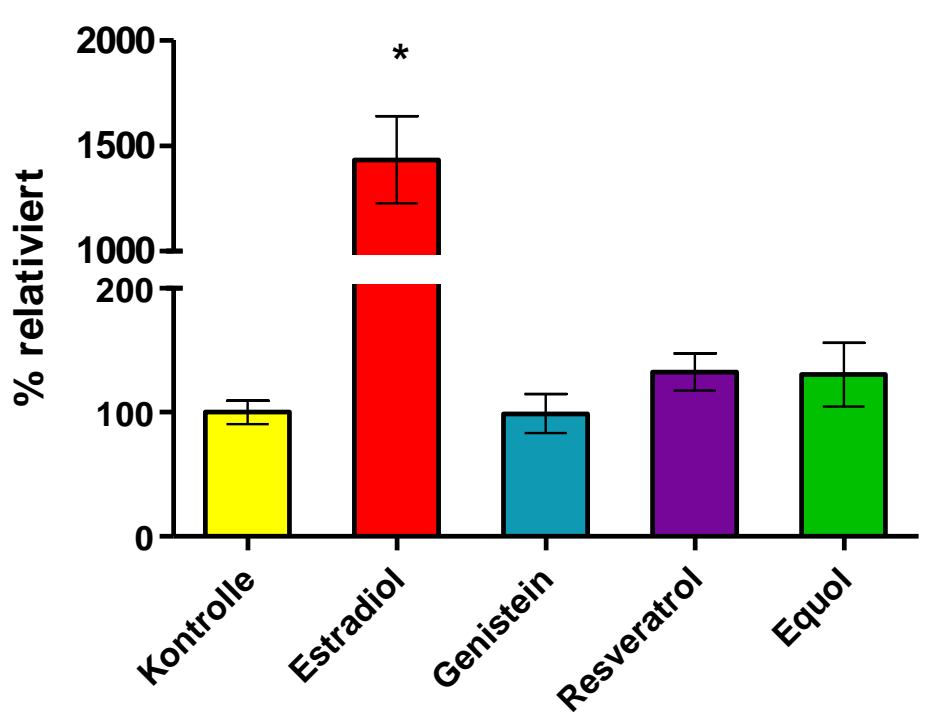

IGF-1 Uterus

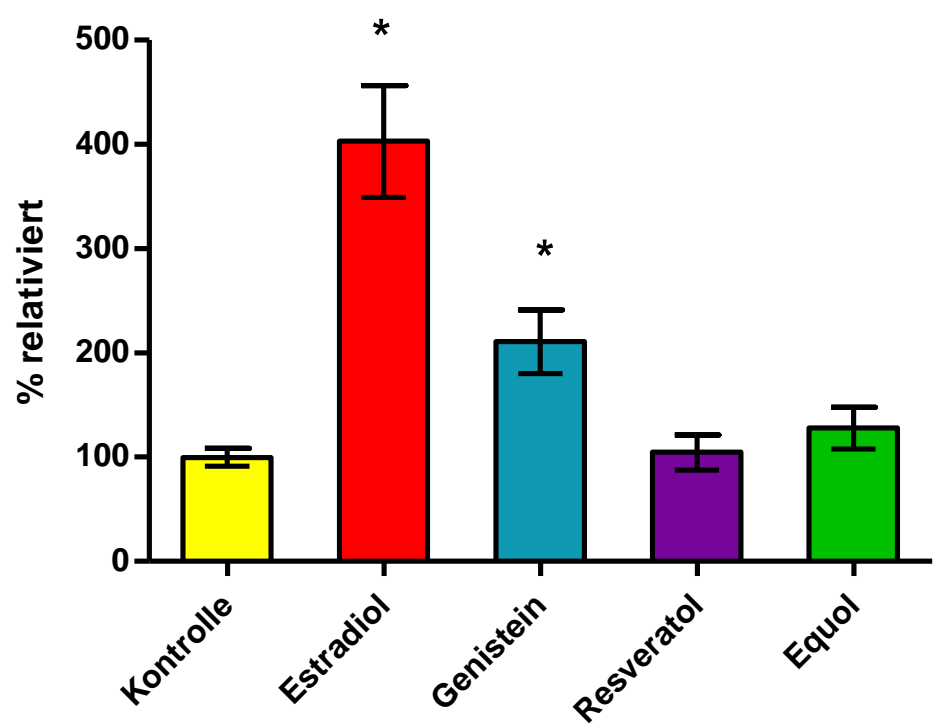

Abbildung 11: Einfluss von Estradiol, Genistein, Resveratrol und Equol auf die Expression von C3 und IGF-1 im Uterus 


\subsection{Untersuchte Veränderungen in der Leber}

\subsubsection{Absolutes und relatives Lebergewicht}

Das absolute Lebergewicht der Mäuse war am Ende des Versuchs in allen Substanzgruppen im Unterschied zur Kontrollgruppe signifikant erhöht (s. Abb. 12).

Beim Vergleich der vier Substanzgruppen untereinander zeigte sich, dass alle Lebergewichte etwa gleich stark erhöht waren (um 1,3g) und sich keiner der Stoffe durch besonders hohe Werte hervortat.

Setzt man das absolute Lebergewicht in Relation zum Körpergewicht, ist eine signifikante Erhöhung der Werte nur noch unter Estradiol- und unter Genistein-Einfluss zu verzeichnen. Das relative Lebergewicht der mit Equol und Resveratrol behandelten Tiere unterschied sich nur marginal von dem der Kontrollgruppe. 

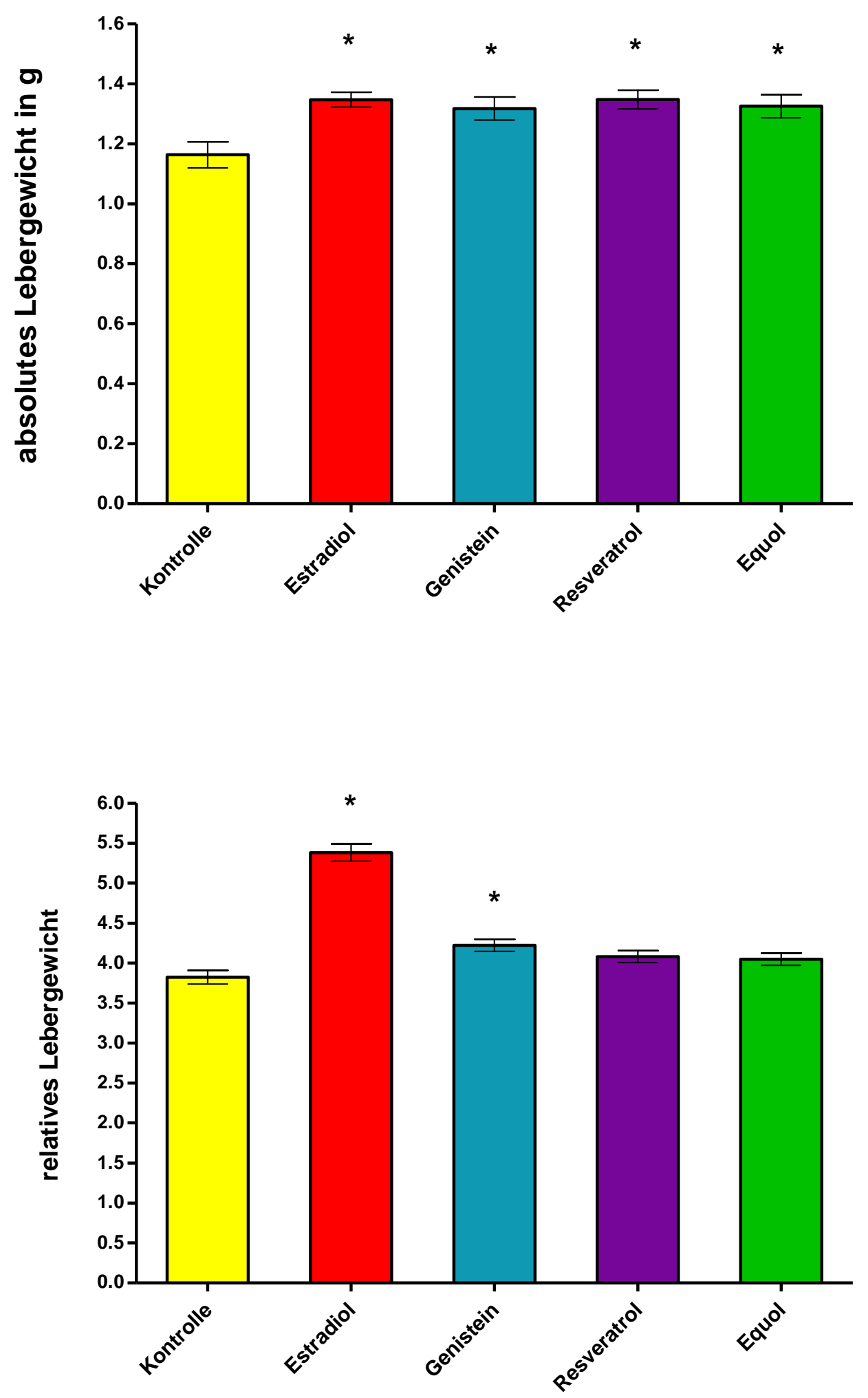

Abbildung 12: Einfluss von Estradiol, Genistein, Resveratrol und Equol auf absolutes und relatives (bezogen auf das Körpergewicht) Lebergewicht der Versuchstiere 


\subsubsection{Genexpression in der Leber}

Neben der Erfassung des Endgewichts wurde in der Leber die Genexpression von IGF-1 und ER $\alpha$ untersucht. Die entsprechenden Graphen zeigt Abbildung 13.

Im Gegensatz zu den erhobenen Daten im Uterus findet sich in der Leber unter den hier vorliegenden Versuchsbedingungen keine signifikante Veränderung der IGF-1 und ER $\alpha$ Expression in der Leber. Auch in Bezug auf die Expression von ER $\alpha$ in der Leber zeigen sich tendenziell höhere Werte bei mit Estradiol und Genistein behandelten Tieren, eine Signifikanz ist jedoch in keinem der Fälle nachweisbar. 

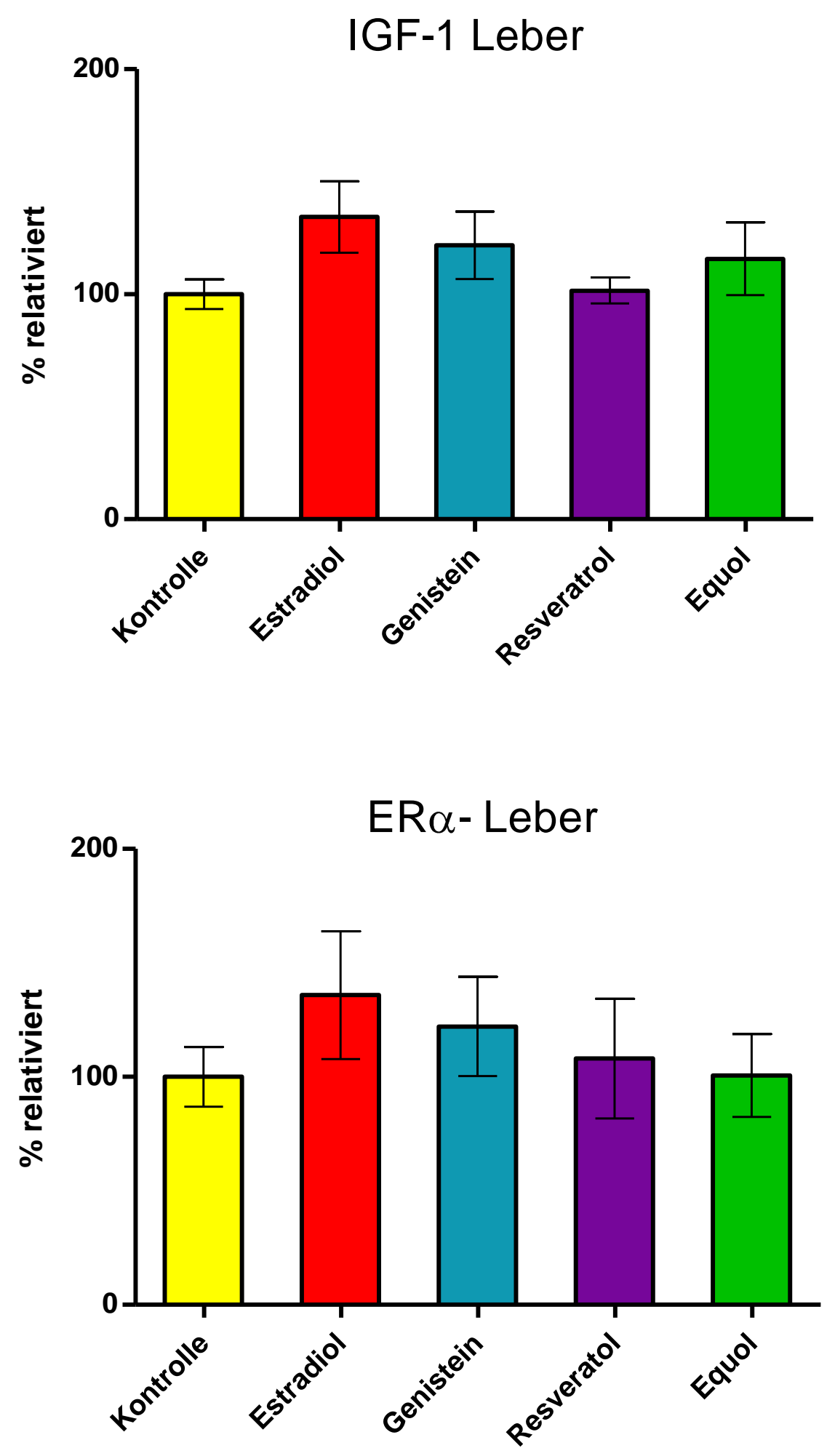

Abbildung 13: Einfluss von Estradiol, Genistein, Resveratrol und Equol auf die ERa und IGF-1Expression in der Leber der Versuchstiere 


\subsection{Untersuchte Veränderungen im Herzen}

\subsubsection{Absolutes und relatives Herzgewicht}

In Abbildung 3.9 sind absolutes und relatives Herzgewicht der Tiere bei Versuchende dargestellt.

Das absolute Herzgewicht lag in allen Substanzgruppen über dem der Soja-freien Kontrollgruppe $(0,1024 \mathrm{~g})$. Einzig das absolute Herzgewicht der Mäuse der E2-Gruppe jedoch war mit durchschnittlichen 0,1131g signifikant erhöht. Die Herzen der Resveratrolgruppe wogen im Durchschnitt 0,1094g, die der Equolgruppe 0,1076g und die der Genisteingruppe 0,1067 .

Das relative Herzgewicht der mit Estradiol-Zusatz gefütterten Mäuse ist ebenfalls signifikant erhöht. Durchschnittlich wiegt der linke Ventrikel dieser Tiere 32,6\% mehr als in der Kontrolle. 

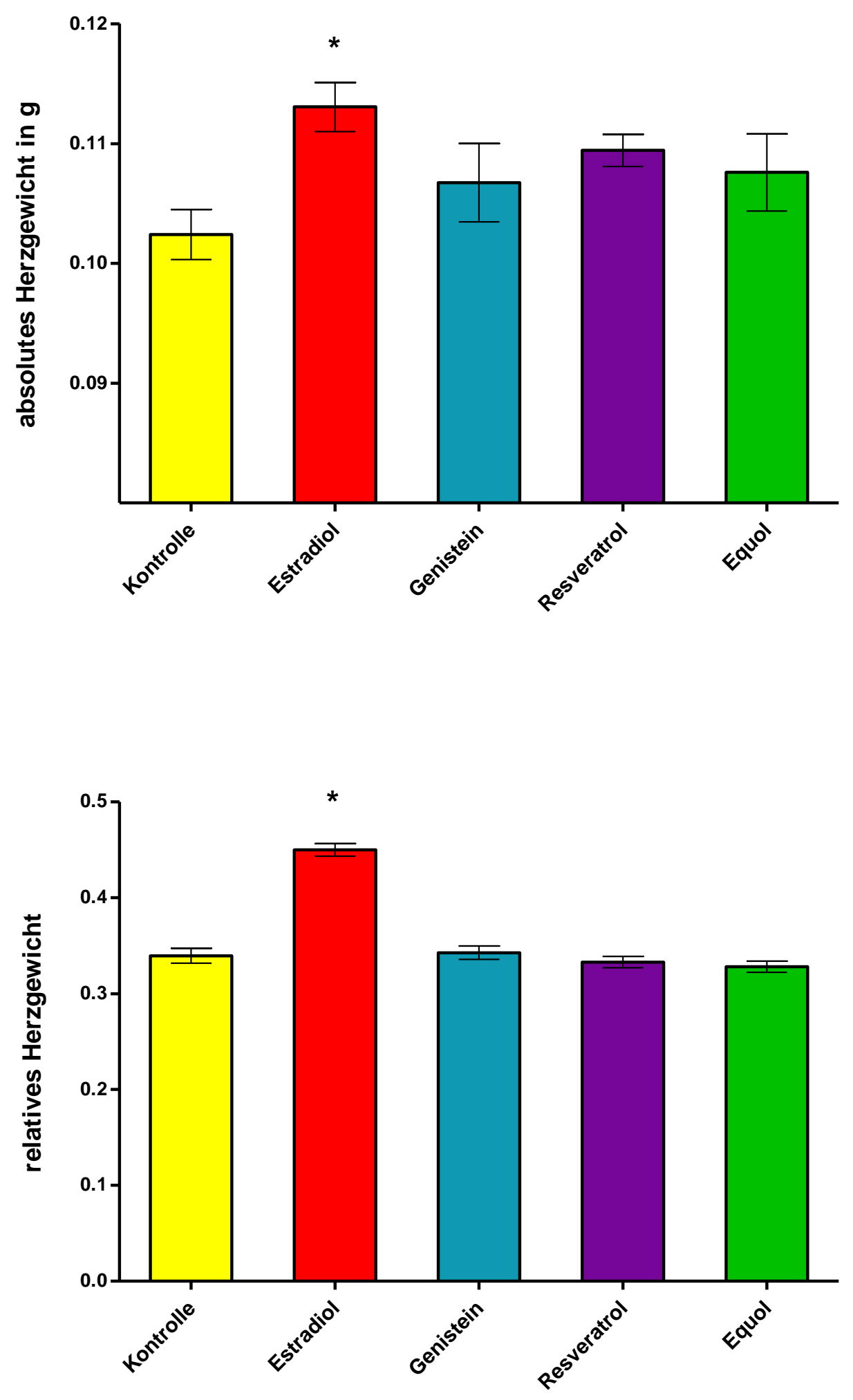

Abbildung 14: Einfluss von Estradiol, Genistein, Resveratrol und Equol auf absolutes und relatives (in Bezug zum Körpergewicht) Herzgewicht 


\subsubsection{Genexpression im Herzen}

In Abbildung 15 ist die gemessene Genexpression von ER $\alpha$ und ER $\beta$ im linken Ventrikel unter dem Einfluss der applizierten Substanzen graphisch veranschaulicht.

Die Expression beider ERs im linken Ventrikel zeigte in allen Gruppen eine hohe Variabilität. Weder für ER $\alpha$ noch für ER $\beta$ konnte ein signifikanter Effekt der Behandlung auf die relativen mRNA-Spiegel beider Rezeptoren nachgewiesen werden. 


\section{$\mathrm{ER} \alpha$ linker Ventrikel}

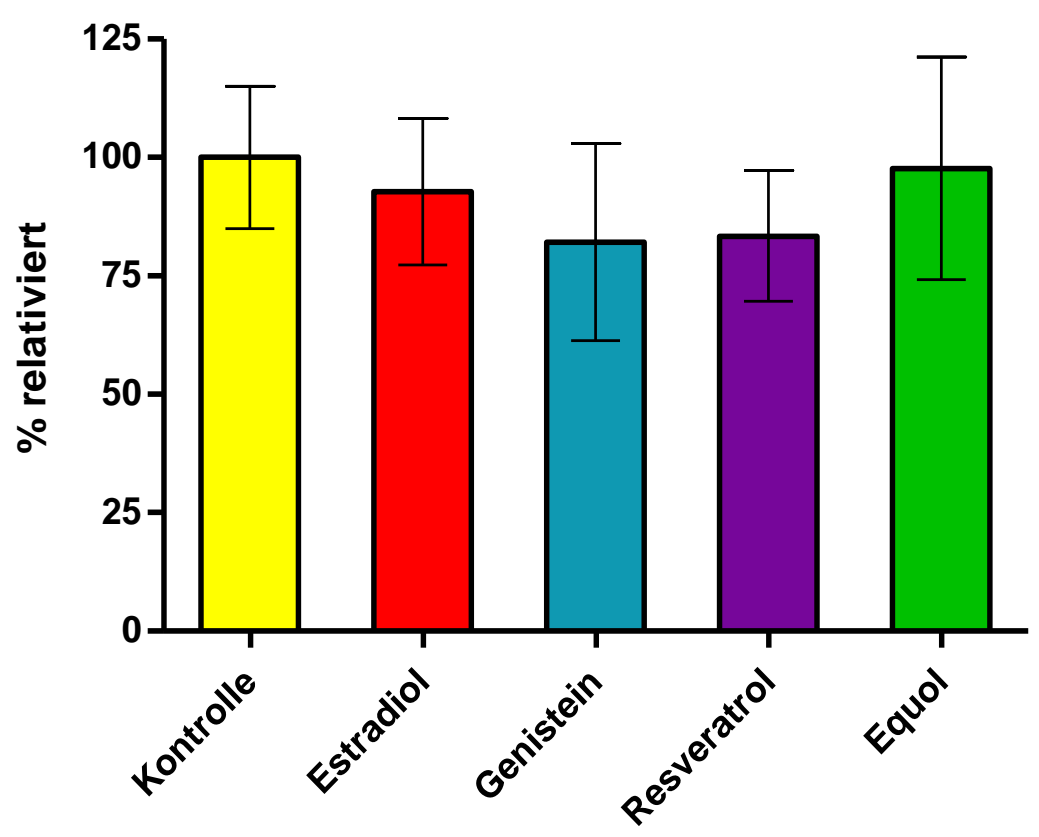

ER $\beta$-linker Ventrikel

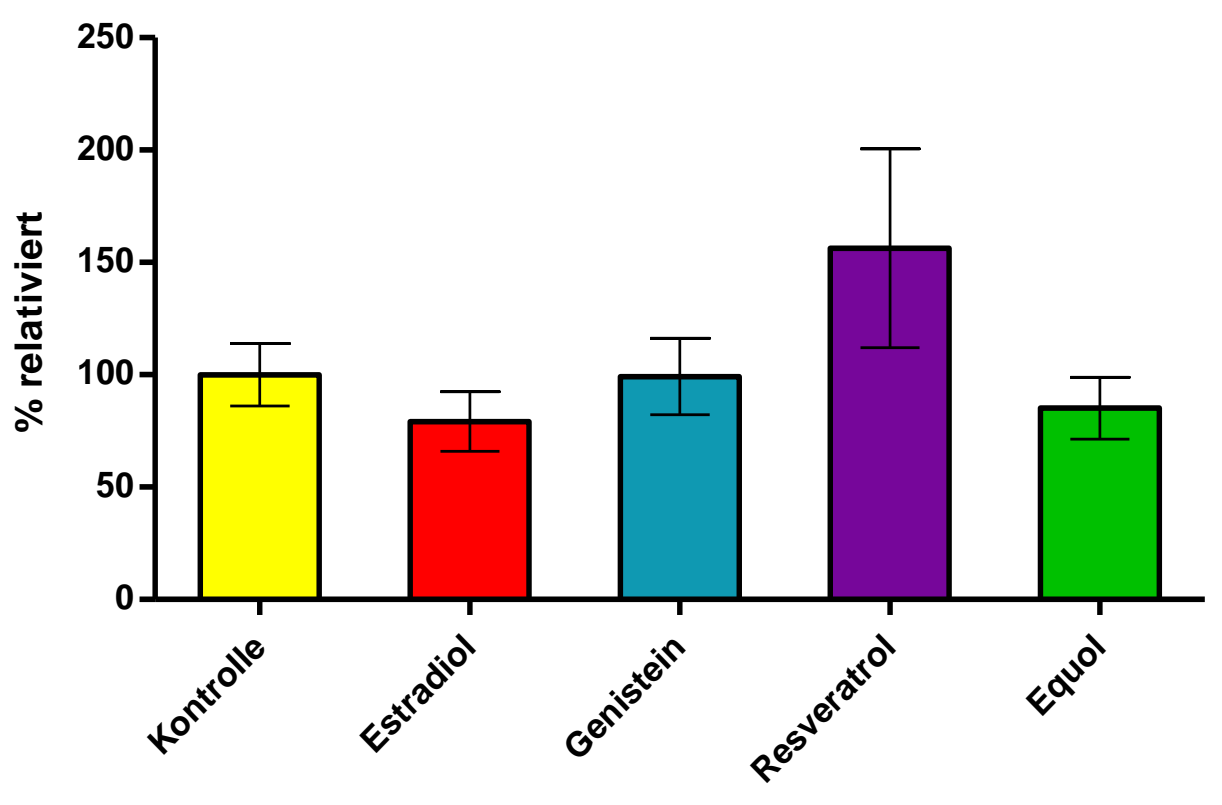

Abbildung 15: Einfluss von Estradiol, Genistein, Resveratrol und Equol auf die Genexpression von ERa und ERß im linken Ventrikel 
Der Einfluss von Estradiol, Genistein, Resveratrol und Equol auf die IGF-1-Expression im linken Ventrikel wird in Abbildung 16 aufgezeigt.

Hier ist eine signifikant erhöhte Expression von IGF-1 im Herz der mit Estradiolzusatz behandelten Versuchstiere zu verzeichnen. Dabei war eine Steigerung auf $166,6 \%$ des Kontrollgruppenwertes auszumachen.

Auch die anderen Substanzen, v. a. Genistein (145,8\%), führten zu einer vermehrten Genexpression. Bei ihnen konnte das Signifikanzniveau jedoch nicht erreicht werden.

IGF-1 linker Ventrikel

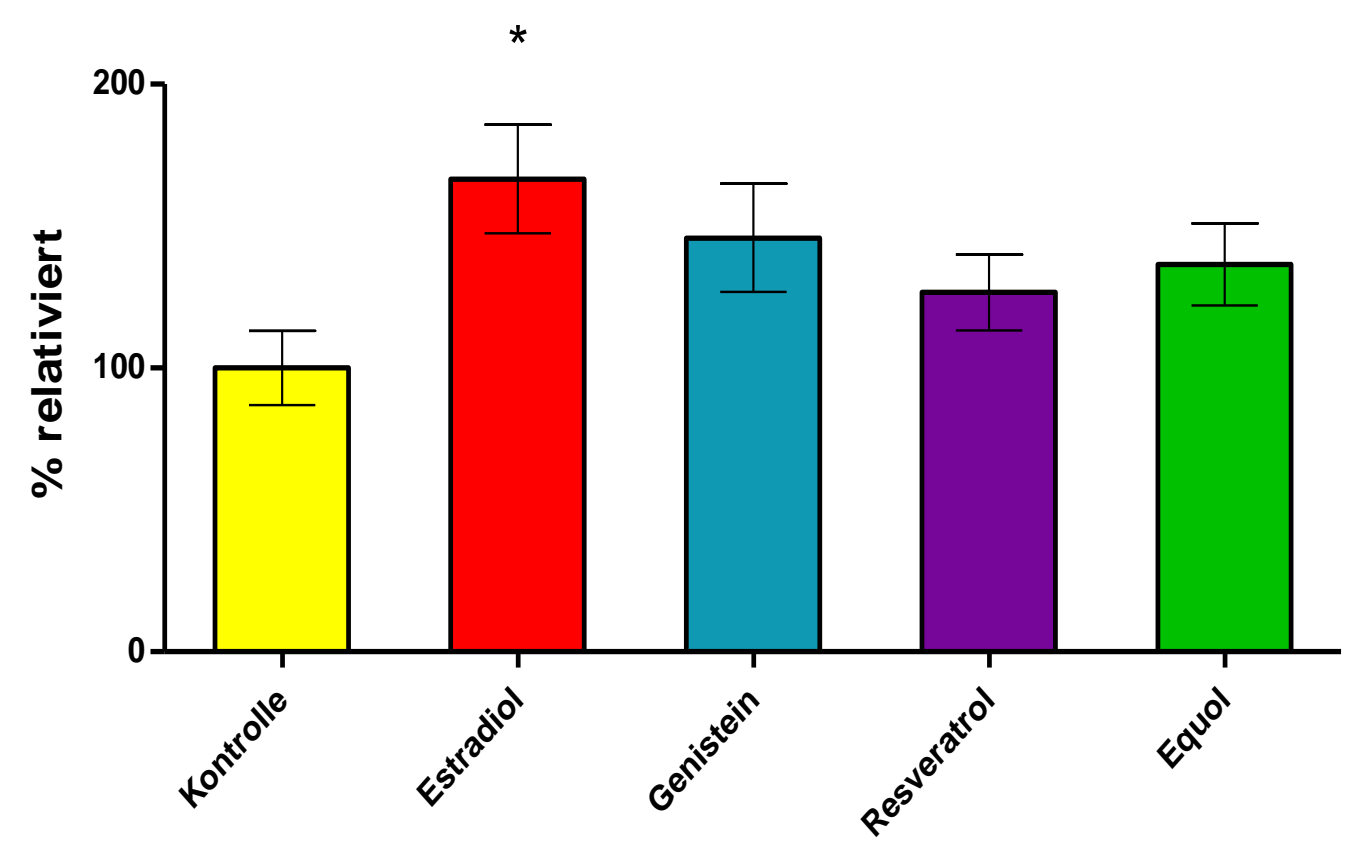

Abbildung 16: Einfluss von Estradiol, Genistein, Resveratrol und Equol auf die Expression von IGF-1 im linken Ventrikel 


\subsection{Untersuchte Veränderungen in der Hypophyse}

\subsubsection{Genexpression in der Hypophyse}

In der Hypophyse wurde die Genexpression von ER $\alpha, E R \beta$ und LH $\beta$ unter dem Einfluss von Estradiol, Genistein, Resveratrol und Equol untersucht.

Der erste Teil von Abbildung 17 stellt die Prozent-relativierte Amplifikation von ER $\alpha$ dar. Es zeigen sich große Unterschiede bezogen auf die vier Substanzgruppen.

Signifikant erhöht ist die Bildung des Estradiolrezeptors alpha unter dem Einfluss von Resveratrol. Hier besteht eine Steigerung auf 165,9\% im Vergleich zu den Werten der Kontrollgruppe.

Der stimulierende Einfluss von Genistein auf die ER $\alpha$-Expression ist mit 150,2\% zwar auch deutlich, jedoch nicht statistisch signifikant.

Weniger ausgeprägt, aber trotzdem erhöht, ist die Expression in der Equol- und EstradiolGruppe.

Im zweiten Teil der Graphik wird die Prozent-relativierte Genexpression des Östrogenrezeptors beta veranschaulicht.

Hier fällt sogleich die massiv gesteigerte Produktion von ER $\beta$ unter Estradiol-Einfluss ins Auge. Während Estradiol in der Hypophyse nur $\mathrm{zu}$ einer minimalen Mehrexpression $(112,9 \%)$ von $\mathrm{ER} \alpha$ führte, ist im Falle von ER $\beta$ eine Steigerung auf fast $600 \%$ der Kontrollgruppe zu verzeichnen.

Ebenfalls findet sich eine verstärkte Genexpression (ca. 240\%) von ER $\beta$ in der mit Resveratrol behandelten Versuchsgruppe. Hier liegt jedoch keine Signifikanz vor.

Während Equol eine unter den Werten der Kontrollgruppe liegende Expression hervorruft, ist in Bezug auf Genistein eine vergleichsweise leichte Steigerung auf $156 \%$ zu beschreiben. 


\section{ER $\alpha$-Hypophyse}

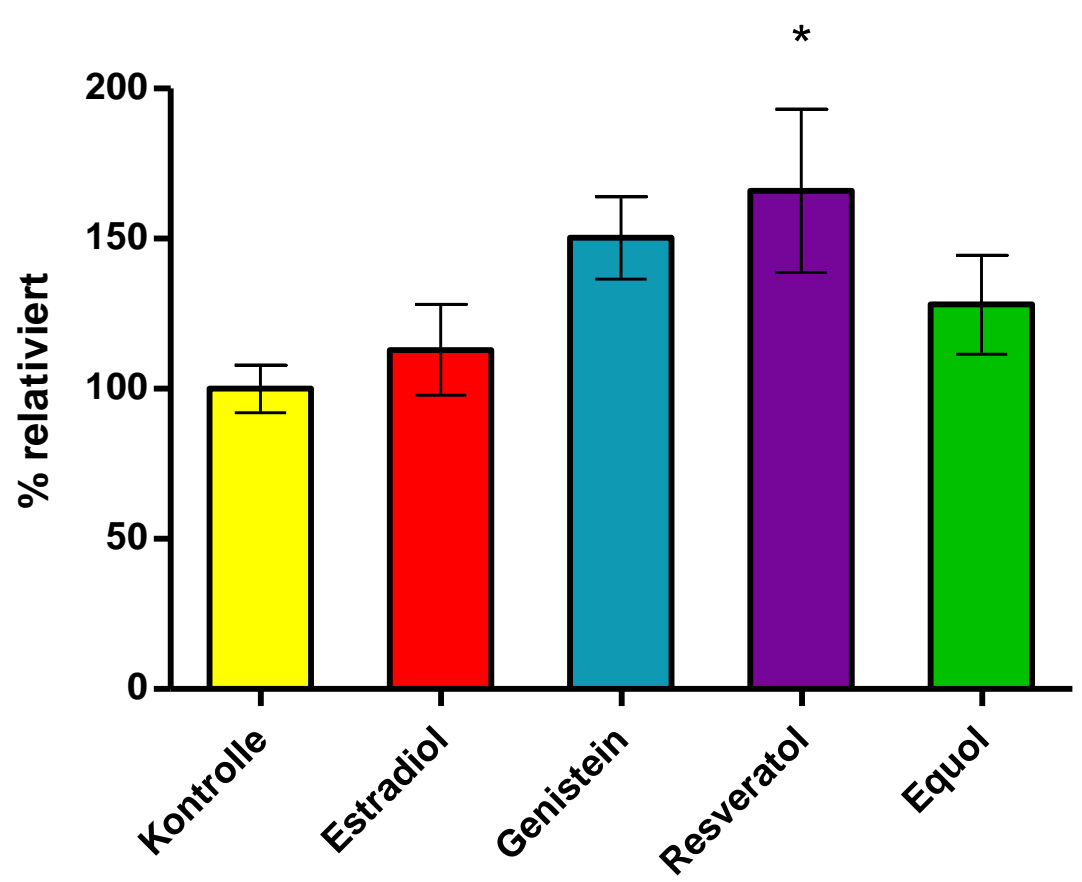

\section{ERß-Hypophyse}

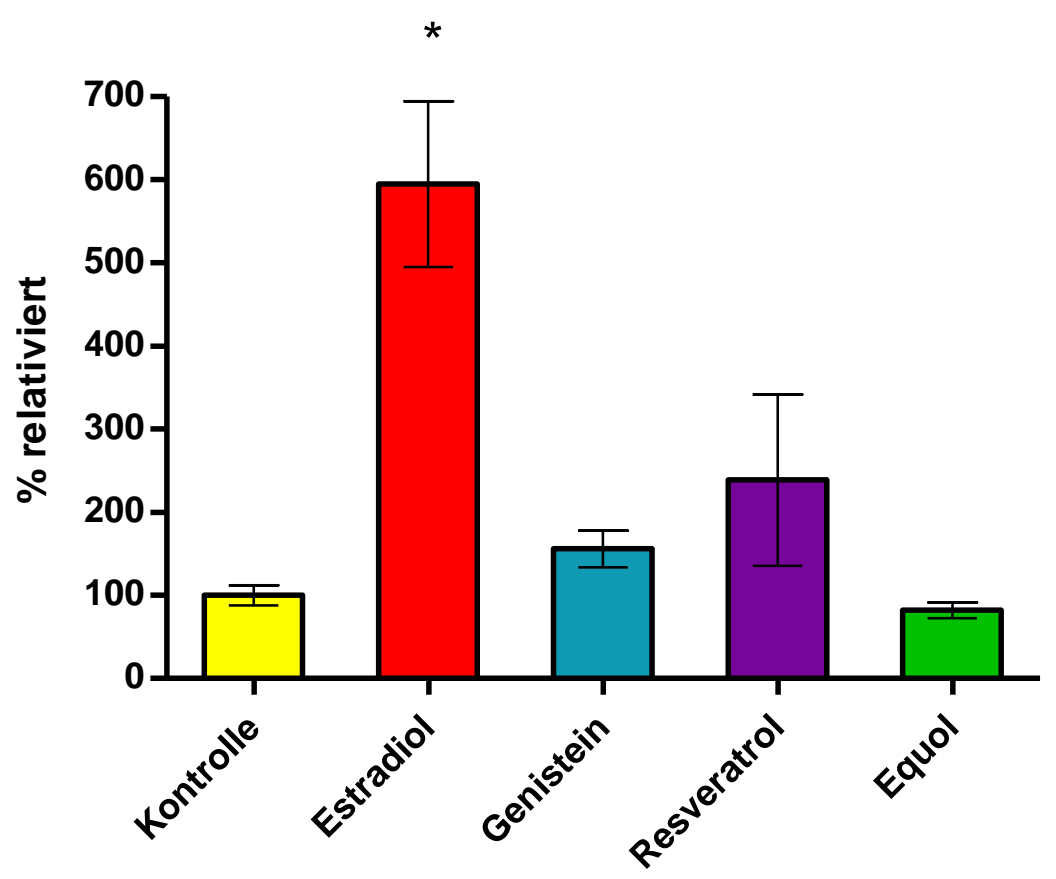

Abbildung 17: Einfluss von Estradiol, Genistein, Resveratrol und Equol auf die Expression von ERa und ERß in der Adenohypophyse der Versuchstiere 
Abbildung 18 veranschaulicht die Einflüsse der untersuchten Substanzen auf die LH $\beta$ Expression in der Hypophyse.

Estradiol und Equol senken die Expression des Proteins auf um die 76\%, Genistein auf 72\% des Kontrollwertes. Resveratrol hingegen zeigt keinen LH $\beta$ senkenden Effekt. Keiner der Parameter ist als signifikant zu deklarieren.

\section{LH $\beta$ Hypophyse}

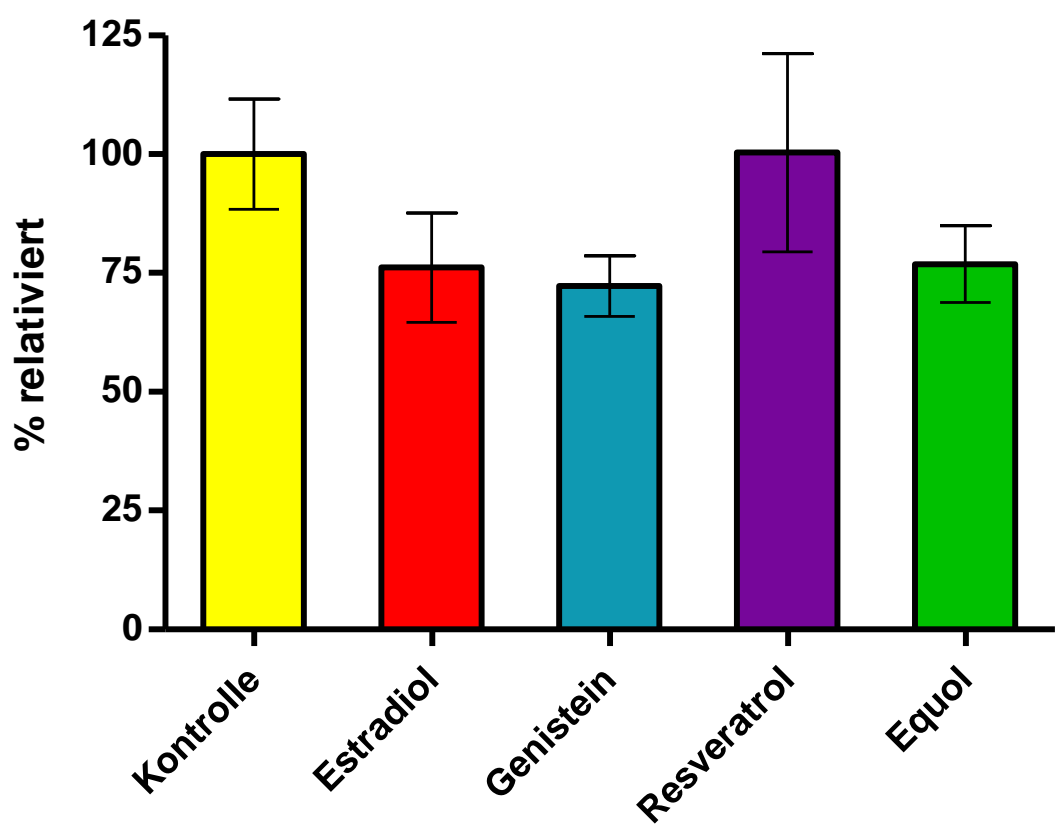

Abbildung 18: Einfluss von Estradiol, Genistein, Resveratrol und Equol auf die Expression von LH $\beta$ in der Adenohypophyse der Versuchstiere

\subsection{Untersuchte Veränderungen an der Tibia}

Im Rahmen der Untersuchung der verschiedenen Wirkungen von Estradiol, Genistein, Resveratrol und Equol auf den Organismus der Versuchstiere wurden neben Organen auch die Knochen der Versuchstiere untersucht. Hierzu wurde bei den unterschiedlichen Analysen jeweils die linke Tibia der Mäuse verwendet. 


\subsubsection{Knochendichte in Spongiosa und Kortikalis}

\subsubsection{Spongiosadichte}

In Abbildung 20 sind Einflüsse von Estradiol, Genistein, Resveratrol und Equol auf die im Kleintier-CT gemessene Spongiosadichte in der Tibia-Metaphyse dargestellt.

Im Vergleich mit der Kontrollgruppe ließ sich für alle vier untersuchten Substanzen eine signifikante Verhinderung der Ovariektomie induzierten Knochendichteabnahme nachweisen. Besonders unter dem Einfluss von Estradiol konnte eine hohe Spongiosadichte erhalten werden. So wurde durchschnittlich ein Wert von 153,3 mg/ccm, im Vergleich zu 119.9 $\mathrm{mg} / \mathrm{ccm}$ in der Kontrollgruppe, erreicht. Genistein als Futterbestandteil führte zu einer verbliebenen Knochendichte von 137,4 mg/ccm, Equol zu einer von 136,4 mg/ccm und Resveratrol zu einer von $134,2 \mathrm{mg} / \mathrm{ccm}$.

\section{Spongiosadichte}

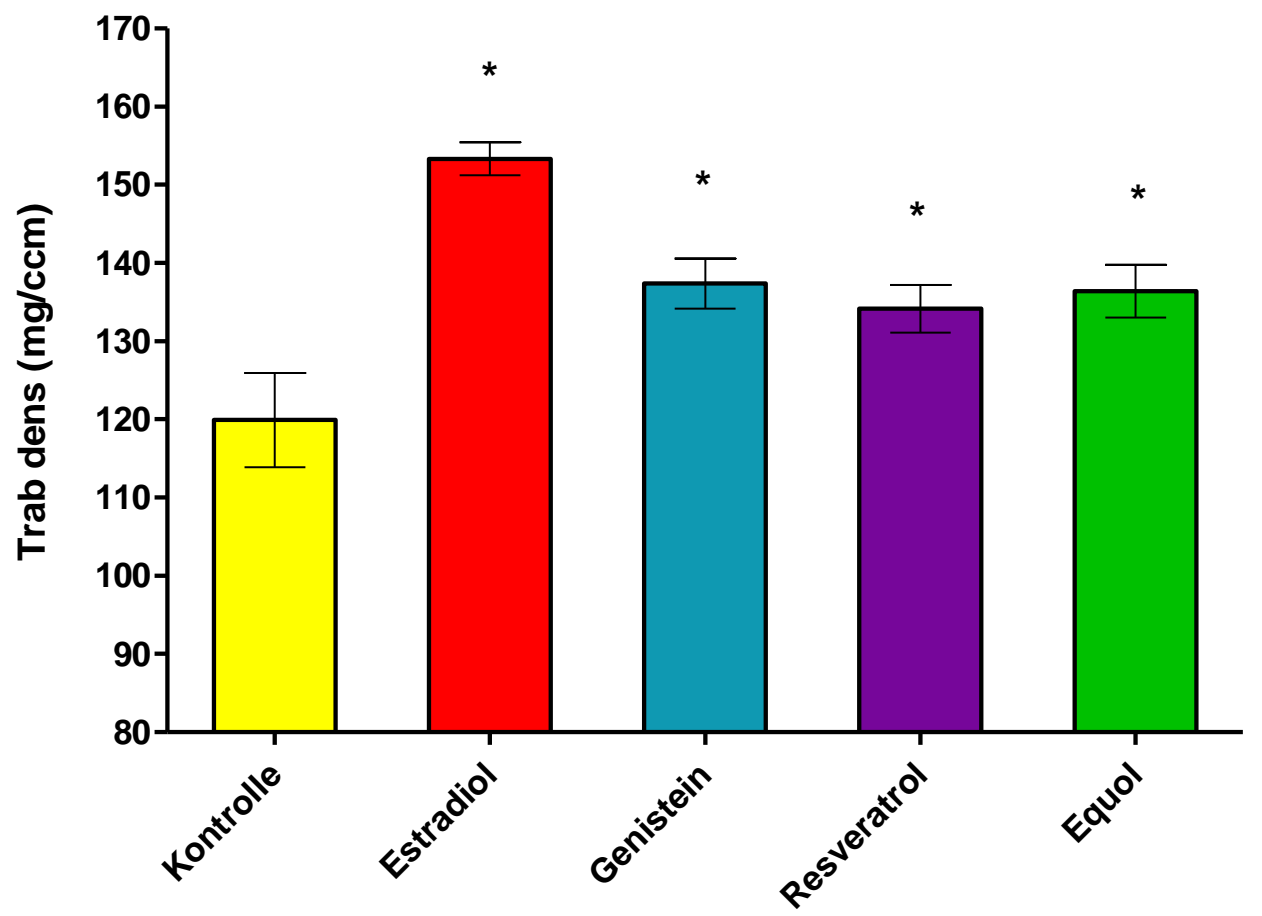

Abbildung 19: Einfluss von Estradiol, Genistein, Resveratrol und Equol auf die Knochendichte in der Spongiosa (gemessen in der Metaphyse) der Tibia. 


\subsubsection{Kortikalisdichte}

In der Abbildung 21 ist zu sehen, welchen Einfluss die vier untersuchten Substanzen auf die Dichte der Kortikalis, gemessen in der Tibia-Diaphyse der Versuchstiere, haben.

Die Kortikalisdichte nahm unter Estradioltherapie signifikant weniger stark ab als in der Kontrollgruppe. Genistein, Equol und Resveratrol hingegen wiesen keinen signifikant verminderten Dichteverlust auf.

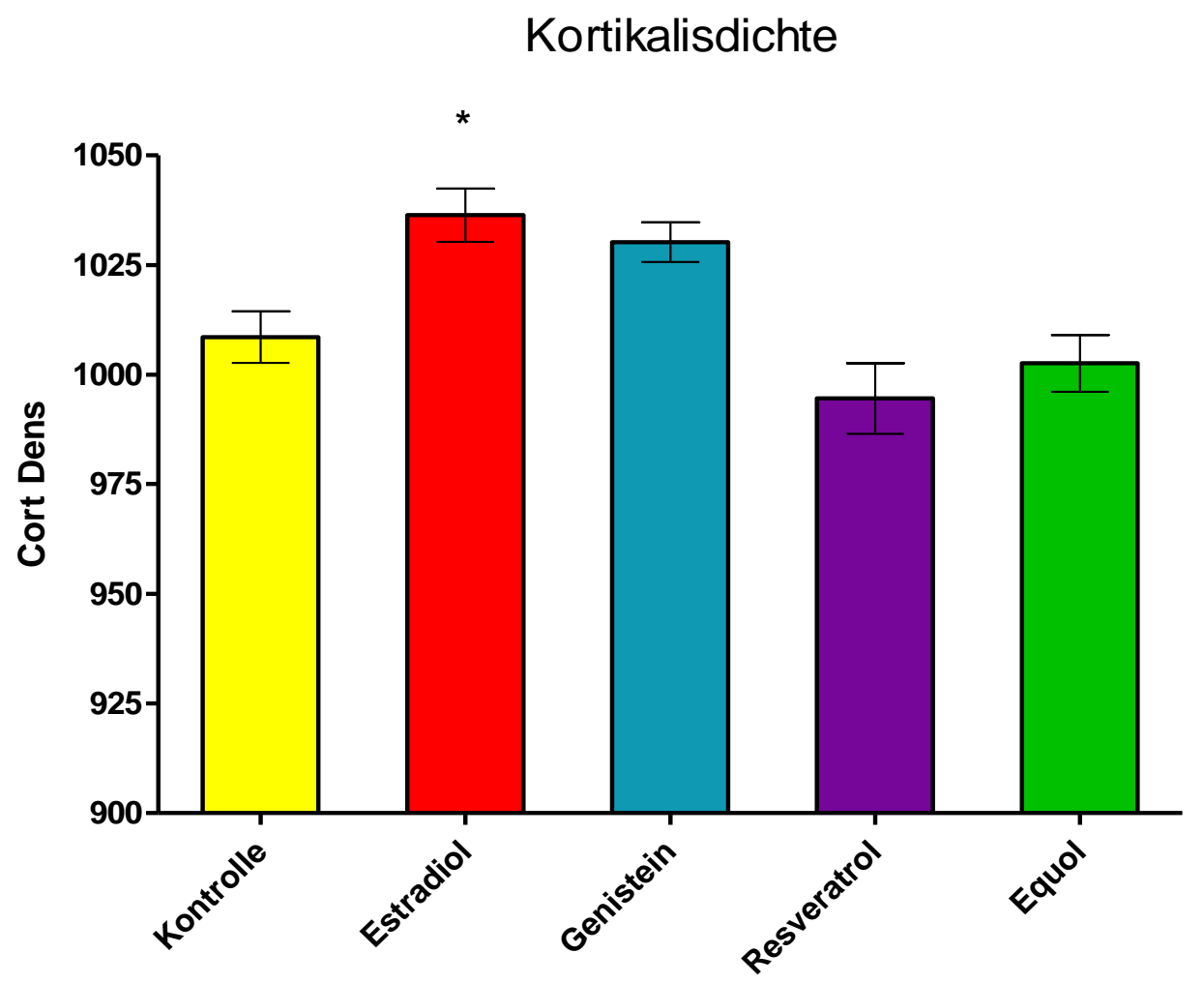

Abbildung 20: Einfluss von Estradiol, Genistein, Resveratrol und Equol auf die Knochendichte in der Kortikalis (gemessen in der Diaphyse) der Tibia. 


\subsubsection{Gesamtdichte von Tibia-Meta- und Diaphyse}

Berechnet man aus den oben beschriebenen Parametern die Gesamtdichte der Tibia in Metaund Diaphyse, ergeben sich folgende Ergebnisse:

Sowohl die Aufnahme von Estradiol, als auch die Aufnahme von Genistein mit der Nahrung führt bei den Versuchstieren in der verwendeten Konzentration zu einer signifikanten Verhinderung Ovariektomie induzierten Knochendichteverlustes. Equol und Resveratrol können den Gesamtdichteverlust nicht signifikant mindern.

\section{Gesamtdichte von Tibia-Meta- und Diaphyse}

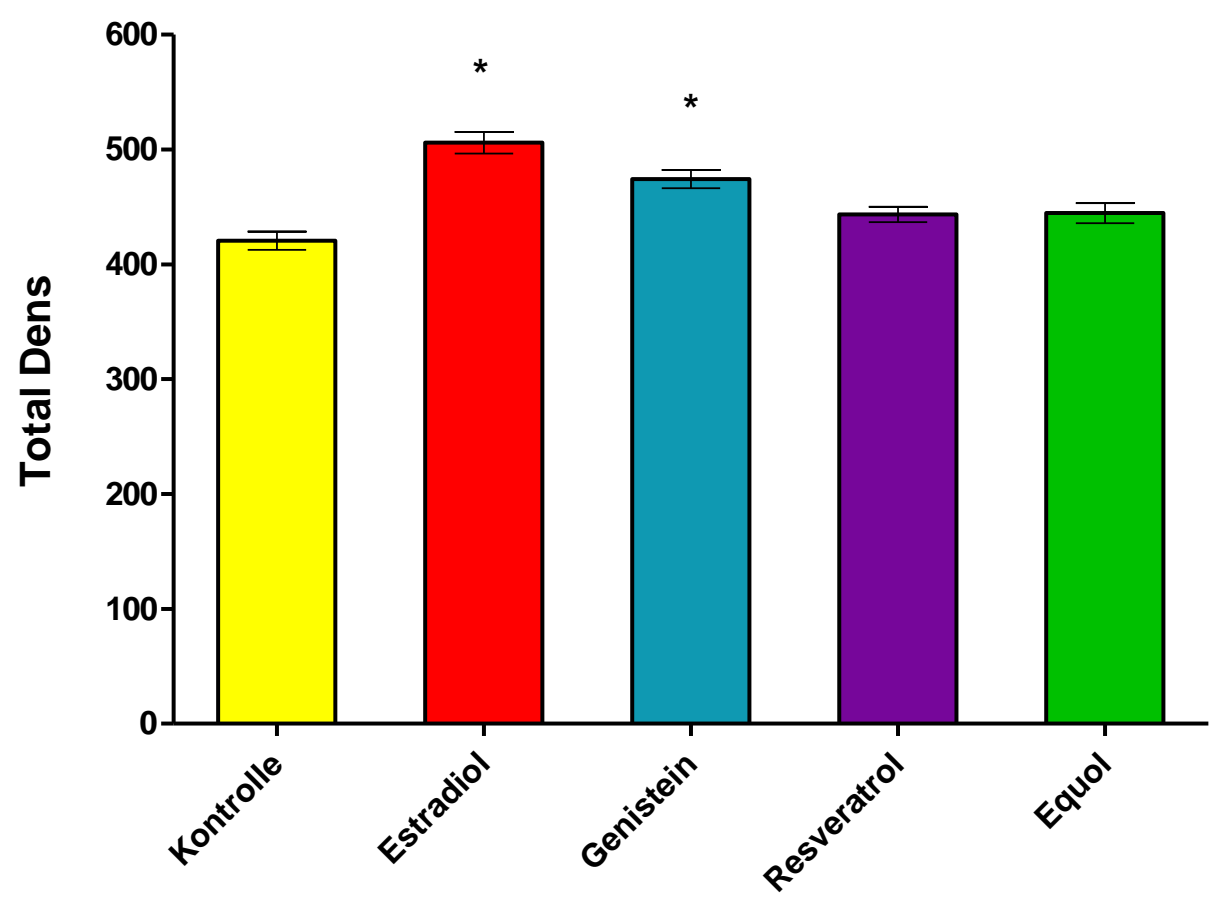

Abbildung 21: Einfluss von Estradiol, Genistein, Resveratrol und Equol auf die Gesamtdichte von TibiaMeta- und Diaphyse 


\subsection{Gemessene Veränderungen im Serum}

Zusätzlich zu den aus Organen und Knochen der Versuchstiere gewonnenen Ergebnissen wurde das Serum der Mäuse am Ende des Versuchs untersucht. Es wurden Analysen von Cholesterol, Triglyceriden, HDL und LDL angefertigt. Auch der Blutspiegel von Estradiol wurde bestimmt.

\subsubsection{Cholesterol, Triglyceride, LDL und HDL im Serum}

Für keine der untersuchten Substanzen konnte ein signifikanter Einfluss auf den Cholesteroloder Triglyceridwert im Serum der Versuchstiere nachgewiesen werden. Auch auf LDL- und HDL-Spiegel ließen sich nur tendenzielle Effekte beobachten (s. Tabelle 6).

Tabelle 6 : Einfluss von Estradiol, Genistein, Resveratrol und Equol auf die Serumwerte von Cholesterol, Triglyceriden, LDL und HDL in mg/dl. Zusätzlich angegeben ist die jeweilige Standardabweichung.

\begin{tabular}{|c|c|c|c|c|}
\hline & $\begin{array}{l}\text { Cholesterol in } \\
\mathrm{mg} / \mathrm{dl}\end{array}$ & $\begin{array}{l}\text { Triglyceride in } \\
\mathrm{mg} / \mathrm{dl}\end{array}$ & $\mathrm{LDL}$ in $\mathrm{mg} / \mathrm{dl}$ & HDL in $\mathrm{mg} / \mathrm{dl}$ \\
\hline Kontrolle & $97,2 \quad+/-14,33$ & $103,1+/-11,51$ & $20,3+/-3,85$ & $84,7+/-14,87$ \\
\hline Estradiol & $92,0 \quad+/-28,90$ & $92,6+/-24,76$ & $17,8+/-2,99$ & $77,2+/-28,65$ \\
\hline Genistein & $111,6+/-16,96$ & $119,1+/-19,36$ & $20,0+/-5,27$ & $99,5+/-14,76$ \\
\hline Resveratrol & $107,7+/-12,95$ & $116,7+/-20,29$ & $20,7+/-3,85$ & $96,9+/-11,86$ \\
\hline Equol & $109,5+/-31,67$ & $109,4+/-16,24$ & $22,9+/-10,12$ & $94,8+/-24,00$ \\
\hline
\end{tabular}

\subsubsection{Estradiol im Serum}

Ebenfalls untersucht, jedoch nicht graphisch dargestellt, wurde der Serumestradiolspiegel und der Einfluss der Versuchssubstanzen auf diesen.

Es konnte eine signifikante Erhöhung des Wertes für Estradiol im Serum auf das Fünffache in der Gruppe der mit Estradiol behandelten Mäuse festgestellt werden.

Die anderen Tiergruppen zeigten einen dem Kontrollwert ähnlichen Estradiolspiegel. 


\section{Diskussion}

\subsection{Mausmodell}

Mit den durchgeführten Versuchen ist es im Rahmen dieser Arbeit gelungen, die langzeitbehandelte ovariektomierte Maus als Modell für die Hormonbehandlung der postmenopausalen Frau zu etablieren. Die gewählten Konzentrationen von Estradiol führten sowohl am Uterus, als auch in Bezug auf Körpergewicht und Serumestradiolwerte zu den erwarteten Effekten(Borisov und Levi 1994, Hertrampf et al. 2006, Kapitola et al. 1994). So wurde eine deutlich signifikante Steigerung des Uterusgewichtes bei gleichzeitig signifikanter Erhöhung der Genexpression der biologischen Östrogen-Marker IGF-1 und C3 unter E2 beobachtet. Darüber hinaus war bei den Estradiol-behandelten Tieren ein signifikant vermindertes Körpergewicht bei vergleichsweise hoher Futteraufnahme zu verzeichnen. Der Serumestradiolwert stieg in der Estradiolgruppe auf das Fünffache des Kontrollwertes an. Die in dieser Arbeit erhobenen Daten können somit bei sich anschließenden Studien als Bezugsgröße dienen und vor allem bei Untersuchungen an Knock-Out-Mäusen als Kontrollwerte genutzt werden.

\subsection{Herz}

In der vorliegenden Arbeit konnte erstmals gezeigt werden, dass das Herzgewicht von ovariektomierten Mäusen durch die exogene Zufuhr von Estradiol signifikant gesteigert wird. Diesen Ergebnissen entsprechend wurde zudem eine signifikante Steigerung der IGF-1Expression im linken Ventrikel nachgewiesen.

Ein solcher Effekt konnte für keine der neben Estradiol untersuchten Substanzen nachgewiesen werden. Ein Herzgewicht beeinflussender Effekt ist weder für Genistein und Equol, noch für Resveratrol an anderen Tiermodellen untersucht worden und demnach bisher nicht bekannt.

Die Suche nach Erklärungen für die Tatsache, dass sich das Risiko für kardiale Erkrankungen mit Eintritt der Menopause bei Frauen dem der Männer angleicht(Gordon et al. 1978), sollte aufgrund dieser Ergebnisse also in nachfolgenden Studien vermehrt auf den Bereich des direkten Einflusses von Estradiol auf das Myokard gelenkt werden. Zweifelsohne sind die bewiesenen Effekte des E2 auf Mechanismen wie NO-Bildung, Atherogenese, Serumlipidspiegel etc. in der Entwicklung kardiovaskulärer Krankheitsbilder von eminenter 
Bedeutung(Miller und Duckles 2008, Saltiki und Alevizaki 2007). Die Entdeckung von Estradiolrezeptoren im Myokard(Grohe et al. 1998, Nordmeyer et al. 2004) und die in dieser Arbeit beobachteten Wirkungen von E2 auf den Herzmuskel unter postmenopausalen Konditionen unterstreichen jedoch die essentielle Rolle, die der direkte Effekt von Estradiol am Herzen in der Pathogenese von postmenopausal auftretenden Herzerkrankungen zu spielen scheint.

Der nachgewiesene, wachstumsstimulierende Einfluss, den Estradiol unter estradiolarmen Bedingungen am Herzen hat, wirft gleichzeitig die Frage auf, wie sich das Herzgewicht bei intakten Tieren unter Einfluss der zugeführten Substanzen entwickelt hätte. Dies ist als Schwachstelle des Versuchsaufbaus anzusehen und sollte in nachfolgenden Studien berücksichtigt werden.

Im Rahmen dieser Arbeit konnte darüber hinaus erstmalig gezeigt werden, dass unter physiologischen Bedingungen weder Estradiol noch einer der anderen applizierten Stoffe bei der Maus zu einer signifikanten Änderung der ER $\alpha$ - oder ER $\beta$-Expression am Myokard führt. Die Regulation der Expression der Östrogenrezeptoren wurde in der Vergangenheit zwar in vitro und in vivo unter pathologischen Bedingungen untersucht(Arias-Loza et al. 2008, Regitz-Zagrosek et al. 2007, Saltiki und Alevizaki 2007). Über deren Regulation unter physiologischen Bedingungen jedoch lagen bisher keine Daten vor.

Wie bereits erwähnt war in den vorliegenden Untersuchungen die durch Genistein induzierte, vermehrte Expression von IGF-1 im Herzen nicht signifikant. Eine direkte Wirkung kann somit nicht belegt werden. Dies schließt jedoch eine indirekte Wirkung des Phytohormons auf den linken Ventrikel nicht aus. Möglich wäre beispielsweise ein nichtöstrogenrezeptorvermittelter Effekt über die Beeinflussung anderer Hormonsysteme wie zum Beispiel dem der Schilddrüse. Diese Vermutung liegt vor allem deshalb nahe, da bereits über die Supprimierung von TSH-Sekretion und Thyroxinsynthese nach Genisteinapplikation berichtet wurde(Chang und Doerge 2000).

\subsection{Uterus}

Wie unter 4.1 erwähnt, führte Estradiol erwartungsgemäß zu einer Stimulierung der Uterusproliferation. Diese zeigte sich sowohl in einer signifikanten Erhöhung des Uterusgewichtes, als auch in einer vermehrten Expression der Markerproteine IGF-1 und C3. 
Diese Beobachtung bestätigt, dass die gewählten Konzentrationen von Estradiol ausreichend waren, um östrogene Effekte auf den Organismus der Versuchstiere hervorzurufen.

Für das Phytohormon Genistein konnte nachgewiesen werden, dass eine Langzeitapplikation bei ,postmenopausalen“ Mäusen zu einer signifikant erhöhten IGF-1-Expression und somit zu einer östrogenartigen Wirkung am Uterus führt. Diese ging jedoch nicht mit einer Erhöhung des Uterusgewichts einher. Genistein nimmt also deutlich via IGF-1 Einfluss auf die Gebärmutter, was zumindest in dieser Konzentration und bei Verabreichung über 3 Monate nicht zu einer Gewichtserhöhung führt. Diese Ergebnisse bestätigen eine Studie von Diel et al., aus der die Wissenschaftler schlossen, Genistein habe nur eine limitierte Fähigkeit, die molekularen Mechanismen der Proliferationsinduktion zu aktivieren, könne aber Östrogensensitive Gene östrogenartig induzieren(Diel et al. 2004). Trotzdem ist ganz klar ein Einfluss der Substanz auf den Uterus zu verzeichnen, sodass gefolgert werden kann, dass es sich bei Genistein nicht um einen SERM handelt. Mögliche uterotrophe Nebenwirkungen durch den Konsum von Genisteinpräparaten können somit nicht ausgeschlossen werden, vor allem da in der Vergangenheit bereits über solche berichtet wurde(Kanno et al. 2003, Power et al. 2006, Unfer et al. 2004).

Große Schwankungsbreiten könnten außerdem bei der Analyse der Östrogenrezeptorexpression im Uterus eventuell eine Signifikanz verhindert haben, was ebenfalls auf eine östrogenartige Wirkung von Genistein am Uterus hätte deuten können. Eine wiederholte Bestimmung dieses Parameters in sich anschließenden Studien ist zu erwägen.

Eine bemerkenswerte Beobachtung ist außerdem, dass Equol in der vorliegenden Studie nicht $\mathrm{zu}$ proliferierenden Effekten am Uterus führt. Sowohl das Uterusgewicht als auch die Expression von Östrogenrezeptoren und biologischen Markerproteinen blieben von einer Langzeitapplikation unbeeinflusst. Vor allem vor dem Hintergrund eines eventuellen Einsatzes von Equol in der Therapie der Osteoporose Typ I ist diese Erkenntnis von enormer Wichtigkeit. Schließlich gibt es andere Studiengruppen, die gegenteilige Ergebnisse veröffentlichten(Phrakonkham et al. 2007, Rachon et al. 2007e). Diese Daten wurden zwar auch nach einem Behandlungszeitraum von drei Monaten erhoben, jedoch benutzten die Wissenschaftler das Modell der ovariektomierten Ratte. Da auch Fujioka et al.(Fujioka et al. 2004) nach vierwöchiger Equolapplikation keine uterotrophen Effekte bei ovariektomierten Mäusen beobachteten, kann hieraus geschlossen werden, dass die Effekte von Equol auf den Uterus bei Mäusen und Ratten unterschiedlich sind. Klinische Studien über die Auswirkungen 
eines über längere Zeit stattgehabten Equolkonsums auf den menschlichen Uterus stehen noch aus. In Bezug auf die Maus kann bei Equol somit von einem SERM gesprochen werden, ein uterotropher Effekt am Menschen kann aber nicht ausgeschlossen werden.

Resveratrol führte unter den gegebenen Konditionen ebenfalls nicht zu einer Stimulierung des Uteruswachstums oder der Markerproteine. Diese Tatsache deckt sich mit Ergebnissen aus Studien, die für Resveratrol eine inhibierende Wirkung auf die Angiogenese, sowie einen antiproliferativen Effekt in endometrialen Tumorzellen zeigen konnten(Bhat KP und Pezzuto 2001, Dann et al. 2009). Über proliferationsfördernde Eigenschaften am Uterus wurde bisher nicht berichtet. Eine uterotrophe Wirkung als Nebenwirkung bei Resveratrol Einnahme kann somit weitestgehend ausgeschlossen werden.

\subsection{Körpergewicht}

Außer der oben diskutierten, wie erwartet stattgehabten Gewichtsentwicklung der Estradiolgruppe wurden interessante Ergebnisse in Bezug auf das Körpergewicht der mit Resveratrol, Genistein und Equol behandelten Tiere erhoben.

So führte die Applikation von Resveratrol über drei Monate interessanterweise zu einer stetigen und, im Vergleich zu den anderen Gruppen, signifikanten Gewichtszunahme bei durchschnittlicher Futteraufnahme. Dies widerspricht Studien, in denen ein nahrungsinduziertes Übergewicht durch Resveratrol verhindert werden konnte(Lagouge et al. 2006). Ob Resveratrol im Rahmen der vorliegenden Versuche die negativen Folgen des Übergewichts (z.B. eine verminderte Insulinsensitivität) minimieren konnte (wie in anderen Studien beobachtet(Baur et al. 2006)), wurde in der vorliegenden Arbeit nicht untersucht.

Die Genistein konsumierenden Tiere erreichten in der vorliegenden Arbeit ein ähnliches Endgewicht wie diejenigen der Kontrollgruppe. In der Literatur finden sich jedoch Angaben, Genistein könne im Tierversuch bei dreiwöchiger Applikation zu einer Senkung des Körpergewichtes bei vermehrter Apoptose von Adipozyten führen(Kim et al. 2006). Allein die Tatsache, dass in der vorliegenden Studie die Einflüsse von Genistein über drei Monate beobachtet wurden, erklärt hierbei nicht die unterschiedlichen Ergebnisse, da hier auch nach drei Wochen kein niedrigeres Gewicht der Genisteingruppe im Vergleich zur Kontrollgruppe zu verzeichnen war. Ein östrogenartiger Effekt des Genisteins auf das Körpergewicht konnte in dieser Arbeit somit am Mausmodell nicht bestätigt werden.

Equol führte ebenfalls zu einer Gewichtsentwicklung, die derjenigen der sojafrei ernährten Tiere ähnelte. Auch für Equol wurde in anderen Studien ein gewichtsreduzierender Effekt 
postuliert(Rachon et al. 2007a). Die Versuche wurden hierbei zwar mit gleichen Equol Futterkonzentrationen, jedoch an Ratten statt an Mäusen durchgeführt, was die unterschiedlichen Versuchsergebnisse erklären könnte.

\subsection{Leber}

Alle untersuchten Substanzen führten in der Maus zu einer signifikanten Erhöhung des absoluten Lebergewichts. IGF-1 und ER $\alpha$ blieben jedoch in allen Gruppen unbeeinflusst. Das relative Lebergewicht war nur für Estradiol und Genistein erhöht.

Aussagen zu vermeintlichen Gründen für diese Resultate sind rein spekulativ. Zu vermuten ist jedoch, dass Estradiol, Genistein, Equol und Resveratrol unter den vorliegenden Umständen $\mathrm{zu}$ einer im Vergleich zur Kontrollgruppe erhöhten hepatischen Metabolisierung führen. Ebenfalls wäre denkbar, dass eine im Vergleich zu Ratten und Menschen unterschiedliche hepatische Metabolisierung (z.B. aufgrund einer anderen Enzymausstattung der Maus(Lim et al. 1994)) zu dem erhöhten Lebergewicht führt.

Ein weitere Erklärungsansatz für das unter Estradiol erhöhte absolute und relative Lebergewicht könnte die Tatsache sein, dass E2 als Wachstum-stimulierender Faktor in der Leber agiert (Dixit et al. 1991).

Dass Genistein in großen Mengen (500mg/kg/Tag) und bei langandauernder Exposition im Rattenmodell zu einer Erhöhung des Lebergewichts führt, ist bekannt(Michael McClain et al. 2006). Ein gleichartiges Ergebnis kann hiermit auch für das Mausmodell bestätigt werden.

\subsection{Serumlipide}

In der vorliegenden Arbeit ließ sich kein Effekt der gewählten Dosen von Estradiol, Genistein, Equol und Resveratrol auf den Serumlipidspiegel beobachten.

Cholesterol, Triglyceride, LDL und HDL wurden nur tendenziell durch Estradiol gesenkt, was im Gegensatz zu klinischen Studien steht, in denen eine signifikante TG- und LDLSenkung(Baksu et al. 2007, Creatsas et al. 2003) sowie eine HDL-Erhöhung(Baksu et al. 2007, Vehkavaara et al. 2001) durch E2-Substitution erreicht werden konnte. Am Modell der Ratte wurde ebenfalls eine Verminderung des HDL unter Estradiolzufuhr nachgewiesen(Rachon et al. 2007a). Auch für Equol fanden andere Wissenschaftler bei gleicher Dosierung einen signifikant positiven Effekt auf das Serumlipidprofil von Ratten(Rachon et al. 2007a). 
In Analogie zu dieser Arbeit brachte eine Metaanalyse von 2003 hervor, dass Genistein keinen signifikanten Einfluss auf die Serumwerte von LDL, HDL und Triglyceriden hat(Yeung und Yu 2003). Für Resveratrol wurde zwar in der Vergangenheit in einem Atherosklerose-Hamstermodell eine Verminderung von LDL-Spiegel und LDL-Oxidation nach in-vivo-Applikation von Resveratrol enthaltenden Lebensmitteln (roter Traubensaft, Rotwein und alkoholfreier Rotwein) beobachtet(Vinson et al. 2001). Die Zufuhr von isoliertem Resveratrol hatte aber auch schon in einer Studie von Turrens et al. keinen Effekt auf das Lipoproteinprofil von Ratten(Turrens et al. 1997).

Da Ergebnisse, die in klinischen Studien und an Ratten erhoben wurden, teilweise nicht mit den für diese Arbeit erhobenen Analysen übereinstimmen, lässt sich hier auf einen Unterschied zwischen Maus- und Rattenmodell, bzw. dem Menschen verweisen. Dies ist nicht ungewöhnlich, da auch für andere Substanzen, wie beispielsweise Tamoxifen, schon unterschiedliche Auswirkungen in den beiden Nagerspezies aufgetreten sind(Lim et al. 1994, Shimizu et al. 1996a). Unter Umständen könnten außerdem die gewählten Dosen der Versuchssubstanzen $\mathrm{zu}$ niedrig sein, um einen Einfluss auf den Lipidstoffwechsel des Mäuseorganismus ausüben zu können. Auch noch unbekannte metabolische Mechanismen oder eine nicht ausreichend lange Versuchsdauer könnten zu einer ausbleibenden Wirkung geführt haben.

In Bezug auf Genistein und Resveratrol kann in dieser Arbeit auch für die Maus die Abwesenheit einer Wirkung der beiden Stoffe auf den Serumlipidspiegel bestätigt werden. Dies könnte im Falle von Resveratrol zu der Hypothese führen, dass die günstigen Einflüsse der Substanz auf kardiovaskuläre Erkrankungen an anderer Stelle zu suchen sind.

\subsection{Hypophyse}

In den Hypophysen der Versuchstiere konnte anhand der LH $\beta$-Bestimmung nur für Resveratrol keine östrogene Wirkung auf das Organ beobachtet werden. Alle anderen Substanzen führten zu erniedrigten Werten von LH $\beta$.

Dass hierbei keine statistische Signifikanz für Estradiol erreicht wurde, könnte einerseits an der verwendeten statistischen Methode liegen. Andererseits ist auch zu erwägen, dass das Hypothalamus-Hypophysen-System der Maus unempfindlicher gegenüber Estradiol ist und somit höhere Dosen als bei der Ratte appliziert werden müssten, um ein signifikantes Ergebnis zu erhalten. Ebenfalls denkbar wäre, dass die Langzeitapplikation der Substanzen zu 
einer Desensibilisierung des Systems geführt hat und deshalb die am Ende des Versuchs gemessene LH $\beta$-Konzentration vergleichsweise hoch war.

Für Genistein und Equol wurden in der Vergangenheit an Ratten gegensätzliche Ergebnisse erhoben(Rachon et al. 2007c, Rimoldi et al. 2007, Svechnikov et al. 2005). Resveratrol führte jedoch schon in Studien am Modell der ovariektomierten Ratte zu keinem östrogenen Effekt (Bottner et al. 2006). Auch hier könnten Unterschiede zwischen Mäusen und Ratten in Bezug auf die Wirkung von Equol und Genistein als Grund für die differierenden Resultate zur Erklärung herangezogen werden.

In Bezug auf die ER $\alpha$ - und ER $\beta$-Genexpression zeigten sich keine einheitlichen Reaktionsmuster. Die signifikant vermehrte Expression von ER $\alpha$ unter Resveratrolzufuhr, als auch die signifikant vermehrte ER $\beta$-Genexpression bei Behandlung mit Estradiol, sind bisher nicht beschrieben. Mögliche Interpretationen dieses Ergebnisses sind rein spekulativ.

Da Resveratrol in Mäusen als einziges zu einer signifikant erhöhten ER $\alpha$-Expression, aber nicht zu einer LHß-Absenkung führt, könnte an dieser Stelle vermutet werden, dass bei Mäusen zwar eine Interaktion zwischen Resveratrol und ER $\alpha$ in der Hypophyse stattfindet, hierdurch aber keine typisch östrogene Wirkung vermittelt wird. Es stellt sich die Frage, ob diese Interaktion eventuell andere, nicht durch LH $\beta$ sichtbar zu machende Wirkungen an der Hypophyse haben könnte, oder ob Resveratrol eventuell antiöstrogene Wirkungen an der Hypophyse vermittelt.Die vermehrte ER $\beta$-Expression einzig durch Estradiol könnte hingegen auf eine Interaktion im Sinne einer östrogenen Wirkung hindeuten.

\subsection{Knochen}

Die quantitative Computertomographie ist ein ausgezeichnetes Verfahren, um Knochenparameter an kleinen Tieren zu bestimmen. Sie ist eine sensitive, reproduzierbare und nicht invasive Methode um Unterschiede in Knochenmasse, Knochendichte und Geometrie des Knochens darzustellen, weshalb sie mittlerweile als etablierte Methode anzusehen ist(Gasser 1995). Bestimmungen ossärer Parameter an Mäusen sind in der Vergangenheit bereits erfolgreich anhand dieses Verfahrens vorgenommen worden(Eckstein et al. 2004). Das qCT erfasst getrennt den kortikalen und den spongiösen Anteil des Knochens. Dies ist als günstig zu erachten, da osteoporotische Veränderungen und andere Stoffwechselstörungen vor allem die trabekulären, stoffwechselaktiven Anteile betreffen. Deshalb sind die Messungen der trabekulären Dichte von entscheidender Wichtigkeit. 
Aus durchgeführten Versuchen ist bekannt, dass die Ovariektomie im Sinne einer induzierten Osteoporose Typ I zu einem signifikant verminderten Knochendichtegehalt führt(Hertrampf et al. 2006).

In der vorliegenden Studie zeigt sich für alle untersuchten Substanzen, dass die Dichte der tibialen Spongiosa durch drei Monate lange Zufuhr des jeweiligen Stoffes p.o. signifikant weniger abnahm. Vor allem Estradiol führte zu einer sehr ausgeprägten Wirkung auf die trabekuläre Dichte. Estradiol, Genistein, Equol und Resveratrol zeigen also im Mausmodell osteoprotektive, bzw. antiosteoporotischen Effekte. Auf die kortikale Dichte hatte jedoch nur Estradiol signifikant positiven Einfluss.

Dass Estradiol einen Knochensubstanz erhaltenden Effekt hat, ist ausreichend in Studien belegt(Hertrampf et al. 2006, O'Connell et al. 1998). Aufgrund der bekannten Nebenwirkungen der Hormonersatztherapie ist die Gabe von Estradiol zur Osteoporoseprophylaxe jedoch nicht in erster Linie indiziert.

Auch in Bezug auf die verschiedenen Phytohormone gibt es bereits multiple Untersuchungen, die sich mit ihrem Einfluss auf den Knochenstoffwechsel befassen.

So konnte für Genistein bereits ein positiver Effekt auf die Knochendichte von Mäusen(Power et al. 2006) und Ratten(Picherit et al. 2001) bewiesen werden. In Analogie zu den Tierversuchen ließ sich diese Beobachtung auch in klinischen Studien reproduzieren(Atteritano et al. 2009, Marini et al. 2007, Morabito et al. 2002). In Bezug auf die Studie von Anderson et al., laut der zwar ein knochensparender Effekt mit niedrigen Dosierungen von Genistein (0,5 und 1,6mg pro Tag) als osteoprotektiv zu verzeichnen ist, höhere Dosen (5mg pro Tag) jedoch zum gegenteiligen Effekt einer beschleunigten Osteoporoseentstehung bei Ratten führen(Anderson et al. 1998), ist zu sagen, dass eine Genisteinaufnahme von 2,34 mg pro Tag in der vorliegenden Studie bei Mäusen zu einer osteoprotektiven Wirkung führte. 1,6mg pro Tag sind also, zumindest bei der Maus, nicht als obere Grenze der osteoprotektiven Wirksamkeit anzusehen. Trotz der in diesem Versuch festgestellten positiven Auswirkungen auf das Knochenprofil kann jedoch keine Genistein Einnahme in den benötigten Dosen über längere Zeit befürwortet werden, da eine uterotrophe Wirkung des Genisteins als wahrscheinlich anzusehen ist (s. 4.3 Uterus, S.59). 
Die vorliegenden Resultate zur osteoprotektiven Eigenschaft des Equols bei Mäusen bestätigen ältere Studien. Von Fujioka et al. wurde für Equol eine Inhibierung des Knochenverlustes in ovariektomierten Mäusen beobachtet(Fujioka et al. 2004) und Rachon et al. bewiesen einen mäßigen, Equol-vermittelten, knochensparenden Effekt bei ovariektomierten Ratten(Rachon et al. 2007b). Nichtsdestotrotz wird die Muttersubstanz des Equols, Daidzein, für die effektivere Substanz in punkto Ovariektomie-induzierter Osteoporose gehalten(Picherit et al. 2000). Wu et al. konstatierten, die Tatsache, dass die Wirkung von Equol auf die Knochendichte in klinischen Studien zu unterschiedlichen Ergebnissen führt, läge an der individuell unterschiedlichen Metabolisierungsrate des Stoffes(Vatanparast und Chilibeck 2007, Wu J et al. 2007). In dieser Studie konnte bei den viel Equol produzierenden Frauen ein signifikanter Einfluss auf die Knochendichte festgestellt werden.

Interessant ist in diesem Kontext, dass es sich bei den in diesem Versuch verwendeten C57 Mäusen um einen Mausstamm handelt, der vergleichsweise wenig Equol produziert(Ward et al. 2005). Trotz dieser Tatsache ist für diese Tiere eine Equol-induzierte, gesteigerte Knochendichte zu beobachten, was für sich anschließende Studien nicht unwichtig sein dürfte.

Auch für Equol können jedoch aufgrund der umstrittenen, eventuell uterotrophen Wirkung keine Empfehlungen im Rahmen der Osteoporoseprophylaxe/-therapie ausgesprochen werden (s. 4.3 Uterus, S. 59).

Resveratrol, so ist bekannt, konnte im Rattenmodell die epiphysäre Knochendichte steigern und führte in Bruchtests $\mathrm{zu}$ einer positiven Wirkung auf die Stabilität von Rattenoberschenkelknochen(Liu ZP et al. 2005, Mizutani et al. 2000). Es liegen jedoch noch keine klinischen Studien zu diesem Thema vor, so dass Angaben zu Empfehlungen eines Resveratrolkonsums aus osteoprotektiven Gründen noch lange nicht möglich sind.

So ergibt sich abschließend folgendes Fazit: Das Mausmodell konnte im Rahmen dieser Arbeit als Modell für die Hormonbehandlung der postmenopausalen Frau erfolgreich etabliert werden. Die erhobenen Daten zur Wirkung von Estradiol, Genistein, Equol und Resveratrol 
auf die untersuchten Organe und Parameter stehen somit in Zukunft als Kontrollwerte für Studien an Knock-out-Mäusen zur Verfügung.

Zudem wurde erstmals beschrieben, dass das Herzgewicht ovariektomierter Mäuse durch die exogene Zufuhr von Estradiol signifikant gesteigert wird. Diese Einflussnahme konnte durch die beobachtete signifikante Steigerung der IGF-1-Expression im linken Ventrikel noch untermauert werden.

In Bezug auf Equol und Resveratrol wurde eine osteoprotektive Wirkung ohne uterotrophe Nebenwirkungen bei Mäusen bewiesen.

Darüber hinaus konnte die SERM-Hypothese für Genistein an Mäusen verworfen werden. 


\section{$5 \quad$ Zusammenfassung}

Die unerwünschten Arzneimittelwirkungen der konventionellen Hormonersatztherapie im Rahmen der Behandlung von postmenopausalen Beschwerden haben zu einem großen Interesse an alternativen Behandlungsmöglichkeiten geführt. Im Zuge dessen sind Phytohormone ins Zentrum des Interesses gerückt, da sie als potentielle SERMs imponieren. Um diese Hypothese zu überprüfen, wurden in den letzten Jahrzehnten multiple Studien zur anti-/östrogenen Wirkung verschiedenster Substanzen am, seit 2001 von der OECD validierten, Modell der ovariektomierten Ratte durchgeführt. In Anlehnung an den normalen Zyklus der Ratte wurde hierbei meist eine Studiendauer von wenigen Tagen nicht überschritten. Zur weitergehenden Erforschung Östrogen-vermittelter Wirkungen wird in neueren Untersuchungen vermehrt mit Knock-out-Mäusen gearbeitet. Ältere Resultate, die an ovariektomierten und intakten Ratten erhoben wurden, können nicht als Kontrollwerte für diese KO-Versuche dienen, da eine direkte Vergleichbarkeit unter den beiden Nagerspezies nicht gegeben ist. Aus diesem Grunde wurde im Rahmen der vorliegenden Arbeit das Modell der ovariektomierten Maus etabliert. Um eine Aussage über die Effekte von Estradiol, Genistein, Equol und Resveratrol an den untersuchten, Östrogen-sensitiven Organen und Parametern bei Applikation über mehrere Zyklen treffen zu können, wurde hierbei der Modus des Langzeitversuchs über drei Monate gewählt. Darüber hinaus widmet sich die vorliegende Arbeit der Frage, aus welchem Grund ein so beträchtlicher Unterschied in der Inzidenz kardiovaskulärer Erkrankungen zwischen den Geschlechtern nur bis zum Eintreten der Menopause vorliegt, und wie dies kausal mit dem postmenopausalen Östrogenmangel zusammenhängen könnte. Im Zuge des neuartigen Studiendesigns wurden hierfür 75 zwei Monate alte C 57 BL/6J-Mäuse nach der Ovariektomie in fünf Gruppen aufgeteilt. Das Futter der Kontrollgruppe war frei von Soja, die anderen Gruppen erhielten entweder mit Estradiol (4,32 mg 17 $\beta$-Estradiolbenzoat/kg sojafreies Futter), Genistein (1000mg/kg SF-Futter), Equol (400mg/kg SF-Futter) oder Resveratrol (840mg/kg SF-Futter) versetzte Nahrung, bis nach drei Monaten der Versuch durch die planmäßige Tötung der Tiere endete. Das Feuchtgewicht von Uterus, Leber und Herz sowie das Körpergewicht wurden bestimmt und die Genexpression von ER $\alpha$ (in Uterus, Leber, linkem Ventrikel und Hypophyse) und ER $\beta$ (in Uterus, linkem Ventrikel und und Hypophyse) per PCR analysiert. Die Expression der biologischen Marker für östrogene Wirkung, C3 (im Uterus), IGF-1 (in Uterus, Leber und linkem Ventrikel) und LH $\beta$ (in der Hypophyse), wurde untersucht und die Serumspiegel für 
Cholesterol, Triglyceride, HDL und LDL bestimmt. Zudem wurde eine Messung der Spongiosa- und Kortikalisdichte in den Tibiae der Versuchstiere durchgeführt. Hierbei konnten multiple, neuartige Ergebnisse generiert werden, von denen mehrere mit den an Ratten erhobenen Daten differieren. So konnte die SERM-Hypothese für Genistein an Mäusen verworfen werden, während Equol und Resveratrol in den vorliegenden Versuchen osteoprotektive Wirkungen ohne uterotrophe Effekte zeigten. Neben der erfolgreichen Etablierung des Mausmodells ist die interessanteste Entdeckung dieser Arbeit jedoch die beobachtete Steigerung des Herzgewichts der ovariektomierten Maus durch Estradiol. Diese Beobachtung und die Entdeckung von Estradiol-Rezeptoren im Myokard(Grohe et al. 1998, Nordmeyer et al. 2004) unterstreichen die essentielle Rolle, die der direkte Effekt von Estradiol am Herzen in der Pathogenese von postmenopausal auftretenden Herzerkrankungen zu spielen scheint und implizieren, dass sich weitergehende Forschungen in diesem Bereich anschließen sollten. 


\section{$6 \quad$ Literaturverzeichnis}

Adlercreutz CH, Goldin BR, Gorbach SL, Hockerstedt KA, Watanabe S, Hamalainen EK, Markkanen MH, Makela TH, Wahala KT, Adlercreutz T (1995): Soybean phytoestrogen intake and cancer risk. J Nutr $\underline{125}, 757 \mathrm{~S}-770 \mathrm{~S}$

Adlercreutz H (1998): Epidemiology of phytoestrogens. Baillieres Clin Endocrinol Metab $\underline{12}$, 605-623

Adlercreutz H (2002): Phyto-oestrogens and cancer. Lancet Oncol $\underline{3}$, 364-373

Adlercreutz H, Mazur W (1997): Phyto-oestrogens and Western diseases. Ann Med 29, 95120

Adlercreutz H, Honjo H, Higashi A, Fotsis T, Hamalainen E, Hasegawa T, Okada H (1991): Urinary excretion of lignans and isoflavonoid phytoestrogens in Japanese men and women consuming a traditional Japanese diet. Am J Clin Nutr 54, 1093-1100

Akiyama T, Ishida J, Nakagawa S, Ogawara H, Watanabe S, Itoh N, Shibuya M, Fukami Y (1987): Genistein, a specific inhibitor of tyrosine-specific protein kinases. J Biol Chem 262 , $5592-5595$

Alekel DL, Germain AS, Peterson CT, Hanson KB, Stewart JW, Toda T (2000): Isoflavonerich soy protein isolate attenuates bone loss in the lumbar spine of perimenopausal women. Am J Clin Nutr $\underline{72}$, 844-852

Allred CD, Allred KF, Ju YH, Clausen LM, Doerge DR, Schantz SL, Korol DL, Wallig MA, Helferich WG (2004): Dietary genistein results in larger MNU-induced, estrogen-dependent mammary tumors following ovariectomy of Sprague-Dawley rats. Carcinogenesis $\underline{25}$, 211218

Anderson JJ, Ambrose WW, Garner SC (1998): Biphasic effects of genistein on bone tissue in the ovariectomized, lactating rat model. Proc Soc Exp Biol Med 217, 345-350

Arias-Loza PA, Jazbutyte V, Pelzer T (2008): Genetic and pharmacologic strategies to determine the function of estrogen receptor alpha and estrogen receptor beta in cardiovascular system. Gend Med 5 Suppl A, S34-45

Arts J, Kuiper GG, Janssen JM, Gustafsson JA, Lowik CW, Pols HA, van Leeuwen JP (1997): Differential expression of estrogen receptors alpha and beta mRNA during differentiation of human osteoblast SV-HFO cells. Endocrinology 138, 5067-5070 
Atkinson C, Compston JE, Day NE, Dowsett M, Bingham SA (2004): The effects of phytoestrogen isoflavones on bone density in women: a double-blind, randomized, placebocontrolled trial. Am J Clin Nutr $\underline{79}$, 326-333

Atteritano M, Mazzaferro S, Frisina A, Cannata ML, Bitto A, D'Anna R, Squadrito F, Macri I, Frisina N, Buemi M (2009): Genistein effects on quantitative ultrasound parameters and bone mineral density in osteopenic postmenopausal women. Osteoporos Int [Pub.med.]

Axelson M, Sjovall J, Gustafsson BE, Setchell KD (1984): Soya--a dietary source of the nonsteroidal oestrogen equol in man and animals. J Endocrinol 102, 49-56

Baksu B, Davas I, Agar E, Akyol A, Uluocak A (2007): Do different delivery systems of estrogen therapy influence serum lipids differently in surgically menopausal women? J Obstet Gynaecol Res $\underline{33}, 346-352$

Basly JP, Lavier MC (2005): Dietary phytoestrogens: potential selective estrogen enzyme modulators? Planta Med 71, 287-294

Baur JA, Pearson KJ, Price NL, Jamieson HA, Lerin C, Kalra A, Prabhu VV, Allard JS, Lopez-Lluch G, Lewis K (2006): Resveratrol improves health and survival of mice on a highcalorie diet. Nature $\underline{444}, 337-342$

Beral V (2003): Breast cancer and hormone-replacement therapy in the Million Women Study. Lancet $\underline{362}, 419-427$

Beral V, Bull D, Green J, Reeves G (2007): Ovarian cancer and hormone replacement therapy in the Million Women Study. Lancet $\underline{369}$, 1703-1710

Berco M, Bhavnani BR (2001): Differential neuroprotective effects of equine estrogens against oxidized low density lipoprotein-induced neuronal cell death. J Soc Gynecol Investig $\underline{8}, 245-254$

Bernstein L, Yuan JM, Ross RK, Pike MC, Hanisch R, Lobo R, Stanczyk F, Gao YT, Henderson BE (1990): Serum hormone levels in pre-menopausal Chinese women in Shanghai and white women in Los Angeles: results from two breast cancer case-control studies. Cancer Causes Control $1,51-58$

Bhat KP, Pezzuto JM (2001): Resveratrol exhibits cytostatic and antiestrogenic properties with human endometrial adenocarcinoma (Ishikawa) cells. Cancer Res $\underline{61}$, 6137-6144

Bhat KPL, Kosmeder JW, 2nd, Pezzuto JM (2001): Biological effects of resveratrol. Antioxid Redox Signal $\underline{3}, 1041-1064$

Bhavnani BR, Cecutti A, Gerulath A, Woolever AC, Berco M (2001): Comparison of the antioxidant effects of equine estrogens, red wine components, vitamin $\mathrm{E}$, and probucol on low-density lipoprotein oxidation in postmenopausal women. Menopause $\underline{8}, 408-419$ 
Bilezikian JP (1998): Estrogens and postmenopausal osteoporosis: was Albright right after all? J Bone Miner Res $\underline{13}$, 774-776

Blum A, Cannon RO, 3rd (1998): Effects of oestrogens and selective oestrogen receptor modulators on serum lipoproteins and vascular function. Curr Opin Lipidol $\underline{9}$, 575-586

Bodine PV, Henderson RA, Green J, Aronow M, Owen T, Stein GS, Lian JB, Komm BS (1998): Estrogen receptor-alpha is developmentally regulated during osteoblast differentiation and contributes to selective responsiveness of gene expression. Endocrinology 139, 20482057

Boersma BJ, Barnes S, Kirk M, Wang CC, Smith M, Kim H, Xu J, Patel R, Darley-Usmar VM (2001): Soy isoflavonoids and cancer -- metabolism at the target site. Mutat Res $\underline{480-481}$, $121-127$

Boos G, Stopper H (2000): Genotoxicity of several clinically used topoisomerase II inhibitors. Toxicol Lett $\underline{116}, 7-16$

Bord S, Horner A, Beavan S, Compston J (2001): Estrogen receptors alpha and beta are differentially expressed in developing human bone. J Clin Endocrinol Metab $\underline{86}, 2309-2314$

Borisov I, Levi N (1994): [Changes in the weight of the uterus, ovaries and adrenal glands in sexually mature rats treated with estradiol and reserpine]. Akush Ginekol (Sofiia) $\underline{33}$, 18-20

Bottner M, Christoffel J, Jarry H, Wuttke W (2006): Effects of long-term treatment with resveratrol and subcutaneous and oral estradiol administration on pituitary function in rats. $\mathbf{J}$ Endocrinol $\underline{189}, 77-88$

Boue SM, Wiese TE, Nehls S, Burow ME, Elliott S, Carter-Wientjes CH, Shih BY, McLachlan JA, Cleveland TE (2003): Evaluation of the estrogenic effects of legume extracts containing phytoestrogens. J Agric Food Chem 51, 2193-2199

Breast cancer... (1997): Breast cancer and hormone replacement therapy: collaborative reanalysis of data from 51 epidemiological studies of 52,705 women with breast cancer and 108,411 women without breast cancer. Collaborative Group on Hormonal Factors in Breast Cancer. Lancet $\underline{350}, 1047-1059$

Brosnihan KB, Moriguchi A, Nakamoto H, Dean RH, Ganten D, Ferrario CM (1994): Estrogen augments the contribution of nitric oxide to blood pressure regulation in transgenic hypertensive rats expressing the mouse Ren-2 gene. Am J Hypertens $\underline{7}$, 576-582

Cabanes A, Wang M, Olivo S, DeAssis S, Gustafsson JA, Khan G, Hilakivi-Clarke L (2004): Prepubertal estradiol and genistein exposures up-regulate BRCA1 mRNA and reduce mammary tumorigenesis. Carcinogenesis $\underline{25}$, 741-748

Cadenas S, Barja G (1999): Resveratrol, melatonin, vitamin E, and PBN protect against renal oxidative DNA damage induced by the kidney carcinogen $\mathrm{KBrO}$. Free Radic Biol Med 26, $1531-1537$ 
Calabrese G (1999): Nonalcoholic compounds of wine: the phytoestrogen resveratrol and moderate red wine consumption during menopause. Drugs Exp Clin Res 25, 111-114

Cantos E, Garcia-Viguera C, de Pascual-Teresa S, Tomas-Barberan FA (2000): Effect of postharvest ultraviolet irradiation on resveratrol and other phenolics of cv. Napoleon table grapes. J Agric Food Chem $\underline{48}$, 4606-4612

Carr MC (2003): The emergence of the metabolic syndrome with menopause. J Clin Endocrinol Metab $\underline{88}, 2404-2411$

Carusi D (2000): Phytoestrogens as hormone replacement therapy: an evidence-based approach. Prim Care Update Ob Gyns $\underline{7}, 253-259$

Cauley JA, Robbins J, Chen Z, Cummings SR, Jackson RD, LaCroix AZ, LeBoff M, Lewis CE, McGowan J, Neuner J (2003): Effects of estrogen plus progestin on risk of fracture and bone mineral density: the Women's Health Initiative randomized trial. JAMA 290, 1729-1738

Celotti E, Ferrarini R, Zironi R, Conte LS (1996): Resveratrol content of some wines obtained from dried Valpolicella grapes: Recioto and Amarone. J Chromatogr A $\underline{730}$, 47-52

Chang HC, Doerge DR (2000): Dietary genistein inactivates rat thyroid peroxidase in vivo without an apparent hypothyroid effect. Toxicol Appl Pharmacol 168, 244-252

Colditz GA, Willett WC, Stampfer MJ, Rosner B, Speizer FE, Hennekens CH (1987): Menopause and the risk of coronary heart disease in women. N Engl J Med 316, 1105-1110

Cooper GS, Ephross SA, Weinberg CR, Baird DD, Whelan EA, Sandler DP (1999): Menstrual and reproductive risk factors for ischemic heart disease. Epidemiology 10, 255-259

Cos P, De Bruyne T, Apers S, Vanden Berghe D, Pieters L, Vlietinck AJ (2003): Phytoestrogens: recent developments. Planta Med 69, 589-599

Couse JF, Curtis SW, Washburn TF, Lindzey J, Golding TS, Lubahn DB, Smithies O, Korach KS (1995): Analysis of transcription and estrogen insensitivity in the female mouse after targeted disruption of the estrogen receptor gene. Mol Endocrinol $\underline{9}, 1441-1454$

Creatsas G, Christodoulakos G, Lambrinoudaki I, Panoulis C, Chondros C, Patramanis P (2003): Serum lipids and apolipoproteins in Greek postmenopausal women: association with estrogen, estrogen-progestin, tibolone and raloxifene therapy. J Endocrinol Invest 26, 545-551

Cullinan-Bove K, Koos RD (1993): Vascular endothelial growth factor/vascular permeability factor expression in the rat uterus: rapid stimulation by estrogen correlates with estrogeninduced increases in uterine capillary permeability and growth. Endocrinology 133, 829-837

Cushing KL, Weiss NS, Voigt LF, McKnight B, Beresford SA (1998): Risk of endometrial cancer in relation to use of low-dose, unopposed estrogens. Obstet Gynecol 91, 35-39 
D'Eon TM, Souza SC, Aronovitz M, Obin MS, Fried SK, Greenberg AS (2005): Estrogen regulation of adiposity and fuel partitioning. Evidence of genomic and non-genomic regulation of lipogenic and oxidative pathways. J Biol Chem $\underline{280}$, 35983-35991

Dann JM, Sykes PH, Mason DR, Evans JJ (2009): Regulation of Vascular Endothelial Growth Factor in endometrial tumour cells by resveratrol and EGCG. Gynecol Oncol $\underline{113}$, 374-378

Dave B, Eason RR, Till SR, Geng Y, Velarde MC, Badger TM, Simmen RC (2005): The soy isoflavone genistein promotes apoptosis in mammary epithelial cells by inducing the tumor suppressor PTEN. Carcinogenesis 느, 1793-1803

Davis SR (2003): Menopause: new therapies. Med J Aust 178, 634-637

Diel P, Olff S, Schmidt S, Michna H (2001): Molecular identification of potential selective estrogen receptor modulator (SERM) like properties of phytoestrogens in the human breast cancer cell line MCF-7. Planta Med 67, 510-514

Diel P, Geis RB, Caldarelli A, Schmidt S, Leschowsky UL, Voss A, Vollmer G (2004): The differential ability of the phytoestrogen genistein and of estradiol to induce uterine weight and proliferation in the rat is associated with a substance specific modulation of uterine gene expression. Mol Cell Endocrinol 221, 21-32

Dixit A, Baquer NZ, Rao AR (1991): Effect of 17 beta-estradiol and ovariectomy on enzymes of carbohydrate metabolism in regenerating mouse liver. Biochem Int 24, 649-659

Draper CR, Edel MJ, Dick IM, Randall AG, Martin GB, Prince RL (1997): Phytoestrogens reduce bone loss and bone resorption in oophorectomized rats. J Nutr $\underline{127}$, 1795-1799

Duncan AM, Merz-Demlow BE, Xu X, Phipps WR, Kurzer MS (2000): Premenopausal equol excretors show plasma hormone profiles associated with lowered risk of breast cancer. Cancer Epidemiol Biomarkers Prev $\underline{9}, 581-586$

Dupont J, Le Roith D (2001): Insulin-like growth factor 1 and oestradiol promote cell proliferation of MCF-7 breast cancer cells: new insights into their synergistic effects. Mol Pathol 54, 149-154

Eckstein F, Weusten A, Schmidt C, Wehr U, Wanke R, Rambeck W, Wolf E, Mohan S (2004): Longitudinal in vivo effects of growth hormone overexpression on bone in transgenic mice. J Bone Miner Res $\underline{19}$, 802-810

Emmen JM, Korach KS (2001): Developing animal models for analyzing SERM activity. Ann N Y Acad Sci 949, 36-43

Fanti P, Monier-Faugere MC, Geng Z, Schmidt J, Morris PE, Cohen D, Malluche HH (1998): The phytoestrogen genistein reduces bone loss in short-term ovariectomized rats. Osteoporos Int $\underline{8}, 274-281$ 
Fioretti F, Tavani A, Gallus S, Franceschi S, La Vecchia C (2000): Menopause and risk of non-fatal acute myocardial infarction: an Italian case-control study and a review of the literature. Hum Reprod 15, 599-603

Freyberger A, Hartmann E, Hildebrand H, Krotlinger F (2001): Differential response of immature rat uterine tissue to ethinylestradiol and the red wine constituent resveratrol. Arch Toxicol $\underline{74}$, 709-715

Fujioka M, Uehara M, Wu J, Adlercreutz H, Suzuki K, Kanazawa K, Takeda K, Yamada K, Ishimi Y (2004): Equol, a metabolite of daidzein, inhibits bone loss in ovariectomized mice. J Nutr 134, 2623-2627

Gallagher PE, Li P, Lenhart JR, Chappell MC, Brosnihan KB (1999): Estrogen regulation of angiotensin-converting enzyme mRNA. Hypertension $\underline{33}$, 323-328

Gallo D, Zannoni GF, Apollonio P, Martinelli E, Ferlini C, Passetti G, Riva A, Morazzoni P, Bombardelli E, Scambia G (2005): Characterization of the pharmacologic profile of a standardized soy extract in the ovariectomized rat model of menopause: effects on bone, uterus, and lipid profile. Menopause 12, 589-600

Gasser JA (1995): Assessing bone quantity by pQCT. Bone 17, 145S-154S

Gordon T, Kannel WB, Hjortland MC, McNamara PM (1978): Menopause and coronary heart disease. The Framingham Study. Ann Intern Med $\underline{89}$, 157-161

Grady D, Gebretsadik T, Kerlikowske K, Ernster V, Petitti D (1995): Hormone replacement therapy and endometrial cancer risk: a meta-analysis. Obstet Gynecol 모, 304-313

Grandien K, Berkenstam A, Gustafsson JA (1997): The estrogen receptor gene: promoter organization and expression. Int J Biochem Cell Biol 29, 1343-1369

Greendale GA, Reboussin BA, Hogan P, Barnabei VM, Shumaker S, Johnson S, BarrettConnor E (1998): Symptom relief and side effects of postmenopausal hormones: results from the Postmenopausal Estrogen/Progestin Interventions Trial. Obstet Gynecol 92, 982-988

Grohe C, Kahlert S, Lobbert K, Vetter H (1998): Expression of oestrogen receptor alpha and beta in rat heart: role of local oestrogen synthesis. J Endocrinol 156, R1-7

Gruber CJ, Tschugguel W, Schneeberger C, Huber JC (2002): Production and actions of estrogens. N Engl J Med 346, 340-352

Haneke KE (2002): trans-Resveratrol - Review of Toxicological Literature. 1-64

Hao HD, He LR (2004): Mechanisms of cardiovascular protection by resveratrol. J Med Food 7, 290-298 
Harris DM, Besselink E, Henning SM, Go VL, Heber D (2005): Phytoestrogens induce differential estrogen receptor alpha- or Beta-mediated responses in transfected breast cancer cells. Exp Biol Med (Maywood) 230, 558-568

Helterbrand JD, Higgs RE, Jr., Iversen PW, Tysarczyk-Niemeyer G, Sato M (1997): Application of automatic image segmentation to tibiae and vertebrae from ovariectomized rats. Bone $\underline{21}, 401-409$

Henderson BE, Ross RK, Judd HL, Krailo MD, Pike MC (1985): Do regular ovulatory cycles increase breast cancer risk? Cancer $\underline{56}, 1206-1208$

Henry LA, Witt DM (2002): Resveratrol: phytoestrogen effects on reproductive physiology and behavior in female rats. Horm Behav $\underline{41}, 220-228$

Hertrampf T, Degen GH, Kaid AA, Laudenbach-Leschowsky U, Seibel J, Di Virgilio AL, Diel P (2006): Combined effects of physical activity, dietary isoflavones and 17beta-estradiol on movement drive, body weight and bone mineral density in ovariectomized female rats. Planta Med $\underline{72}$, 484-487

Hillier SG, Whitelaw PF, Smyth CD (1994): Follicular oestrogen synthesis: the 'two-cell, two-gonadotrophin' model revisited. Mol Cell Endocrinol 100, 51-54

Hodis HN, Mack WJ, Lobo RA, Shoupe D, Sevanian A, Mahrer PR, Selzer RH, Liu Cr CR, Liu Ch CH, Azen SP (2001): Estrogen in the prevention of atherosclerosis. A randomized, double-blind, placebo-controlled trial. Ann Intern Med 135, 939-953

Hsieh YC, Yang S, Choudhry MA, Yu HP, Rue LW, 3rd, Bland KI, Chaudry IH (2005): PGC-1 upregulation via estrogen receptors: a common mechanism of salutary effects of estrogen and flutamide on heart function after trauma-hemorrhage. Am J Physiol Heart Circ Physiol 289, H2665-2672

Jang M, Cai L, Udeani GO, Slowing KV, Thomas CF, Beecher CW, Fong HH, Farnsworth NR, Kinghorn AD, Mehta RG (1997): Cancer chemopreventive activity of resveratrol, a natural product derived from grapes. Science $\underline{275}$, 218-220

Jeune MA, Kumi-Diaka J, Brown J (2005): Anticancer activities of pomegranate extracts and genistein in human breast cancer cells. J Med Food $\underline{8}, 469-475$

Joannou GE, Kelly GE, Reeder AY, Waring M, Nelson C (1995): A urinary profile study of dietary phytoestrogens. The identification and mode of metabolism of new isoflavonoids. $\mathrm{J}$ Steroid Biochem Mol Biol 54, 167-184

Jordan VC (2001): The past, present, and future of selective estrogen receptor modulation. Ann N Y Acad Sci 949, 72-79

Kalu DN (1991): The ovariectomized rat model of postmenopausal bone loss. Bone Miner $\underline{15}$, 175-191 
Kamei Y, Suzuki M, Miyazaki H, Tsuboyama-Kasaoka N, Wu J, Ishimi Y, Ezaki O (2005): Ovariectomy in mice decreases lipid metabolism-related gene expression in adipose tissue and skeletal muscle with increased body fat. J Nutr Sci Vitaminol (Tokyo) $\underline{51}$, 110-117

Kanno J, Onyon L, Haseman J, Fenner-Crisp P, Ashby J, Owens W (2001): The OECD program to validate the rat uterotrophic bioassay to screen compounds for in vivo estrogenic responses: phase 1. Environ Health Perspect 109, 785-794

Kanno J, Onyon L, Peddada S, Ashby J, Jacob E, Owens W (2003): The OECD program to validate the rat uterotrophic bioassay. Phase 2: dose-response studies. Environ Health Perspect $\underline{111}, 1530-1549$

Kao YC, Zhou C, Sherman M, Laughton CA, Chen S (1998): Molecular basis of the inhibition of human aromatase (estrogen synthetase) by flavone and isoflavone phytoestrogens: A site-directed mutagenesis study. Environ Health Perspect 106, 85-92

Kapitola J, Andrle J, Kubickova J (1994): [The effect of estradiol, norethisterone and testosterone on regional circulation and relative weight of the testes, ovaries and uterus in rats]. Sb Lek $\underline{95}$, 189-198

Kardos A, Casadei B (1999): Hormone replacement therapy and ischaemic heart disease among postmenopausal women. J Cardiovasc Risk $\underline{6}$, 105-112

Karim R, Mack WJ, Lobo RA, Hwang J, Liu CR, Liu CH, Sevanian A, Hodis HN (2005): Determinants of the effect of estrogen on the progression of subclinical atherosclerosis: Estrogen in the Prevention of Atherosclerosis Trial. Menopause 12, 366-373

Key TJ, Pike MC (1988): The role of oestrogens and progestagens in the epidemiology and prevention of breast cancer. Eur J Cancer Clin Oncol 24, 29-43

Kijkuokool P, Parhar IS, Malaivijitnond S (2006): Genistein enhances N-nitrosomethylureainduced rat mammary tumorigenesis. Cancer Lett 242, 53-59

Kim HK, Nelson-Dooley C, Della-Fera MA, Yang JY, Zhang W, Duan J, Hartzell DL, Hamrick MW, Baile CA (2006): Genistein decreases food intake, body weight, and fat pad weight and causes adipose tissue apoptosis in ovariectomized female mice. J Nutr 136, 409414

Komm BS, Rusling DJ, Lyttle CR (1986): Estrogen regulation of protein synthesis in the immature rat uterus: the analysis of proteins released into the medium during in vitro incubation. Endocrinology 118, 2411-2416

Kopp P (1998): Resveratrol, a phytoestrogen found in red wine. A possible explanation for the conundrum of the 'French paradox'? Eur J Endocrinol 138, 619-620

Kousidou OC, Mitropoulou TN, Roussidis AE, Kletsas D, Theocharis AD, Karamanos NK (2005): Genistein suppresses the invasive potential of human breast cancer cells through 
transcriptional regulation of metalloproteinases and their tissue inhibitors. Int J Oncol $\underline{26}$, 1101-1109

Krebs EE, Ensrud KE, MacDonald R, Wilt TJ (2004): Phytoestrogens for treatment of menopausal symptoms: a systematic review. Obstet Gynecol 104, 824-836

Kuiper GG, Enmark E, Pelto-Huikko M, Nilsson S, Gustafsson JA (1996): Cloning of a novel receptor expressed in rat prostate and ovary. Proc Natl Acad Sci U S A 93, 5925-5930

Kuiper GG, Carlsson B, Grandien K, Enmark E, Haggblad J, Nilsson S, Gustafsson JA (1997): Comparison of the ligand binding specificity and transcript tissue distribution of estrogen receptors alpha and beta. Endocrinology 138, 863-870

Kuiper GG, Lemmen JG, Carlsson B, Corton JC, Safe SH, van der Saag PT, van der Burg B, Gustafsson JA (1998): Interaction of estrogenic chemicals and phytoestrogens with estrogen receptor beta. Endocrinology 139, 4252-4263

Lagouge M, Argmann C, Gerhart-Hines Z, Meziane H, Lerin C, Daussin F, Messadeq N, Milne J, Lambert P, Elliott P (2006): Resveratrol improves mitochondrial function and protects against metabolic disease by activating SIRT1 and PGC-1alpha. Cell $\underline{127}, 1109-1122$

Lamartiniere CA (2002): Timing of exposure and mammary cancer risk. J Mammary Gland Biol Neoplasia $\underline{7}, 67-76$

Landau IT, Zucker I (1976): Estrogenic regulation of body weight in the female rat. Horm Behav $\underline{7}, 29-39$

Le Roith D, Scavo L, Butler A (2001): What is the role of circulating IGF-I? Trends Endocrinol Metab $\underline{12}, 48-52$

Lee SK, Mbwambo ZH, Chung H, Luyengi L, Gamez EJ, Mehta RG, Kinghorn AD, Pezzuto JM (1998): Evaluation of the antioxidant potential of natural products. Comb Chem High Throughput Screen $\underline{1}, 35-46$

Levi F, Pasche C, Lucchini F, Ghidoni R, Ferraroni M, La Vecchia C (2005): Resveratrol and breast cancer risk. Eur J Cancer Prev 14, 139-142

Liang M, Ekblad E, Gustafsson JA, Nilsson BO (2001): Stimulation of vascular protein synthesis by activation of oestrogen receptor beta. J Endocrinol 171, 417-423

Lim CK, Yuan ZX, Lamb JH, White IN, De Matteis F, Smith LL (1994): A comparative study of tamoxifen metabolism in female rat, mouse and human liver microsomes. Carcinogenesis $\underline{15}, 589-593$

Lin JK, Tsai SH (1999): Chemoprevention of cancer and cardiovascular disease by resveratrol. Proc Natl Sci Counc Repub China B 23, 99-106 
Lindberg MK, Moverare S, Skrtic S, Gao H, Dahlman-Wright K, Gustafsson JA, Ohlsson C (2003): Estrogen receptor (ER)-beta reduces ERalpha-regulated gene transcription, supporting a "ying yang" relationship between ERalpha and ERbeta in mice. Mol Endocrinol 17, 203-208

Ling S, Komesaroff P, Sudhir K (2006): Cellular mechanisms underlying the cardiovascular actions of oestrogens. Clin Sci (Lond) $\underline{111}$, 107-118

Liu B, Edgerton S, Yang X, Kim A, Ordonez-Ercan D, Mason T, Alvarez K, McKimmey C, Liu N, Thor A (2005): Low-dose dietary phytoestrogen abrogates tamoxifen-associated mammary tumor prevention. Cancer Res $\underline{65}, 879-886$

Liu MM, Albanese C, Anderson CM, Hilty K, Webb P, Uht RM, Price RH, Jr., Pestell RG, Kushner PJ (2002): Opposing action of estrogen receptors alpha and beta on cyclin D1 gene expression. J Biol Chem 277, 24353-24360

Liu ZP, Li WX, Yu B, Huang J, Sun J, Huo JS, Liu CX (2005): Effects of trans-resveratrol from Polygonum cuspidatum on bone loss using the ovariectomized rat model. J Med Food $\underline{8}$, 14-19

Loukovaara M, Carson M, Palotie A, Adlercreutz H (1995): Regulation of sex hormonebinding globulin production by isoflavonoids and patterns of isoflavonoid conjugation in HepG2 cell cultures. Steroids $\underline{60}, 656-661$

Lu LJ, Anderson KE, Grady JJ, Kohen F, Nagamani M (2000): Decreased ovarian hormones during a soya diet: implications for breast cancer prevention. Cancer Res $\underline{60}$, 4112-4121

Lubahn DB, Moyer JS, Golding TS, Couse JF, Korach KS, Smithies O (1993): Alteration of reproductive function but not prenatal sexual development after insertional disruption of the mouse estrogen receptor gene. Proc Natl Acad Sci U S A 90, 11162-11166

Lydeking-Olsen E, Beck-Jensen JE, Setchell KD, Holm-Jensen T (2004): Soymilk or progesterone for prevention of bone loss--a 2 year randomized, placebo-controlled trial. Eur J Nutr $\underline{43}, 246-257$

Mackey RH, Kuller LH, Sutton-Tyrrell K, Evans RW, Holubkov R, Matthews KA (2005): Hormone therapy, lipoprotein subclasses, and coronary calcification: the Healthy Women Study. Arch Intern Med 165, 510-515

Manson JE, Bassuk SS (2007): Invited commentary: hormone therapy and risk of coronary heart disease why renew the focus on the early years of menopause? Am J Epidemiol 166, 511-517

Manson JE, Allison MA, Rossouw JE, Carr JJ, Langer RD, Hsia J, Kuller LH, Cochrane BB, Hunt JR, Ludlam SE (2007): Estrogen therapy and coronary-artery calcification. N Engl J Med 356, 2591-2602 
Marini H, Minutoli L, Polito F, Bitto A, Altavilla D, Atteritano M, Gaudio A, Mazzaferro S, Frisina A, Frisina N (2007): Effects of the phytoestrogen genistein on bone metabolism in osteopenic postmenopausal women: a randomized trial. Ann Intern Med 146, 839-847

Martinez J, Moreno JJ (2000): Effect of resveratrol, a natural polyphenolic compound, on reactive oxygen species and prostaglandin production. Biochem Pharmacol $\underline{59}$, 865-870

Matthews KA, Meilahn E, Kuller LH, Kelsey SF, Caggiula AW, Wing RR (1989): Menopause and risk factors for coronary heart disease. N Engl J Med 321, 641-646

Mattivi F (1993): Solid phase extraction of trans-resveratrol from wines for HPLC analysis. Z Lebensm Unters Forsch $\underline{196}, 522-525$

Michael McClain R, Wolz E, Davidovich A, Pfannkuch F, Edwards JA, Bausch J (2006): Acute, subchronic and chronic safety studies with genistein in rats. Food Chem Toxicol 44 , $56-80$

Miller VM, Mulvagh SL (2007): Sex steroids and endothelial function: translating basic science to clinical practice. Trends Pharmacol Sci $\underline{28}$, 263-270

Miller VM, Duckles SP (2008): Vascular actions of estrogens: functional implications. Pharmacol Rev $\underline{60}, 210-241$

Minami T, Oomura Y, Nabekura J, Fukuda A (1990): 17 beta-estradiol depolarization of hypothalamic neurons is mediated by cyclic AMP. Brain Res $\underline{519}, 301-307$

Mizutani K, Ikeda K, Kawai Y, Yamori Y (2000): Resveratrol attenuates ovariectomyinduced hypertension and bone loss in stroke-prone spontaneously hypertensive rats. J Nutr Sci Vitaminol (Tokyo) $\underline{46}, 78-83$

Morabito N, Crisafulli A, Vergara C, Gaudio A, Lasco A, Frisina N, D'Anna R, Corrado F, Pizzoleo MA, Cincotta M (2002): Effects of genistein and hormone-replacement therapy on bone loss in early postmenopausal women: a randomized double-blind placebo-controlled study. J Bone Miner Res 17, 1904-1912

Moutsatsou P (2007): The spectrum of phytoestrogens in nature: our knowledge is expanding. Hormones (Athens) $\underline{6}, 173-193$

Mudali S, Dobs AS, Ding J, Cauley JA, Szklo M, Golden SH (2005): Endogenous postmenopausal hormones and serum lipids: the atherosclerosis risk in communities study. $\mathrm{J}$ Clin Endocrinol Metab 90, 1202-1209

Mueller SO, Simon S, Chae K, Metzler M, Korach KS (2004): Phytoestrogens and their human metabolites show distinct agonistic and antagonistic properties on estrogen receptor alpha (ERalpha) and ERbeta in human cells. Toxicol Sci $\underline{80}, 14-25$ 
Murphy LJ, Murphy LC, Friesen HG (1987): Estrogen induces insulin-like growth factor-I expression in the rat uterus. Mol Endocrinol $1,445-450$

Mystkowski P, Seeley RJ, Hahn TM, Baskin DG, Havel PJ, Matsumoto AM, Wilkinson CW, Peacock-Kinzig K, Blake KA, Schwartz MW (2000): Hypothalamic melanin-concentrating hormone and estrogen-induced weight loss. J Neurosci 20, 8637-8642

Nagata C, Takatsuka N, Inaba S, Kawakami N, Shimizu H (1998): Effect of soymilk consumption on serum estrogen concentrations in premenopausal Japanese women. J Natl Cancer Inst $\underline{90}, 1830-1835$

Nemoto Y, Toda K, Ono M, Fujikawa-Adachi K, Saibara T, Onishi S, Enzan H, Okada T, Shizuta Y (2000): Altered expression of fatty acid-metabolizing enzymes in aromatasedeficient mice. J Clin Invest 105, 1819-1825

Nickenig G, Baumer AT, Grohe C, Kahlert S, Strehlow K, Rosenkranz S, Stablein A, Beckers F, Smits JF, Daemen MJ (1998): Estrogen modulates AT1 receptor gene expression in vitro and in vivo. Circulation 97, 2197-2201

Nordmeyer J, Eder S, Mahmoodzadeh S, Martus P, Fielitz J, Bass J, Bethke N, Zurbrugg HR, Pregla R, Hetzer R (2004): Upregulation of myocardial estrogen receptors in human aortic stenosis. Circulation $\underline{110}$, 3270-3275

O'Connell D, Robertson J, Henry D, Gillespie W (1998): A systematic review of the skeletal effects of estrogen therapy in postmenopausal women. II. An assessment of treatment effects. Climacteric $\underline{1}, 112-123$

Palmer JR, Rosenberg L, Shapiro S (1992): Reproductive factors and risk of myocardial infarction. Am J Epidemiol 136, 408-416

Pathirage N, Di Nezza LA, Salmonsen LA, Jobling T, Simpson ER, Clyne CD (2006): Expression of aromatase, estrogen receptors, and their coactivators in patients with endometrial cancer. Fertil Steril $\underline{86}, 469-472$

Patisaul HB, Melby M, Whitten PL, Young LJ (2002): Genistein affects ER beta- but not ER alpha-dependent gene expression in the hypothalamus. Endocrinology 143, 2189-2197

Phipps WR, Duncan AM, Kurzer MS (2002): Isoflavones and postmenopausal women: a critical review. Treat Endocrinol 1, 293-311

Phrakonkham P, Chevalier J, Desmetz C, Pinnert MF, Berges R, Jover E, Davicco MJ, Bennetau-Pelissero C, Coxam V, Artur Y (2007): Isoflavonoid-based bone-sparing treatments exert a low activity on reproductive organs and on hepatic metabolism of estradiol in ovariectomized rats. Toxicol Appl Pharmacol 224, 105-115

Picherit C, Coxam V, Bennetau-Pelissero C, Kati-Coulibaly S, Davicco MJ, Lebecque P, Barlet JP (2000): Daidzein is more efficient than genistein in preventing ovariectomy-induced bone loss in rats. J Nutr $\underline{130}, 1675-1681$ 
Picherit C, Chanteranne B, Bennetau-Pelissero C, Davicco MJ, Lebecque P, Barlet JP, Coxam V (2001): Dose-dependent bone-sparing effects of dietary isoflavones in the ovariectomised rat. Br J Nutr $\underline{85}, 307-316$

Pickar JH, Thorneycroft I, Whitehead M (1998): Effects of hormone replacement therapy on the endometrium and lipid parameters: a review of randomized clinical trials, 1985 to 1995. Am J Obstet Gynecol 178, 1087-1099

Pierce JG, Parsons TF (1981): Glycoprotein hormones: structure and function. Annu Rev Biochem $\underline{50}, 465-495$

Pino AM, Valladares LE, Palma MA, Mancilla AM, Yanez M, Albala C (2000): Dietary isoflavones affect sex hormone-binding globulin levels in postmenopausal women. J Clin Endocrinol Metab 토, 2797-2800

Power KA, Ward WE, Chen JM, Saarinen NM, Thompson LU (2006): Genistein alone and in combination with the mammalian lignans enterolactone and enterodiol induce estrogenic effects on bone and uterus in a postmenopausal breast cancer mouse model. Bone $\underline{39}, 117-124$

Price KR, Fenwick GR (1985): Naturally occurring oestrogens in foods--a review. Food Addit Contam 2, 73-106

Rachon D, Vortherms T, Seidlova-Wuttke D, Wuttke W (2007a): Effects of dietary equol on body weight gain, intra-abdominal fat accumulation, plasma lipids, and glucose tolerance in ovariectomized Sprague-Dawley rats. Menopause 14, 925-932

Rachon D, Seidlova-Wuttke D, Vortherms T, Wuttke W (2007b): Effects of dietary equol administration on ovariectomy induced bone loss in Sprague-Dawley rats. Maturitas $\underline{58}, 308$ 315

Rachon D, Vortherms T, Seidlova-Wuttke D, Wuttke W (2007c): Effects of dietary equol on the pituitary of the ovariectomized rats. Horm Metab Res 39, 256-261

Rachon D, Vortherms T, Seidlova-Wuttke D, Wuttke W (2007d): Dietary daidzein and puerarin do not affect pituitary LH expression but exert uterotropic effects in ovariectomized rats. Maturitas $\underline{57}, 161-170$

Rachon D, Vortherms T, Seidlova-Wuttke D, Menche A, Wuttke W (2007e): Uterotropic effects of dietary equol administration in ovariectomized Sprague-Dawley rats. Climacteric $\underline{10}, 416-426$

Rachon D, Menche A, Vortherms T, Seidlova-Wuttke D, Wuttke W (2008): Effects of dietary equol administration on the mammary gland in ovariectomized Sprague-Dawley rats. Menopause $\underline{15}, 340-345$

Rees M, Stevenson J (2008): Primary prevention of coronary heart disease in women. Menopause Int $\underline{14}, 40-45$ 
Regitz-Zagrosek V, Wintermantel TM, Schubert C (2007): Estrogens and SERMs in coronary heart disease. Curr Opin Pharmacol 7, 130-139

Ren MQ, Kuhn G, Wegner J, Chen J (2001): Isoflavones, substances with multi-biological and clinical properties. Eur J Nutr $\underline{40}, 135-146$

Rickard DJ, Monroe DG, Ruesink TJ, Khosla S, Riggs BL, Spelsberg TC (2003): Phytoestrogen genistein acts as an estrogen agonist on human osteoblastic cells through estrogen receptors alpha and beta. J Cell Biochem $\underline{89}$, 633-646

Rimoldi G, Christoffel J, Seidlova-Wuttke D, Jarry H, Wuttke W (2007): Effects of chronic genistein treatment in mammary gland, uterus, and vagina. Environ Health Perspect $\underline{115}$ Suppl 1, 62-68

Rinderknecht E, Humbel RE (1978): The amino acid sequence of human insulin-like growth factor I and its structural homology with proinsulin. J Biol Chem 253, 2769-2776

Rizzoli R, Bonjour JP (1997): Hormones and bones. Lancet 349 Suppl 1, sI20-23

Romero-Perez AI, Ibern-Gomez M, Lamuela-Raventos RM, de La Torre-Boronat MC (1999): Piceid, the major resveratrol derivative in grape juices. J Agric Food Chem 4ㄱ, 1533-1536

Rosenberg L, Hennekens CH, Rosner B, Belanger C, Rothman KJ, Speizer FE (1981): Early menopause and the risk of myocardial infarction. Am J Obstet Gynecol 139, 47-51

Rossouw JE, Anderson GL, Prentice RL, LaCroix AZ, Kooperberg C, Stefanick ML, Jackson RD, Beresford SA, Howard BV, Johnson KC (2002): Risks and benefits of estrogen plus progestin in healthy postmenopausal women: principal results From the Women's Health Initiative randomized controlled trial. JAMA $\underline{288}, 321-333$

Rowland IR, Wiseman H, Sanders TA, Adlercreutz H, Bowey EA (2000): Interindividual variation in metabolism of soy isoflavones and lignans: influence of habitual diet on equol production by the gut microflora. Nutr Cancer $\underline{36}, 27-32$

Rutanen EM (1998): Insulin-like growth factors in endometrial function. Gynecol Endocrinol $\underline{12}, 399-406$

Sacks FM, Walsh BW (1990): The effects of reproductive hormones on serum lipoproteins: unresolved issues in biology and clinical practice. Ann N Y Acad Sci 592, 272-285; discussion 334-245

Saltiki K, Alevizaki M (2007): Coronary heart disease in postmenopausal women; the role of endogenous estrogens and their receptors. Hormones (Athens) $\underline{6}, 9-24$

Sathyamoorthy N, Wang TT (1997): Differential effects of dietary phyto-oestrogens daidzein and equol on human breast cancer MCF-7 cells. Eur J Cancer 33, 2384-2389 
Scheiber MD, Liu JH, Subbiah MT, Rebar RW, Setchell KD (2001): Dietary inclusion of whole soy foods results in significant reductions in clinical risk factors for osteoporosis and cardiovascular disease in normal postmenopausal women. Menopause $\underline{8}, 384-392$

Schmidt S, Michna H, Diel P (2005): Combinatory effects of phytoestrogens and 17betaestradiol on proliferation and apoptosis in MCF-7 breast cancer cells. J Steroid Biochem Mol Biol 94, 445-449

Sehmisch S, Uffenorde J, Maehlmeyer S, Tezval M, Jarry H, Stuermer KM, Stuermer EK (2009): Evaluation of bone quality and quantity in osteoporotic mice - The effects of genistein and equol. Phytomedicine [Pub.med.]

Setchell KD (1998): Phytoestrogens: the biochemistry, physiology, and implications for human health of soy isoflavones. Am J Clin Nutr $\underline{68}$, 1333S-1346S

Setchell KD, Lydeking-Olsen E (2003): Dietary phytoestrogens and their effect on bone: evidence from in vitro and in vivo, human observational, and dietary intervention studies. Am J Clin Nutr $\underline{78}$, 593S-609S

Setchell KD, Brown NM, Lydeking-Olsen E (2002): The clinical importance of the metabolite equol-a clue to the effectiveness of soy and its isoflavones. J Nutr 132, 3577-3584

Setchell KD, Brown NM, Desai PB, Zimmer-Nechimias L, Wolfe B, Jakate AS, Creutzinger V, Heubi JE (2003): Bioavailability, disposition, and dose-response effects of soy isoflavones when consumed by healthy women at physiologically typical dietary intakes. J Nutr $\underline{133}$, 1027-1035

Shimizu H, Ross RK, Bernstein L, Pike MC, Henderson BE (1990): Serum oestrogen levels in postmenopausal women: comparison of American whites and Japanese in Japan. $\mathrm{Br} \mathbf{J}$ Cancer $\underline{62}, 451-453$

Shimizu H, Ito Y, Matsuzaki Y, Iijima H, Ogawa T (1996a): 4,5-dichlorophthaloyl group for amino protection in carbohydrate chemistry. Biosci Biotechnol Biochem $\underline{60}, 73-76$

Shimizu H, Ohtani K, Kato Y, Tanaka Y, Mori M (1996b): Withdrawal of [corrected] estrogen increases hypothalamic neuropeptide Y (NPY) mRNA expression in ovariectomized obese rat. Neurosci Lett 204, 81-84

Shimomura K, Shimizu H, Tsuchiya T, Abe Y, Uehara Y, Mori M (2002): Is leptin a key factor which develops obesity by ovariectomy? Endocr J $\underline{49}$, 417-423

Shimomura Y, Shimizu H, Takahashi M, Sato N, Uehara Y, Fukatsu A, Negishi M, Kobayashi I, Kobayashi S (1990): The significance of decreased ambulatory activity during the generation by long-term observation of obesity in ovariectomized rats. Physiol Behav $\underline{47}$, $155-159$ 
Stampfer MJ, Colditz GA, Willett WC, Manson JE, Rosner B, Speizer FE, Hennekens CH (1991): Postmenopausal estrogen therapy and cardiovascular disease. Ten-year follow-up from the nurses' health study. N Engl J Med $\underline{325}$, 756-762

Sundstrom SA, Komm BS, Xu Q, Boundy V, Lyttle CR (1990): The stimulation of uterine complement component C3 gene expression by antiestrogens. Endocrinology 126, 1449-1456

Svechnikov K, Supornsilchai V, Strand ML, Wahlgren A, Seidlova-Wuttke D, Wuttke W, Soder O (2005): Influence of long-term dietary administration of procymidone, a fungicide with anti-androgenic effects, or the phytoestrogen genistein to rats on the pituitary-gonadal axis and Leydig cell steroidogenesis. J Endocrinol 187, 117-124

Tataryn IV, Meldrum DR, Lu KH, Frumar AM, Judd HL (1979): LH, FSH and skin temperaure during the menopausal hot flash. J Clin Endocrinol Metab $\underline{49}, 152-154$

Turner RT, Evans GL, Zhang M, Maran A, Sibonga JD (1999): Is resveratrol an estrogen agonist in growing rats? Endocrinology $140,50-54$

Turrens JF, Lariccia J, Nair MG (1997): Resveratrol has no effect on lipoprotein profile and does not prevent peroxidation of serum lipids in normal rats. Free Radic Res $\underline{27}, 557-562$

Unfer V, Casini ML, Costabile L, Mignosa M, Gerli S, Di Renzo GC (2004): Endometrial effects of long-term treatment with phytoestrogens: a randomized, double-blind, placebocontrolled study. Fertil Steril $\underline{82}$, 145-148, quiz 265

Valenzano DR, Terzibasi E, Genade T, Cattaneo A, Domenici L, Cellerino A (2006): Resveratrol prolongs lifespan and retards the onset of age-related markers in a short-lived vertebrate. Curr Biol 16, 296-300

Vantyghem SA, Wilson SM, Postenka CO, Al-Katib W, Tuck AB, Chambers AF (2005): Dietary genistein reduces metastasis in a postsurgical orthotopic breast cancer model. Cancer Res $\underline{65}, 3396-3403$

Vatanparast H, Chilibeck PD (2007): Does the effect of soy phytoestrogens on bone in postmenopausal women depend on the equol-producing phenotype? Nutr Rev $\underline{65}$, 294-299

Vehkavaara S, Silveira A, Hakala-Ala-Pietila T, Virkamaki A, Hovatta O, Hamsten A, Taskinen MR, Yki-Jarvinen H (2001): Effects of oral and transdermal estrogen replacement therapy on markers of coagulation, fibrinolysis, inflammation and serum lipids and lipoproteins in postmenopausal women. Thromb Haemost $\underline{85}$, 619-625

Vinson JA, Teufel K, Wu N (2001): Red wine, dealcoholized red wine, and especially grape juice, inhibit atherosclerosis in a hamster model. Atherosclerosis $\underline{156}, 67-72$

Walsh BW, Schiff I, Rosner B, Greenberg L, Ravnikar V, Sacks FM (1991): Effects of postmenopausal estrogen replacement on the concentrations and metabolism of plasma lipoproteins. N Engl J Med 325, 1196-1204 
Wang DY, Key TJ, Pike MC, Boreham J, Chen J (1991): Serum hormone levels in British and rural Chinese females. Breast Cancer Res Treat 18 Suppl 1, S41-45

Ward WE, Kim S, Chan D, Fonseca D (2005): Serum equol, bone mineral density and biomechanical bone strength differ among four mouse strains. J Nutr Biochem $\underline{16}, 743-749$

Weiderpass E, Adami HO, Baron JA, Magnusson C, Bergstrom R, Lindgren A, Correia N, Persson I (1999): Risk of endometrial cancer following estrogen replacement with and without progestins. J Natl Cancer Inst 91, 1131-1137

Whitehead SA, Cross JE, Burden C, Lacey M (2002): Acute and chronic effects of genistein, tyrphostin and lavendustin A on steroid synthesis in luteinized human granulosa cells. Hum Reprod 17, 589-594

Wu AH, Ziegler RG, Pike MC, Nomura AM, West DW, Kolonel LN, Horn-Ross PL, Rosenthal JF, Hoover RN (1996): Menstrual and reproductive factors and risk of breast cancer in Asian-Americans. Br J Cancer $\underline{73}$, 680-686

Wu J, Oka J, Ezaki J, Ohtomo T, Ueno T, Uchiyama S, Toda T, Uehara M, Ishimi Y (2007): Possible role of equol status in the effects of isoflavone on bone and fat mass in postmenopausal Japanese women: a double-blind, randomized, controlled trial. Menopause $\underline{14}, 866-874$

Wu JM, Wang ZR, Hsieh TC, Bruder JL, Zou JG, Huang YZ (2001): Mechanism of cardioprotection by resveratrol, a phenolic antioxidant present in red wine (Review). Int J Mol Med $\underline{8}, 3-17$

Wuttke W, Jarry H, Westphalen S, Christoffel V, Seidlova-Wuttke D (2002): Phytoestrogens for hormone replacement therapy? J Steroid Biochem Mol Biol 83, 133-147

Yamagishi T, Otsuka E, Hagiwara H (2001): Reciprocal control of expression of mRNAs for osteoclast differentiation factor and OPG in osteogenic stromal cells by genistein: evidence for the involvement of topoisomerase II in osteoclastogenesis. Endocrinology 142, 3632-3637

Yamamoto S, Sobue T, Kobayashi M, Sasaki S, Tsugane S (2003): Soy, isoflavones, and breast cancer risk in Japan. J Natl Cancer Inst $\underline{95}$, 906-913

Yeung J, Yu TF (2003): Effects of isoflavones (soy phyto-estrogens) on serum lipids: a metaanalysis of randomized controlled trials. Nutr $\mathrm{J} \underline{2}, 15$

Ziegler RG, Hoover RN, Pike MC, Hildesheim A, Nomura AM, West DW, Wu-Williams AH, Kolonel LN, Horn-Ross PL, Rosenthal JF (1993): Migration patterns and breast cancer risk in Asian-American women. J Natl Cancer Inst 모, 1819-1827 


\section{$7 \quad$ Abbildungsverzeichnis}

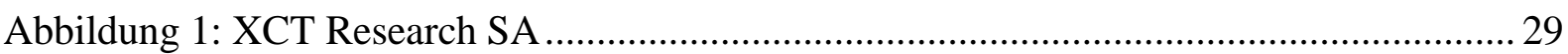

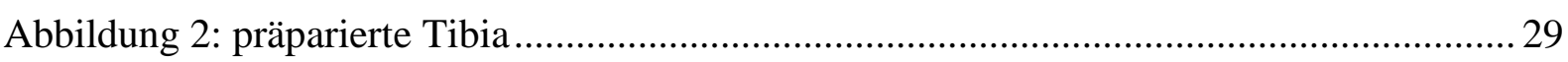

Abbildung 3: Pre-Scan mit eingezeichneten Messlinien.......................................................... 30

Abbildung 4: Slice 1, erste Messlinie auf Höhe Spongiosa ................................................. 30

Abbildung 5: Slice 2, zweite Messlinie auf Höhe Spongiosa ................................................. 31

Abbildung 6: Slice 3, Messlinie auf Höhe Kortikalis .......................................................... 31

Abbildung 7: Körpergewichtsverlauf über 3 Monate. Dargestellt sind die Mittelwerte. Der Übersichtlichkeit halber sind keine Fehlerbalken dargestellt. ....................................... 34

Abbildung 8: Einfluss von Estradiol, Genistein, Resveratrol und Equol auf das Körpergewicht

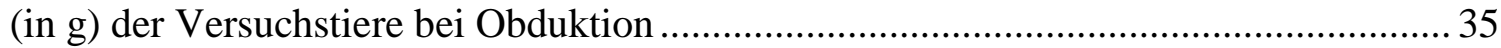

Abbildung 9: Wirkung von Estradiol, Genistein, Resveratrol und Equol auf das absolute und relative Uterusgewicht

Abbildung 10: Einfluss von Estradiol, Genistein, Resveratrol und Equol auf die Expression von ER $\alpha$ und $\mathrm{ER} \beta$ im Uterus.

Abbildung 11: Einfluss von Estradiol, Genistein, Resveratrol und Equol auf die Expression von $\mathrm{C} 3$ und IGF-1 im Uterus.

Abbildung 12: Einfluss von Estradiol, Genistein, Resveratrol und Equol auf absolutes und relatives (bezogen auf das Körpergewicht) Lebergewicht der Versuchstiere

Abbildung 13: Einfluss von Estradiol, Genistein, Resveratrol und Equol auf die ER $\alpha$ und IGF1-Expression in der Leber der Versuchstiere

Abbildung 14: Einfluss von Estradiol, Genistein, Resveratrol und Equol auf absolutes und relatives (in Bezug zum Körpergewicht) Herzgewicht

Abbildung 15: Einfluss von Estradiol, Genistein, Resveratrol und Equol auf die Genexpression von ER $\alpha$ und ER $\beta$ im linken Ventrikel .............................................. 49

Abbildung 16: Einfluss von Estradiol, Genistein, Resveratrol und Equol auf die Expression von IGF-1 im linken Ventrikel.

Abbildung 17: Einfluss von Estradiol, Genistein, Resveratrol und Equol auf die Expression von ER $\alpha$ und ER $\beta$ in der Adenohypophyse der Versuchstiere

Abbildung 18: Einfluss von Estradiol, Genistein, Resveratrol und Equol auf die Expression von LH $\beta$ in der Adenohypophyse der Versuchstiere

Abbildung 19: Einfluss von Estradiol, Genistein, Resveratrol und Equol auf die Knochendichte in der Spongiosa (gemessen in der Metaphyse) der Tibia. ..................... 54

Abbildung 20: Einfluss von Estradiol, Genistein, Resveratrol und Equol auf die Knochendichte in der Kortikalis (gemessen in der Diaphyse) der Tibia. ........................ 55

Abbildung 21: Einfluss von Estradiol, Genistein, Resveratrol und Equol auf die Gesamtdichte von Tibia-Meta- und Diaphyse 


\section{Tabellenverzeichnis}

Tabelle 1: Konzentration der Substanzen im Futter und ihre Aufnahme pro Tier pro Tag ..... 21

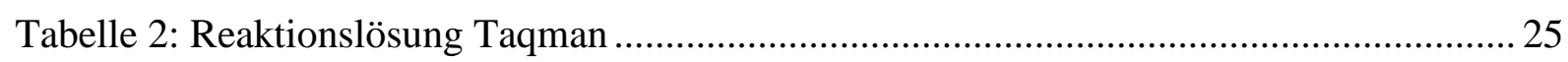

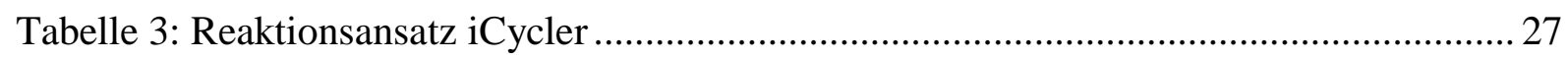

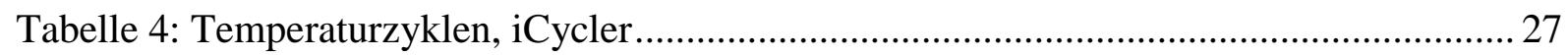

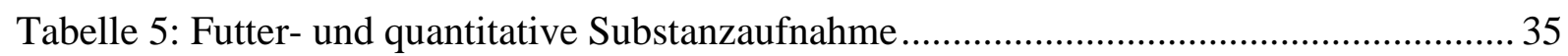

Tabelle 6 : Einfluss von Estradiol, Genistein, Resveratrol und Equol auf die Serumwerte von Cholesterol, Triglyceriden, LDL und HDL in $\mathrm{mg} / \mathrm{dl}$. Zusätzlich angegeben ist die

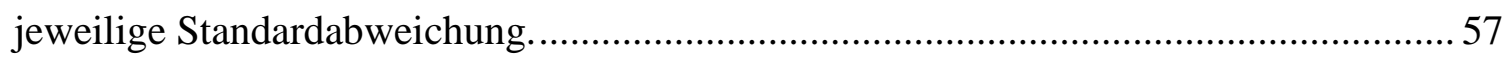




\section{Danksagung}

Allen voran möchte ich an dieser Stelle ganz herzlich meinem Doktorvater, Prof. Dr. rer. nat. Hubertus Jarry, für die erstklassige Betreuung dieser Dissertation danken. Seine stete Ansprechbarkeit sowie seine fachliche und menschliche Kompetenz haben einen großen Beitrag zur Fertigstellung dieser Arbeit geleistet.

Zudem gilt mein Dank allen weiteren Mitarbeitern und Mitarbeiterinnen der Abteilung für experimentelle Endokrinologie der Universitätsklinik Göttingen und ihrem Leiter Herrn Prof. Dr. med. W. Wuttke. Insbesondere Frau Dr. med. vet. Tina Vortherms und Herrn Markus Wuttke vielen Dank für die geduldige Unterstützung bei der Anwendung des Kleintier CTs und für die Einführung in das Statistikprogramm. Ebenso ein herzliches „Dankeschön“ an Frau Dr. Dana Seidlová-Wuttke für die Hilfestellungen bei der Auswertung der an den Knochen erhobenen Ergebnisse.

Des Weiteren vielen herzlichen Dank für die, zum Teil über den Feierabend hinaus bestehende, Unterstützung von Martina Bremer, sowie von allen weiteren MTAs der Abteilung.

$\mathrm{Zu}$ guter Letzt einen ganz lieben, herzlichen Dank meinem „Pipettierkompagnon“ Carl Opitz, der diese Arbeit in jeglicher Hinsicht zu einem Erfolg hat werden lassen. 
